\title{
Flax as a bio-based biomedical textile material
}

Citation for published version (APA):

Michel, S. A. A. X. (2014). Flax as a bio-based biomedical textile material. [Doctoral Thesis, Maastricht University]. Maastricht University. https://doi.org/10.26481/dis.20140626sm

Document status and date:

Published: 01/01/2014

DOI:

10.26481/dis.20140626sm

Document Version:

Publisher's PDF, also known as Version of record

\section{Please check the document version of this publication:}

- A submitted manuscript is the version of the article upon submission and before peer-review. There can be important differences between the submitted version and the official published version of record.

People interested in the research are advised to contact the author for the final version of the publication, or visit the DOI to the publisher's website.

- The final author version and the galley proof are versions of the publication after peer review.

- The final published version features the final layout of the paper including the volume, issue and page numbers.

Link to publication

\footnotetext{
General rights rights.

- You may freely distribute the URL identifying the publication in the public portal. please follow below link for the End User Agreement:

www.umlib.nl/taverne-license

Take down policy

If you believe that this document breaches copyright please contact us at:

repository@maastrichtuniversity.nl

providing details and we will investigate your claim.
}

Copyright and moral rights for the publications made accessible in the public portal are retained by the authors and/or other copyright owners and it is a condition of accessing publications that users recognise and abide by the legal requirements associated with these

- Users may download and print one copy of any publication from the public portal for the purpose of private study or research.

- You may not further distribute the material or use it for any profit-making activity or commercial gain

If the publication is distributed under the terms of Article $25 \mathrm{fa}$ of the Dutch Copyright Act, indicated by the "Taverne" license above, 


\section{Flax as a bio-based biomedical textile material}


Flax as a bio-based biomedical textile material

(C) Copyright S.A.A.X. Michel, Maastricht 2014

ISBN 978-94-6259-171-4

Printed by: Ipskamp Drukkers

Front \& back covers: "Flax Plant and parachutes" \& "Gill Fishing Nets" by Philip Armstrong, reproduced courtesy of Newtownabbey Borough Council, Northern Ireland 


\title{
Flax as a bio-based biomedical textile material
}

\author{
DISSERTATION \\ to obtain the degree of Doctor at Maastricht University \\ on the authority of the Rector Magnificus \\ Prof. dr. L.L.G. Soete \\ in accordance with the decision of the board of deans \\ to be defended in public \\ on Thursday 26 June 2014, at 16.00 hours
}

$$
\text { by }
$$

Sophie Angélique Anne Xutchill Michel 


\section{Supervisor:}

Prof. dr. ir. L.H. Koole

\section{Co-supervisors:}

Dr. M.L.W. Knetsch

Dr. D.G.M. Molin

\section{Assessment Committee:}

Prof. dr. S. Rastogi (Chairman)

Prof. dr. M.J. Post

Prof. dr. P.H.M. Savelkoul

Prof. dr. H. ten Cate

Prof. dr. C. Jérôme, Université de Liège, Belgium

Prof. dr. M Ameloot, Universiteit Hasselt, Belgium

This study was a part of the Interreg IV-A project "BioMiMedics" (www.biomimedics.org). The Universities of Maastricht (The Netherlands), Liege (Belgium), Hasselt (Belgium) and Aachen (Germany; RWTH and Fachhochschule), as well as several regional biotechnological enterprises cooperate in "BioMiMedics".

This particular study was financed through generous contributions of the EU (through Interreg IV-A), the government of the Province Dutch Limburg, the Dutch National Ministery of Economic Affairs, Agriculture \& Innovation, Maastricht University, the Limburg Bank for Industry Innovation (LIOF), and the company INterface BIOmaterials BV in Geleen, Netherlands. Furthermore, the generous support of the company van der Bilt Seeds \& Flax (Sluiskil, the Netherlands) is gratefully acknowledged. 


\section{Table of contents}

Chapter 1 General Introduction

Chapter 2 Utilization of flax fibers for biomedical applications

Chapter 3 Treatment of flax mesh and fibers with dopamine. 57 Aspects of cytocompatibility, immunogenicity and limited self-polymerisation

Chapter 4 Flax as a blood-contacting material. Effect of an albumin 81 coating in vitro and in vivo

Chapter 5 Studies on the potential use of flax (linen) as a biomedical 107 material. Application of a synthetic antimicrobial surface coating

Chapter 6 General Discussion

Summary

Samenvatting

Résumé

Acknowledgements

Curriculum Vitae

List of publications 



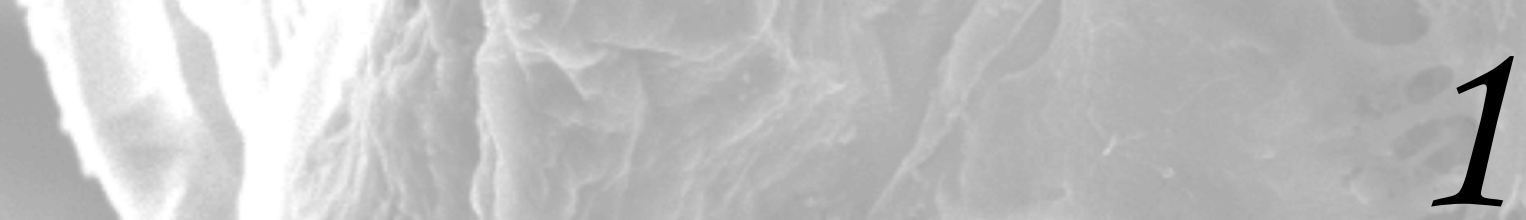

General Introduction 


\section{Preface}

The utilization of plant fibers by mankind goes back to at least Upper Paleolithic. Historically, plant fibers were first employed to sew garments and manufacture tools as shoes or handle. This is confirmed by the discovery of some twisted and died flax fibers dating from 30.000 years ago [1,2]. There are some evidences that the invention of the weaving technique, defined by the Oxford dictionary as the process of forming a fabric by interlacing long threads passing in one direction with others at a right angle to them, occurred at this same period. Yet, mechanization of the weaving technique (i.e. invention of the loom) occurred much later in history, probably at the very end of the Upper Paleolithic. Indeed, the oldest piece of woven textile ever found dates back to 12.000 years ago [3]. From this period on, techniques of production much evolved. It led to finer textiles which could be tailor-made to a wide diversity of applications (clothes, sails, delivery bags,...). A new revolution in textile industry occurred at the beginning of the first millennium, with the invention of the knitting technique $[4,5]$, defined by the Oxford dictionary as the manufacturing of a garment by looping and entwining yarns by hand by means of long eyeless needles or by machine. This technique was initially created to bring elasticity to fabric. Indeed, a knitted textile can stretch in all directions, whereas woven ones can only stretch along the bias. This elasticity is for example essential for socks or hats. Here again, technique quickly improved with the development of various knitted design and so, ultimately, mechanical properties.

Nowadays, plant fibers are still mostly used to manufacture threads and numerous different kinds of textiles. More rarely, they are used as reinforcement materials, as in the traditional wattle and daub. Strangely, the potential utility of natural plant fibers in the biomedical field has not attracted so much attention up to now. Yet, plant fibers can form threads of different thickness, and these threads can be knitted into a huge diversity of designs so that a wide range of mechanical properties can be obtained. This could offer interesting perspectives in the biomedical field. In particular, the potential of flax fibers for biomedical applications is investigated in this thesis. 


\section{Flax fibers for biomedical applications}

\section{Growing of flax plant and obtaining of flax fibers}

Flax plants (also known as linseed or linum usitatissum) are in their very high majority cultivated in spring $[2,6,7]$. Once seeded, they will generally grow for two months before the blossoming occurs. The harvesting generally occurs one month after this blossoming [6]. Several steps are then needed to isolate the flax fibers. At first, flax plants are dew-retted, meaning they are laid on large fields for several weeks (fig. 1) [6]. This process will allow the inner part of the plant to rot, and in particular, it will decompose the pectin matrix keeping the fibers together [7-10]. Then, flax fibers are extracted from the plant by pounding and cleaned by multiple successive combs $[7,10]$.

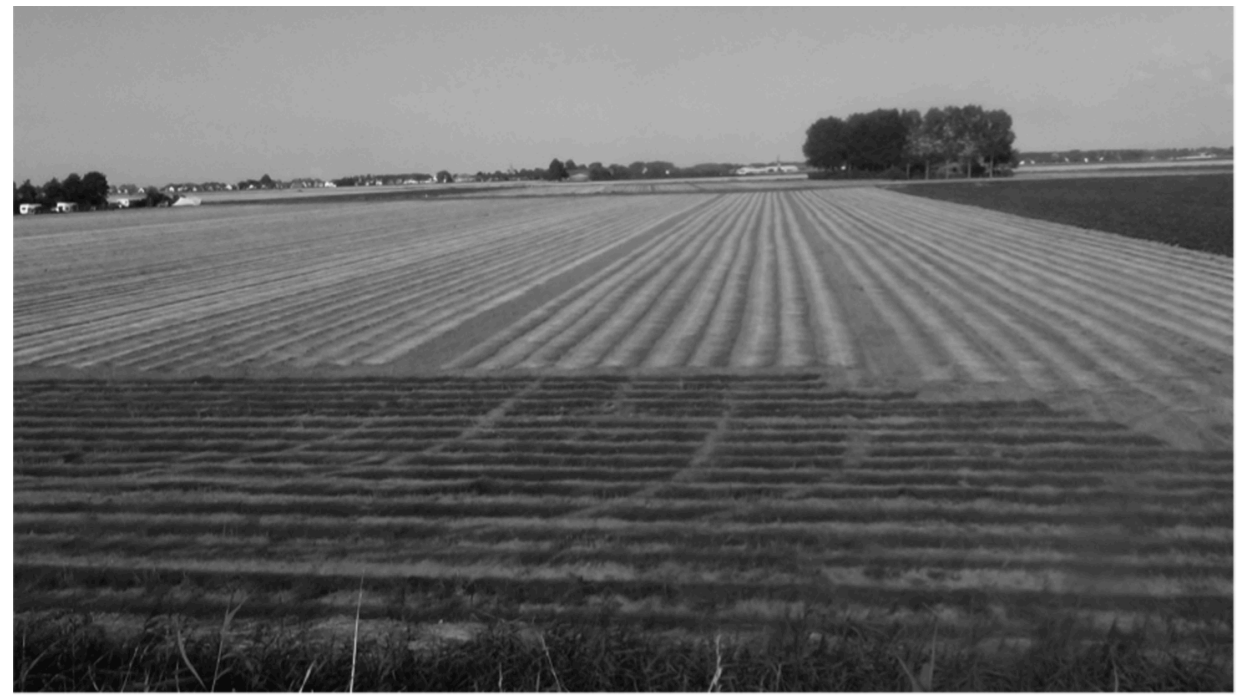

Figure 1. Dew retting of flax plants, directly after harvesting. The flax plants are spread on the soil, and the combined action of bacteria, sun, air, and dew produces fermentation. This takes most of the stem material around the fiber bundles away. After approximately 6 weeks retting is completed, and fibers can be separated.

Flax fibers composition

All plant fibers are composed of cellulose, hemicellulose, lignin and pectin [1115]. Each of these compounds, possessing highly different structures and/or chemical properties, will bring along different properties to plant fibers [2,11,16-18]. Different ratios and organisation of these compounds inside the fibers make that such diverse plant fibers can be found in nature [13-15,17]. 
Flax fibers are composed of $64.1 \%$ cellulose [17], which is a polysaccharide consisting of a linear chain of several hundreds to over ten thousand $\beta(1->4)$ linked D-glucose units $\left(\mathrm{C}_{6} \mathrm{H}_{10} \mathrm{O}_{5}\right)_{n}[17,18]$. Because each D-glucose unit possesses three hydroxyls groups, cellulose chains can form multiple intra and intermolecular hydrogen bounds (i.e. intramolecular hydrogen bounds stabilizing the D-glucose units together along one single cellulose chain, intermolecular hydrogen bounds allowing different cellulose chains to interact with each other) [19-21]. Thanks to these interactions, layers of cellulose chains running in parallel to each other will form [20,22]: a micelle of cellulose is the association of 50 to 100 molecules of cellulose and it has a theoretical elastic modulus of up to 134 GPa [11,14,23-26]. The gathering of several micelles together (up to 20 in flax fibers) forms a microfibril of cellulose: micelles, forming the crystalline regios, are incorporated inside a matrix of amorphous pectin and hemicellulose $[13,23,27,28]$. A microfibril is the base unit of the cell wall and because its diameter is of $10-20 \mathrm{~nm}$, it can be seen using a scanning electron microscope (SEM) (fig. 2) $[14,23,28]$. Microfibrils, forming highly organised and crystalline areas, possess high Young's modulus $(70 \mathrm{GPa})$ and are the main structural compounds conferring strength to plant fibers $[2,17]$. Finally, in the secondary cell wall, microfibrils of cellulose, embedded in a matrix of hemicelluloses and lignin $[11,14,17,23]$, run in parallel to each other, forming with the axis of the fiber a certain angle called the microfibrillar angle (MFA) $[2,11,17,28,29]$.

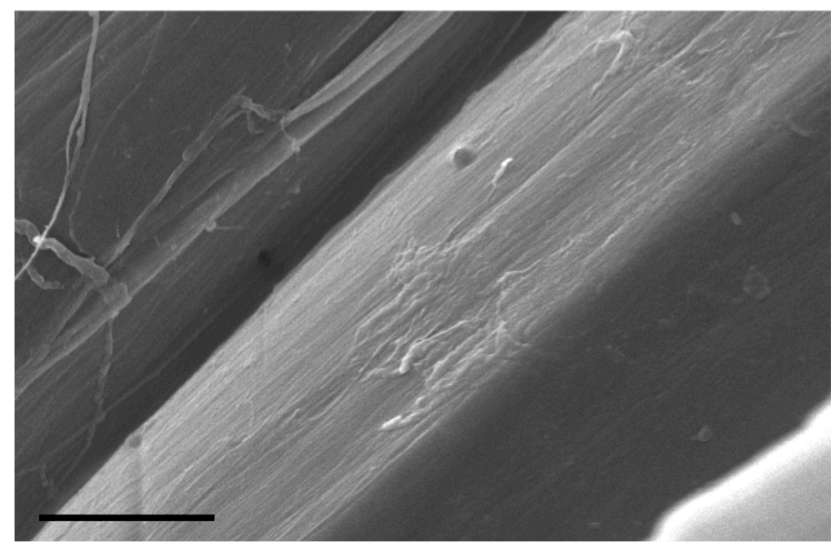

Figure 2. SEM image of a flax fiber seen at an high magnification. Microfibrils of cellulose, running in parallel to each other, can be seen. Their microfibrillar angle with the axis of the flax fiber is of approximately $10^{\circ}$. Scale bar represents $5 \mu \mathrm{m}$.

The encrusting components are present in much fewer proportions as compared to cellulose. They refer to the components that cannot be removed by 
a standard acidic hydrolysis, i.e. hemicellulose and pectin whose proportion is of respectively $16.7 \%$ and $1.8 \%$ in flax fibers [17,30]. These both compounds are amorphous and branched polysaccharides [2,17]. Their chemical compositions vary a lot in nature, according that they both comprise various monomers that can polymerise in several different ways [17,30-33]. Pectin differs from hemicellulose in that they are mostly composed of galacturonic acid [17,32]. For example the US Food and Drug Administration states that pectins should contain no less than $65 \%$ of galacturonic acid to be authorized as food additive $[31,34]$.

Among flax fibers components, only lignin is hydrophobic [35,36]. Lignin is a three-dimensional amorphous polymer made of multiple phenylpropane-based units linked together in highly complex ways $[2,18,17,36]$. Its main role is to provide strength and stiffness to the cell walls $[18,33,36,37]$. Moreover, due to its chemical structure, lignin is highly resistant to chemical and biological degradation, which also explain that flax fibers are not degraded during the rotting process [33,36-38]. Most of the lignin is present in the pectin matrix holding the fibers together and acts as a reinforcing material [33,38]. It is also present in the cell walls of flax fibers and in their secondary wall, notably in the S1 layer $[33,38]$. Since lignin, present at a relatively low percentage, is the only hydrophobic compound present in flax fibers, they are widely considered as hydrophilic materials $[2,17]$. Yet, due to the fact that practically all the hydroxyls groups of cellulose are involved into intra/intermolecular hydrogen bounds, flax fibers are completely insoluble in water and most organic solvents $[20,21,39]$. To dissolve them, it is necessary to destroy the hydroxyls bounds, which can only be obtained after a deprotonation. Hence, flax fibers solubilisation is achieved by using concentrated bases $(\mathrm{pH}>12)[20,21,39]$.

To finish, it must be said that great fluctuations exist among literature reports concerning flax fibers composition, and that the one given here should be only considered as a representative example of it. It is indeed well recognized that flax fibers composition can vary a lot depending on for example the flax variety and maturity, soil quality, weather conditions, or retting process $[2,10,17,23,26,28,40]$.

\section{Flax fiber structure and mechanical properties}

The mechanical behaviour of the elementary fibers is related to the cell wall structure and the mechanical properties of the constituents [24,29]. The structure of flax fibers can be assimilated to a composite material made of two main layers (fig. 3) $[14,7,23,26]$. These layers are corresponding to the different cell walls of the fiber $[2,7,11,23-29]$. Going from the periphery to the centrum 
of the fibers, they are first composed of a thin primary cell wall of approximately $\approx 0.2 \mu \mathrm{m}$, then of a broad secondary cell wall, and finally of an empty circular space, called lumen, which accounts for less than $10 \%$ of the fiber radius $[2,7,10,26,28,29]$. The secondary cell wall is itself divided into three sub-layers, defined as S1 $(0.5-2 \mu \mathrm{m})$, S2 $(5-10 \mu \mathrm{m})$ and S3 $(0.5-1 \mu \mathrm{m})[26,28,29]$.
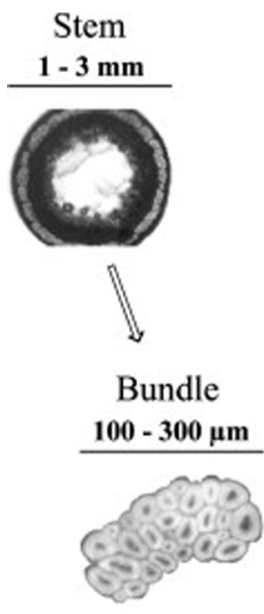
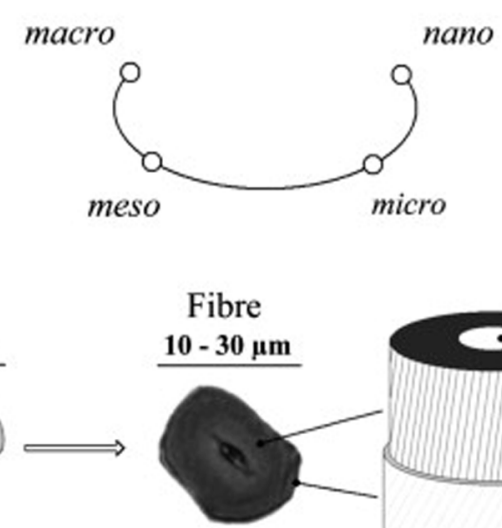

Fibre

\section{Microfibril}

$10 \mathrm{~nm}$

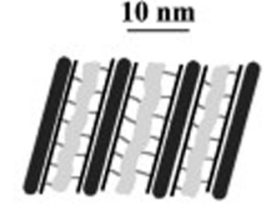

7

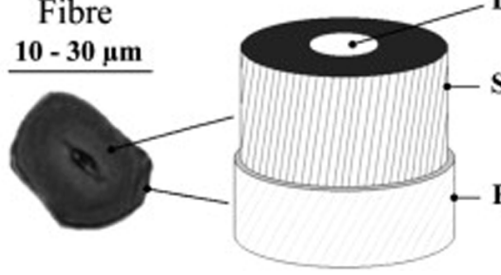

Lumen size $=1-10 \mu \mathrm{m}$

Secondary Cell Wall

thickness $=5-15 \mu \mathrm{m}$ angle $=10^{\circ}$

Primary Cell Wall

thickness $=0.2 \mu \mathrm{m}$

Figure 3. Organisation and structure of a flax fiber: from the flax stem to the microfibril of cellulose. Reprinted from [28], with permission from Elsevier.

In flax fibers, primary cell wall is composed of cellulose microfibrils (8$14 \%)$ embedded in a matric of hemicellulose and pectin $[11,14,29,41]$. Cellulose microfibrils appear to be poorly crystallised and randomly oriented, although a general transverse orientation seems to stand out $[11,14,29,41,42]$. As a consequence, the primary cell wall is very elastic and can easily deform and expand during plant growth $[11,14,26]$. On the contrary, the secondary cell wall is composed of numerous highly oriented and crystalline microfibrils of cellulose (from 64 to $74 \%$ ) embedded into a matrix of hemicellulose and lignin [23]. Because the secondary wall, and especially the S2 layer, is so thick as compared to the primary wall, it is responsible for the mechanical properties of the fiber $[2,10,11,28]$. In plant fibers, mechanical properties generally depend on the percentage of cellulose and on the MFA: the higher the amount of cellulose and the smaller the MFA, the better the mechanical properties [11,29]. Flax fibers contain similar percentage of cellulose as compared to other plant fibers [14,17], but their MFA is very low (between 10 to $11^{\circ}$ ) $[2,7,10,14,17,23-26,28,29]$. As a consequence, they present very good mechanical properties which make them 
good candidates for replacing glass fibers in the reinforcement of composites [2,7,10,17,23,25-29]: their tensile strength and elastic moduli are very high (respectively $1339 \mathrm{MPa}$ and $58 \mathrm{GPa}$ on average) [14] - it implies that they are the strongest fibers in nature [17] - and their deformation at break very small (1-4 $\%$ [14]. On the opposite, cotton fibers, which contain a higher percentage of cellulose of $82.7 \%$ [17] but have a higher MFA (from $45^{\circ}$ at the beginning at the $\mathrm{S}_{1}$ layer to $20^{\circ}$ at the end of the $\mathrm{S}_{3}$ layer) $[43,44]$, exhibit poor mechanical properties (tensile strength of $287-597 \mathrm{MPa}$; elastic moduli of $5.5-12.6 \mathrm{GPa}$; rupture at break of $7-10 \%[14,29])$.

\section{Utility for biomedical applications}

Plant fibers, being mainly composed of hemicellulose and cellulose, could represent interesting green and bio-based materials to manufacture biomedical devices. Since humans do not have the appropriate enzymes to decompose cellulose, it is expected that these fibers will be non-biodegradable in vivo [45]. Many biomaterials sharing this characteristic are currently available on the market, and they can be used in a wide range of applications [46]. Moreover, plant stands composition seems favourable to us. Much research has already shown that hemicelluloses are biocompatible in vivo $[47,48]$. Because when pure they can degrade in the human body, they have long been used as encapsulating compound for drug delivery in the pharmaceutical industry [47]. Cellulose and its derivatives (oxidized cellulose, cellulose acetate, ethyl cellulose) have also been widely described as compatible and safe in vivo [49-52]. Moreover, extensive research has also been done on bacterial cellulose, showing that this material produced by bacteria could also be used safely in many diverse applications [53,54]. Bacterial cellulose is biocompatible, non-toxic, transparent and highly hydrophilic, being composed of more than $99 \%$ water [55]. Since it is composed of pure cellulose I microfibrils disorderly oriented, it displays both high mechanical properties and elasticity $[53,54,56]$. These uncommon properties make it one of the most promising material in skin tissue repair: it provides a moist environment while absorbing the exudate of the wound, present an excellent moulding ability, and can be easily released from the injury without pain $[55,57]$. Bacterial cellulose has also been used successfully as a scaffold for vascular graft, nerve regeneration or cartilage tissue engineering [58-61]. Finally, once implanted in vivo, no macroscopic or microscopic signs of inflammation could be seen $[59,62]$.

Among this investigation for biocompatible and implantable cellulosebased materials, research on the potential utility of plant fibers have been 
negligible. Amidst all plant strands, we believe that flax fibers represent the most interesting material for biomedical applications. Flax fibers are renewable, environment-friendly and low-cost materials that are both biodegradable in nature and recyclable $[2,10,13,23]$. Particularly interesting for biomedical applications is the fact that they are low dense (1.54) with high mechanical properties and stiffness $[2,10,14,23,63]$. Hence, since they do not exhibit any plastic behaviour, they will not irreversibly deform and should keep their tensile strength once implanted. Furthermore, flax fibers are rather long (300 - 600 $\mathrm{mm}$ ) as compared to other fibers (as an example cotton strands are only 12 - 62.8 $\mathrm{mm}$ long) [63]. It means that once they are combined into a thread, fibers do not easily separate from each other. This requirement is a critical one for permanent devices: indeed, once implanted, the material will be submitted to the immune response, wound healing process, and tissue regeneration which may lead to various mechanical forces and chemical attacks on its surface $[64,65]$. Moreover, friction between the material and the surrounding tissues might be important under movement [66,67]. As a consequence, if the material is not stable enough before implantation, it is widely probable that it will fall into pieces once implanted and/or with time. We do not expect such a problem with flax threads. Finally, we were triggered by the fact that flax filaments are hollow tubular structures. The lumens could potentially be exploited as temporary reservoirs for active molecules to be slowly released in situ. Such agents could be used to stimulate local healing or to reduce the risk for biomaterial-related infections.

Few papers deal with the utilization of flax fibers in vitro and in vivo, and results are globally scattered. On one hand, composites containing $20 \%$ flax fibers showed good biocompatibility in vitro and in vivo [68-70], but on the other hand, flax meshes implanted in rats showed massive inflammatory reaction with abscesses [71]. This result is not flax-dependent: subcutaneous implantation of cotton fibers also led to severe inflammatory infiltrates (granulocyte and lymphocyte cell population with the presence of foreign body giant cells) [72]. Such in vivo findings are not very surprising. The potential inflammatory nature of organic dusts (as in cotton fibers) is well known in the textile industry [73]. Several studies showed that people working in a cotton-environment were significantly more likely to suffer from byssinosis and chronic bronchitis as compared to people working with man-made fibers $[74,75]$. This is due to the fact that these cotton dusts, as any other organic dusts, contain bacterial endotoxins $[73,76,77]$. Endotoxins are components of the external membrane of Gram-negative bacteria, and they comprise a polysaccharide part attached to a lipid one (called lipid A) [73]. This lipid A is responsible for most of the toxic effects induced by endotoxins [76]: rapid influx of neutrophils to the 
contaminated place, along with production of cytokines (IL-1 and TNF $\alpha$ ) or oxygen metabolites $\left(\mathrm{O}_{2}\right)[73,77]$. Obviously, the presence of endotoxins on a biomaterial would lead to adverse in vivo effects once this one implanted, and this might explain the negative results obtained previously [71,72]. It also reveals that plant fibers (as flax) should be purified before implantation, i.e. flax fibers should be treated with solutions that are known for their ability to remove endotoxins [78]. Once this safety measure taken, and due to all their unique properties described above, we believe that purified flax fibers could represent new interesting materials in many biomedical applications, as for example to manufacture hernia repair meshes, blood vessels or wound dressings.

\section{Potential applications for flax fibers}

Considering that there is a huge knowledge about the weaving/knitting of flax fibers, we believe they could be used to successfully manufacture biomedical textiles. Textiles are quite commonly needed in surgery, as for example to design surgical meshes for hernia repair, slings for organ prolapse or scaffolds for tissue engineering. Moreover vascular grafts (blood vessel prostheses), artificial tendons/ligaments and sutures are also made with textiles. Techniques employed to obtain such different structures for so various applications are numerous: fibers are either knitted (for meshes or slings), woven (for vascular tubes or wound dressings), braided (for sutures) or non-woven (i.e. forming a sheet - for scaffolds in tissue engineering). Furthermore, and for each category, various subtechniques are present: e.g. several knitting methods exist including warp, weft or circular knitting (fig. 4) [79]. Thanks to this, textiles and designs can be tailormade so to reach the optimum requirements specific to one application and body place. In particular, by playing on the pattern and nature of the fibers (their intrinsic properties and diameters), various pore sizes, mechanical properties and elasticity levels can be obtained. Because linen is already known for centuries, techniques to apply flax in the production of textiles are well developed, and textile engineers can easily determine the design meeting the mechanical requirements. This makes it a suitable candidate for biomedical textiles.

Among all existing biomedical textiles, it is hypothesized that flax fibers could have a high potential of utility in the manufacturing of new hernia repair meshes, blood vessels and wound dressings. The high mechanical properties of flax fibers are favourable regarding hernia meshes and blood vessels. Elasticity can be introduced by choosing the right design and anti- inflammatory/antimicrobial agents could be loaded in the lumen of the fibers. The hydrophilic 

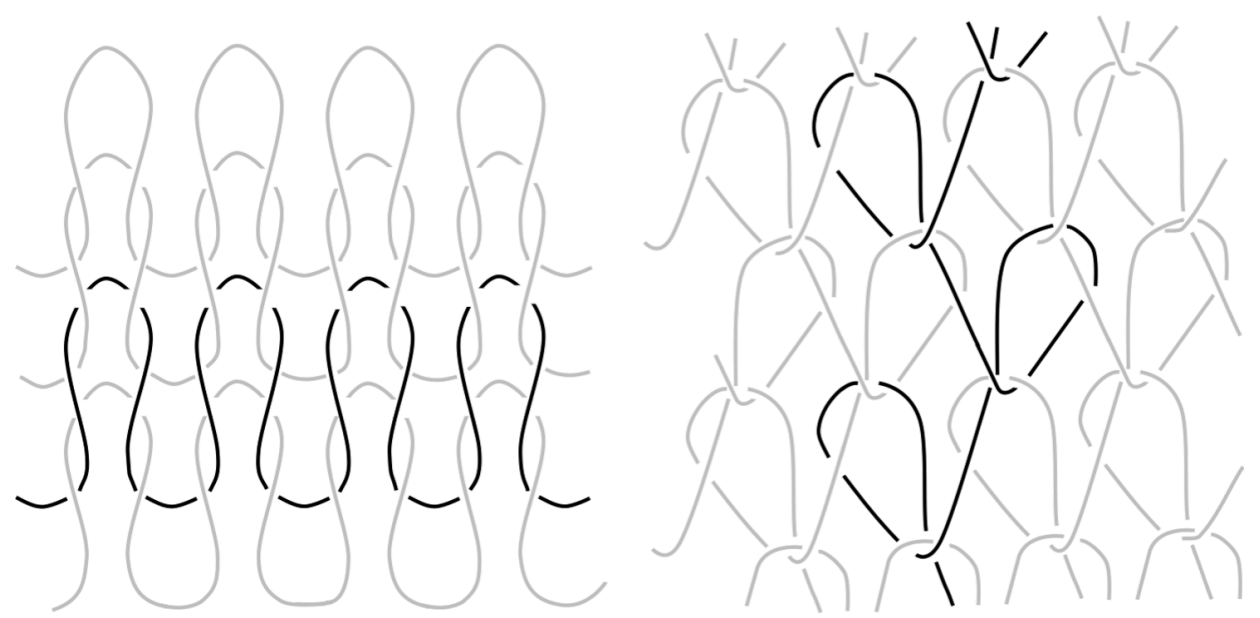

Figure 4. Weft (left) and warp (right) knitting techniques to produce textiles.

nature of flax fibers is another positive point for wound dressings: wetted fibers could prevent fluid loss, maintain the ideal moisture level, and absorb excess of wound secretions and exudates [80]. Moreover, here again, the presence of antibacterial drugs in the lumen of the fibers could prevent infections.

\section{Incisional hernia meshes}

The British Hernia Society defines a hernia as a defect (hole) in the abdominal muscles through which the abdominal content (usually fat but sometimes intestines or other abdominal structure) can profuse (fig. 5) [81]. Several kinds of hernia exist [82], but in this thesis we will only focus on incisional hernia. The development of abdominal surgery in the nineteenth century led to incisional hernia. Such herniations occur frequently after large abdominal procedures (e.g. intestinal or vascular surgery) and they present a painful bulge at or near the incision scar [83-85]. The first documented repair procedure goes back to 1836 [86]. During this operation, which was done prior to the apparition of anesthesia or asepsis, the sac, including the skin, was inverted through the hernia aperture into the abdominal cavity before the edges of the defect being sutured together. Although such procedures leaded to excessive tension on the suture line and so high recurrence rates (up to $54 \%$ for primary repair) due to tissue rupture along suture line or ischemia, suture repair remained the standard repair technique up to the 1970s [87-88]. From 1900, prosthetic hernia meshes also appeared: such materials were implanted so to reinforce the abdominal membrane [86]. The key 


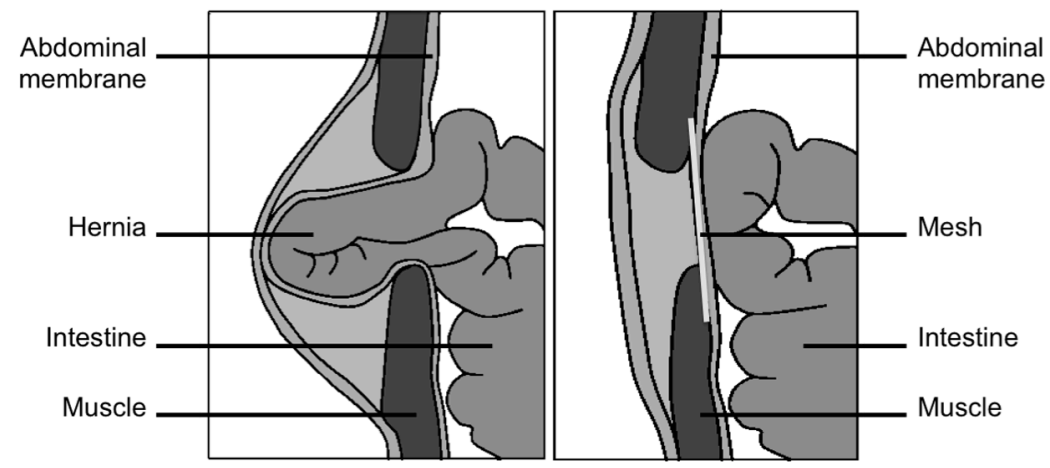

Figure 5. Transversal sections of a sick abdomen before and after mesh implantation. Before operation, intestines profuse through the abdominal wall (presence of an hernia). Such a defect is corrected by the implantation of a mesh on the internal side of the muscle layer which brings back the intestines into their normal position.

idea of that time period was that best meshes would be those made of very strong material and able to induce most fibrosis to prevent from recurrence problems [89]. Hence, successively silver, stainless steel and tantalum meshes were used [88]. Unfortunately, these materials were either toxic or fragmenting, either incompatible with the apparition of the magnetic resonance imaging technique [88]. Surprisingly, the search for alternative implantable mesh materials underwent a strong rise during Second World War. Tantalum and stainless steel became valuable metals only dedicated to the war effort, meaning that mesh suppliers had to look for new options [86]. "New plastics" rapidly caught their attention and in 1958, Usher described for the first time the utilization of a knitted monofilament polypropylene (PP) mesh to repair incisional hernia [86,89]. Clinically, polymer meshes (in most cases manufactured from PP fibers, otherwise from poly(ester) (PE) or poly(tetrafluoroethene) (PTFE) fibers; all hydrophobic materials) are still the most commonly used prosthetics for ventral hernia repair $[88,89]$. Moreover, the utilization of these meshes allows to reach much lower recurrence rates as compared to suture repair [87,88], although it is also clear that the technique is still far from optimal. For instance meshes lead to an inflammatory response and to adhesions between the visceral side of the mesh and adjacent organs, which can cause serious complications as chronic pain, intestinal obstruction and enteric fistulas [90-93].

To solve such problems, numerous studies have addressed the question what would be the optimal mesh biomaterial and mesh design (e.g. porosity, elasticity, strength, weight per $\mathrm{cm}$ square,...) [94-97]. For example, there is now a reasonable consensus that a synthetic mesh should combine large pore size with 
light-weight [98-100]. In parallel, there has been a search for new mesh materials, being especially biological meshes $[89,101]$. The latter are cross-linked and completely de-cellularized collagen-rich tissues from an animal source (e.g. bovine skin) which provide neovascularization, regeneration due to infiltration of native fibroblast and new collagen deposition $[88,102]$. Because typical patients with incisional abdominal hernia have a connective tissue disorder (such as an increase in type-III collagen expression or lower-than-normal collagen type I) [103], the ideal mesh should not only serve as a mechanical reinforcement, but also work as a bioscaffold that interferes positively with healing, i.e. strongly promoting collagen type I synthesis [104]. Biological meshes were expected to be favorable in this aspect. Moreover, there are fully biodegradable, meaning that future surgery will be greatly facilitated in case of recurrence [102]. Nevertheless, especially due to their biodegradability, concerns have been raised about their effect on the recurrence rates and results are globally very scattered; only long term study/use will allow definitive conclusions [101,102]. Hence, despite their relatively high prices, it is unclear whether the "biological" meshes really perform better than their synthetic counterparts [101,102]. For this reason, it seems logic to also include biological meshes from a plant origin in the search for the ideal biological mesh materials.

\section{Vascular grafts}

Atherosclerosis is the major death cause in the Western world, accounting for one in three all deaths, mostly due to inhabitants lack of activity and bad eating habits [82]. Exactly how atherosclerosis occurs is still unclear, although main stages toward its establishment are nowadays well described.

All blood vessels consist of three layers, each of them playing a crucial role to maintain vessels good performances (fig. 6) [105-108]. The innermost layer of a vessel, called tunica intima, is made of endothelial cells and it is in direct contact with blood flow. Its main role is to act as a filter between blood and underlying tissues, and to avoid spontaneous thrombosis. Media layer, called tunica media, is mostly composed of smooth muscle cells and collagen. It confers mechanical strength to the vessel and regulates the blood flow by contractions and relaxations. Finally, the outermost layer of vessel, called tunica adventitia, contains fibroblast embedded in an extra-cellular matrix that supports vascular innervation. 


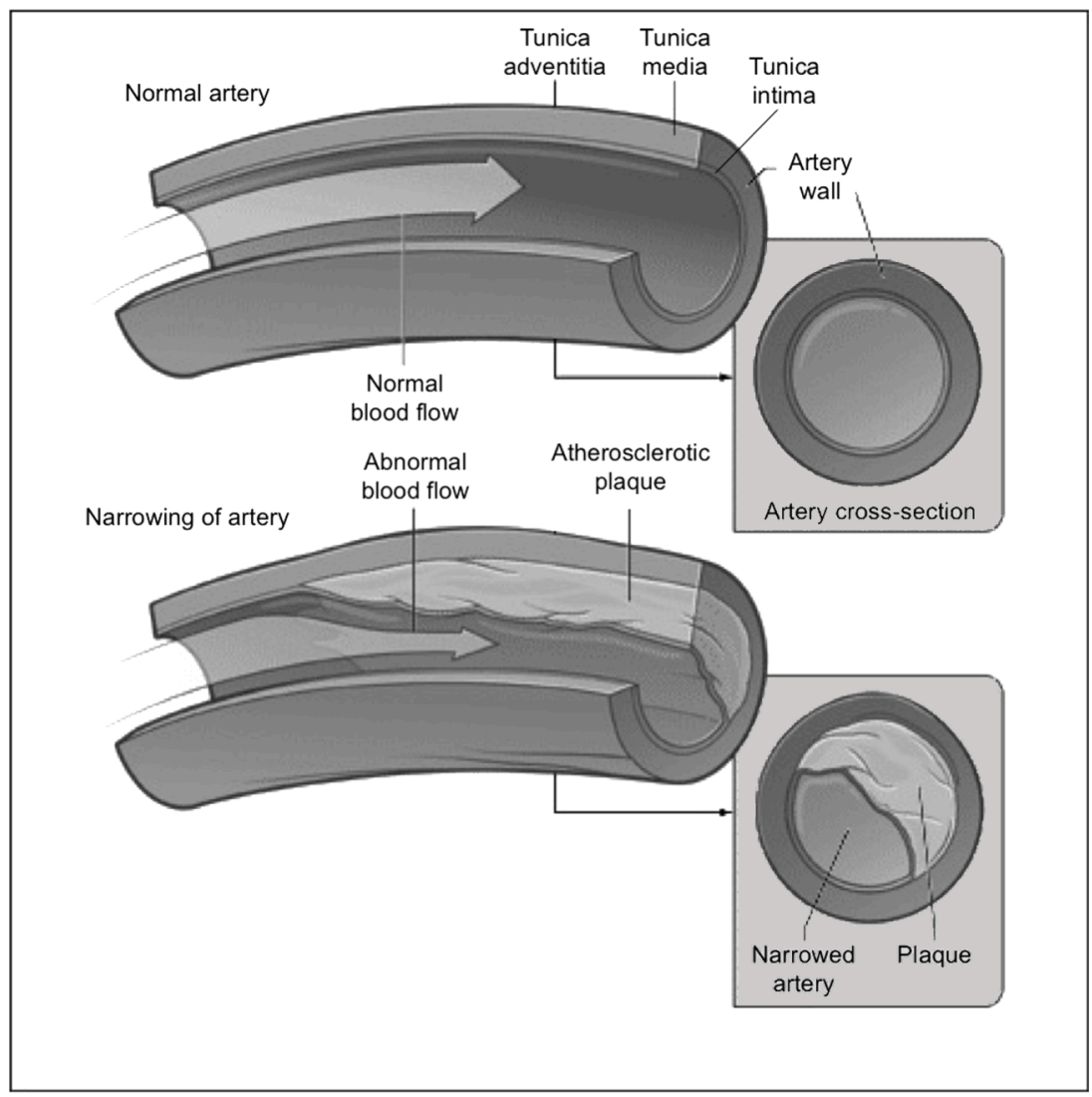

Figure 6. Morphology of a healthy (up) and atherosclerotic (down) human artery. The three different layers composing blood vessels can also be seen on the up image.

In people whose blood contains higher-than-normal amounts of lowdensity-lipoprotein (LDL) (mostly due to unhealthy diet and so high quantity of saturated fat), atherosclerosis may occur [82]. Following endothelial cells inflammation, LDL might penetrate into the tunica intima and get oxidized, leading to the activation of the immune system $[109,110]$. This leads to the recruitment of monocytes from blood, which will, after penetration into the tunica intima, differentiate into macrophages and ingest the LDL molecules, forming foam cells [109]. Foam cells form a stable plaque and continuously trigger the whole immune system, which promotes atherosclerosis progression [110]. As a consequence, blood vessel size gradually decreases (fig. 6). In worst cases, blood vessel can even be completely occluded [106].

Angioplasty or stenting is the commonest way to treat atherosclerosis. However, in worst cases (multiple artherosclerosis or total occlusion of the 
vessel), surgery will be necessary with replacement or bypass of the damaged blood vessel with artificial one [111]. Synthetic grafts were first used in surgery in 1952, when Voorhess implanted Vinyon-N cloth in dogs. Later, DeBakey successfully implanted Dacron as an arterial prosthesis, which lead to its commercialisation in 1957. Similarly, ePTFE grafts became commercially available in the 70's. Nowadays, Dacron and ePTFE are still the two most commonly used materials for vascular grafts manufacturing [112].

Although such grafts performed well when replacing large calibre vessels, they led to high failure rates when their diameter was under $6 \mathrm{~mm}$ $[105,107]$. Such failures were mostly due to acute thrombosis and intimal hyperplasia [113-115]. Because endothelial cells prevent thrombosis in vivo, they are interesting as coverage for vascular grafts [114]. In 1975, Mansfield et al were the first one who had the idea of seeding endothelial cells on synthetic grafts $[106,114]$. It is now established that this technique leads to reduce graft infections and increase graft patency: in a 9-years follow-up study, patency rates were of respectively $65 \%$ and $16 \%$ for seeded and non-seeded ePTFE grafts [116]. Numerous papers have addressed what should be the ideal scaffold, with main requirements being: (1) biocompatibility, (2) non-thrombogenicity, (3) mechanical strength, (4) resistance to infection and (5) technologically facile $[112,117,118]$. In these different aspects, flax fibers once woven/knitted into a vascular tube could represent an interesting new kind of scaffold for cardiovascular surgery, provided that its surface can be easily covered by endothelial cells to achieve long-term patency [118-120].

\section{Wound dressings}

The treatment of wounds is probably one of the oldest areas of specialisation in medicine. Already in $1550 \mathrm{BC}$, a papyrus describes that dressings composed of honey, grease and lint should be used to treat wounds [121]. Wound dressings (WD) can be used in as various fields as for severe injuries (e.g. war, car accident, ...), burns or chronic wounds (e.g. diabetic ulcer). It is widely accepted that they should (1) maintain a moist environment at the wound site by preventing fluid loss while absorbing excess exudate to encourage granulation and assist epithelialisation, (2) be impermeable to heat loss and bacteria, (3) allow gaseous exchange $\left(\mathrm{O}_{2} / \mathrm{CO}_{2}\right)$, (4) present no toxicity, (5) be easily removable (i.e. without causing additional traumas) [122-124]. In addition to this, the ideal WD should adhere firmly to the wound while authorizing movements, provide pain relief, allow infrequent changes and finally be cost effective with a long shelf-life [122-125]. Considering all these requirements, it is 
obvious that the ideal dressing does not exist. Hence, everything is a matter of compromises and priorities.

For example, a standard complication in wounds is bacterial infection $[122,126]$. Such a problem should be solved immediately, as it may lead to further complication, and even death [127]. Among the wide variety of antimicrobial products that can be used, silver is probably the most important one [128-130]. Its antimicrobial properties are already known since the nineteenth century, although Moyer was first one to prove in 1965 that a concentration of $0.5 \%$ silver nitrate $\left(\mathrm{AgNO}_{3}\right)$ in solution was the minimum needed to kill bacteria in vitro $[131,132]$. Its huge popularity arises from the fact that it presents a broad-spectrum of antibacterial activity, i.e. it is toxic to gramnegative and gram-positive bacteria [128].

The exact mechanism behind the anti-bacterial activity of silver nanoparticles is still not well understood [128,133]. However, it is known that the presence of $\mathrm{Ag}^{+}$ion is necessary to it [133-135]. Hence, although silver is not easy to oxidize (being a half-noble metal), it becomes highly sensitive to oxygen in a nano form $[133,135]$. As a consequence, in ambient conditions, a layer of chemisorbed $\mathrm{Ag}^{+}$forms on the particle surface. Experiments have shown that in the absence of this layer, no antimicrobial activity could be detected [135]. It is not demonstrated if it is by its elution or by direct contact that silver ions kill bacteria. Most probably, it is a combination of both mechanisms [133]. However, it is known that once present on the cytoplasmic membrane of bacteria, $\mathrm{Ag}^{+}$leads to mitonchondria dysfunction and so DNA damage and bacteria death [130,134, 136].

Interestingly, few dressings on the market combine hydrophilicity and antimicrobial properties [128]. As an example, super-hydrophilic materials exist, but they cannot be functionalized with antibacterial drugs and they are expensive to produce [128]. In this regard, the utilization of flax fibers, being a hydrophilic material, might bring some progress in this field, provided that silver can be grafted on the fibers while preserving its antimicrobial properties. 


\section{Aim of the thesis}

This thesis aims at providing a new class of implantable biomedical textiles with the utilisation of plant fibers. In this thesis, we especially focused on the use of flax fibers. Nowadays, most of the implantable textiles are made out of plastics. Although this led to major improvements, there are still issues concerning limitations (e.g. for blood vessels with a diameter inferior to $6 \mathrm{~mm}$ ) and potential complications. Furthermore, with the rise of environment awareness, there is now a tendency to look for green and sustainable alternatives to plastics.

The biocompatibility of flax fibers in vitro and in vivo was assessed in Chapter 2. For practical reasons, flax fibers were knitted into a mesh using the design of a commercially available abdominal mesh. First experiments showed that flax mesh was toxic in vivo, presumably due to the presence of huge amounts of endotoxins on its surface. A treatment build on bio-based solvents only (acetic acid, $\mathrm{NaCl}$, ethanol) was designed to purify the fibers. Such solvents were used to conserve at the end of the process green fibers with minimal environment impact. In vitro experiments showed that the purified flax mesh was compatible to cells. Implantation in rats showed that purified flax mesh led to similar immune response as a standard plastic mesh.

In Chapters 3 \& 4, flax fibers, knitted into the design of a mesh, were covered with two different coatings (namely polydopamine and albumin) to mask the presence of the endotoxins, and so, ultimately, lower the immunologic in vivo response. Moreover, it was expected that such coatings could further increase cellular adhesion. Presence of a polydopamine coating on flax fibers did not have any effect on cell adhesion and highly promoted the immune response of the resulting fibers in vitro, as described in Chapter 3. On the contrary, Chapter 4 shows that the albumin coating promoted endothelial cell adhesion, provided that dynamic conditions were used, and increased blood compatibility, with significant delay of thrombin generation and reduced platelet spreading. Albumin coating also decreased endotoxin signal by approximately $27 \%$. Flax fibers of three different diameters with or without albumin coating were further implanted in rats. Histological analysis showed that the severity of the inflammatory response was related to the diameter of the fiber, i.e. in vivo results were better with smaller threads. The presence of an albumin coating also led to a smaller immune response (i.e. reduced inflammation and less necrosis inside the flax bundles). 
Finally, flax fibers were covered with a SlipSkin ${ }^{\circledR}$ coating composed of 50 $\%$ NVP and $50 \%$ BMA in Chapter 5. Primary experiments showed that nonpurified fibers were still toxic to cells once coated, meaning that only purified fibers could be used as a scaffold for the coating. Under these conditions, fibers covered with SlipSkin ${ }^{\circledR}$ were non-toxic to cells in vitro. The addition of $20 \%$ silver nanoparticles in the coating successfully brought antibacterial properties to the fibers. Resulting fibers could be used to manufacture new kinds of wound dressings.

\section{References}

1. Kvavadze E, Bar-Yosef O, Berlfer-Cohen A, Boaretto E, Jakeli N, Matskevich Z, Meshveliani T. 30,000-year-old wild flax fibers. Science. 2009;325(5946):1359.

2. Yan L, Chouw N, Jayaraman K. Flax fibre and its composites - a review. Composites Part B. 2014;56:296-317.

3. Jolie E A, Lynch T F, Geib P R, Adovasio J M. Cordage, textiles and the late Pleistocene peopling of the Andes. Curr Anthropol. 2011;52(2):285-96

4. Cornu G, Martiniani-Reber M, editors. Tissus d'Egypte. Témoins du monde arabe, VIII-XVe siècle. Abaron. 1993.

5. Rutt R, editor. A history of hand knitting. Blatsford ltd. 1987.

6. Martin N, Mouret N, Davies P, Baley C. Influence of the degree of retting of flax fibers on the tensile properties of single fibers and short fiber/polypropylene composites. Ind crops prod. 2013;49:755-67.

7. Charlet K, Jernot J-P, Gomina M, Baley C, Bizet L, Brëard J. Morphology and mechanical behavior of a natural composite: the flax fiber. $16^{\text {th }}$ international conference in composite materials.

8. Mooney C, Stolle-Smits T, Schols H, de Jong E. Analysis of retted and non retted flax fibres by chemical and enzymatic means. J Biotechnol 2001;89(2-3):205-16.

9. Meijer W, Vertregt N, Rutgers B, van de Waart M. The pectin content as a measure of the retting and rettability of flax. Ind Crops Prod 1995;4(4):273-84.

10. Lefeuvre A, Bourmaud A, Lebrun L, Morvan C, Baley C. A study of the yearly reproducibility of flax fiber tensile properties. Ind Crops Prod 2013;50:400-7.

11. Burgert I. Exploring the micromechanical design of plant cell walls. Am J Bot 2006;93(10):1391-401.

12. Bledzki A K, Gassan J. Composites reinforced with cellulose based fibres. Prog Polym Sci 1999;24:221-74.

13. Bismarck A, Aranberri-Askargorta I, Springer J. Surface characterization of flax, hemp and cellulose fibers; surface properties and the water uptake behavior. Polym composites 2002;23(5):872-94.

14. Baley C. Fibres naturelles de renfort pour matériaux composites. Technique de l'Ingénieur. Reference number: N2220

15. Cuissinat C, Navard P. Swelling and dissolution of cellulose, part III: plant fibers in aqueous systems. Cellulose 2008;15(1):67-74. 
16. McGraw-Hill Dictionary of Scientific and Technical Terms, Vol. 6. McGraw-Hill Professional; 2002.

17. Bledzki A K, Gassan J. Composites reinforced with cellulose based fibres. Prog Polym Sci 1999;24:221-74.

18. Trouy-Triboulot M-C, Triboulot P. Matériau bois - structure et caractéristiques. Technique de l'Ingénieur. Reference number: C925.

19. Gilbert R D, Kadla J F. Polysaccharides - Cellulose. In: Kaplan D L, editor. Biopolymers from renewable resources. Springer Berlin Heidelberg. 1998:47-95.

20. Gavillon R, Preparation et caractérisation de matériaux cellulosique ultra poreux. $\mathrm{PhD}$ Thesis. Ecole des Mines de Paris, France. 2007.

21. Klemm D, Heublein B, Fink H-P, Bohn A. Cellulose: fascinating biopolymer and sustainable raw material. Angew Chem Int Ed 2005;44:3358-93.

22. Wada M, Ike M, Tokuyasu K. Enzymatic hydrolysis of cellulose I is greatly accelerated via its conversion to the cellulose II hydrate form. Polym Degrad Stabil 2010;95:543-8.

23. Baley C. Analysis of the flax fibres tensile behavior and analysis of the tensile stiffness increase. Compos Part A-Appl S 2002;33:939-48.

24. Nilsson T, Gustafsson P J. Influence of dislocations and plasticity on the tensile behavior of flax and hemp fibres. Compos Part A-Appl S 2007;38:1722-8.

25. Raj G, Balnois E, Baley C, Grohens Y. Role of polysaccharides on mechanical and adhesion properties of flax fibres in flax/PLA biocomposite. International Journal of Polymer Science 2011; article ID 503940:11 pages.

26. Baley C, Le Duigou A, Bourmaud A, Davies P. Influence of drying on the mechanical behavior of flax fibres and their unidirectional composites. Compos Part A-Appl S 2012;43:1226-33.

27. Stamboulis A, Baillie C A, Peijs T. Effects of environmental conditions on mechanical and physical properties of flax fibres. Compos Part A-Appl S 2001;32:1105-15.

28. Charlet K, Baley C, Morvan C, Jernot J P, Gomina M, Bréard J. Characteristics of Hermès flax fibres as a function of their location in the stem of the derived unidirectional composites. Compos Part A-Appl S 2007;38:1912-21.

29. Bourmaud A, Morvan C, Bouali A, Placet V, Perré P, Baley C. Relationships between micro-fibrillar angle, mechanical properties and biochemical composition of flax fibers. Ind Crops Prod 2013;44:343-51.

30. Morvan C, Andème-Onzighi C, Girault R, Himmelsbach D S, Driouich A, Akin D E. Building flax fibres: more than one brick in the walls. Plant Physiol Bioch 2003;41:93544.

31. Maxwell E G, Belshaw N J, Waldron K W, Morris V J. Pectin - an emerging new bioactive food polysaccharide. Trends Food Sci Tech 2012;24:64-73.

32. Munarin F, Tanzi M C, Petrini P. Advances in biomedical applications of pectin gels. Int J Biol Macromol 2012;51(4):681-9.

33. Martínez Á T, Speranza M, Ruiz-Dueñas F J, Ferreira P, Camarero S, Guillén F, Martínez M J, Gutiérrez A, del Río J C. Biodegradation of lignocellulosics: microbial, chemical, and enzymatic aspects of the fungal attack of lignin. Int Microbiol 2005;8:195-204.

34. Food additives in Europe 2000 - Status of safety assessments of food additives presently permitted in the EU. 2002;ISBN 92-893-0829-X:431.

35. Hubbe M A, Lucia L A. The "love-hate" relationship present in lignocellulosic materials. BioResources 2007;2(4):534-5. 
36. Laurichesse S, Averous L. Chemical modification of lignins: towards biobased polymers. Prog Polym Sci 2013.

37. Frei M. Lignin: Characterisation of a multifaceted crop component. The Scientific world journal 2013; article ID 436517:25 pages.

38. Day A, Ruel K, Neutelings G, Cronier D, David H, Hawkins S, Chabbert B. Lignification in the flax stem: evidence for an unusual lignin in bast fibers. Planta 2005;222:234-45.

39. Sasaki M, Adschiri T, Arai K. Production of cellulose II from native cellulose by nearand supercritical water solubilisation. J Agric Food Chem 2003;51:5376-81.

40. Pillin I, Kervoelen A, Bourmaud A, Goimard J, Montrelay N, Baley C. Could oleaginous flax fibers be used as reinforcement for polymers? Ind Crops Prod 2011;34:1556-63.

41. Carpita N C, Gibeaut D M. Structural models of primary cell walls in flowering plants: consistency of molecular structure with the physical properties of the walls during growth. The Plant Journal 1993;3(1):1-30.

42. Beck C B. Structure and development of the cell wall. In: Beck C B, editor. An introduction to plant structure and development. Cambridge University Press. 2005:57-80.

43. Haigler $\mathrm{C} \mathrm{H}$. Physiology and anatomical factors determining fiber structure and utility. In: Steward J McD, Oosterhuis D M, Heitholt J J, Mauney J R, editors. Physiology of Cotton. Springer Netherlands. 2010:33-47.

44. Haigler C H. Substrate supply for cellulose synthesis and its stress sensitivity in the cotton fiber. In: Brown R M Jr, Saxena I M, Editors. Cellulose: molecular and structural biology. Selected articles on the synthesis, structure, and applications of cellulose. Springer Netherlands. 2007:147-168.

45. $\mathrm{Hu} \mathrm{Y}$, Catchmark J M. Integration of cellulases into bacterial cellulose: toward bioabsorbable cellulose composites. J Biomed Mater Res B 2011;97(1):114-23.

46. Ratner B D. Biomaterials science: an interdisciplinary endeavor. In: Ratner B D, Hoffman A S, Schoen F J, Lemons J E, editors. Biomaterials science: an introduction to materials in medecine. Academic Press. 1996:1-8.

47. Hansen N M L, Plackett D. Sustainable films and coatings from hemicellulose: a review. Biomacromolecules 2008;9(6):1493-505.

48. Coviello T, Matricardi P, Marianecci C, Alhaique F. Polysaccharide hydrogels for modified release formulations. J Controlled release 2007;119:5-24.

49. Märtson M, Viljanto J, Hurme T, Laippala P, Saukko P. Is cellulose sponge degradable or stable as implantation material? An in vivo subcutaneous study in the rat. Biomaterials 1999;20:1989-95.

50. Singh M, Ray A R, Vasudevan P, Verma K, Guha S K. Potential biosoluble carriers: biocompatibility and biodegradability of oxidized cellulose. Biomat, med dev, art org 1979;7(4):495-512.

51. Dimitrijevich S D, Tatarko M, Gracy R W, Wise G E, Oakford L X. In vivo degradation of oxidized, regenerated cellulose. Carbohyd Res 1990;198:331-41.

52. Elçin A E. In vitro and in vivo degradation of oxidized acetyl- and ethyl-cellulose sponges. Artif cells nanomed biotechnol 2006;34:407-18.

53. Shah N, Ul-Islam M, Khattak W A, Park J K. Overview of bacterial cellulose composites: a multipurpose advanced material. Carbohyd Polym 2013;98:1585-98. 
54. Torres F G, Commeaux S, Troncoso O P. Biocompatibility of bacterial cellulose based biomaterials. J Funct Biomater 2012;3:864-78.

55. Fu L, Zhang J, Yang G. Present status and applications of bacterial cellulose based materials for skin tissue repair. Carbohyd Polym 2013;92:1432-44.

56. Gea S, Bilotti E, Reynolds C T, Soykeabkeaw N, Peijs T. Bacterial cellulose-poly(vinyl alcohol) nanocomposites prepared by an in-situ process. Mater lett 2010;64:901-4.

57. Czaja W, Krystynowicz A, Bielecki S, Brown R M Jr. Microbial cellulose - the natural power to heal wounds. Biomaterials 2006;27:145-51.

58. Bäckdahl H, Helenius G, Bodin A, Nannmark U, Johansson B R, Risberg B, Gatenholm P. Mechanical properties of bacterial cellulose and interactions with smooth muscle cells. Biomaterials 2006;27:2141-9.

59. Wippermann J, Schumann D, Klemm D, Kosmehl H, Salehi-Gelani S, Wahlers T. Preliminary results of small arterial substitute performed with a new cylindrical biomaterial composed of bacterial cellulose. Eur J Endovasc Surg 2009;37:592-6.

60. Kowalska -Ludwicka K, Cala J, Grobelski B, Sygut D, Jesionek-Kupnicka D, Kolodziejczyk M, Bielecki S, Pasieka Z. Modified bacterial cellulose tubes for regeneration of damaged peripheral nerves. Arch Med Sci 2013;9(3):527-34.

61. Oliveira J T, Reis R L. Polysaccharide-based materials for cartilage tissue engineering applications. J Tissue Eng Regen Med 2011;5:421-36.

62. Helenius G, Bäckdahl H, Bodin A, Nannmark U, Gatenholm P, Risberg B. In vivo biocompatibility of bacterial cellulose. J Biomed Mater Res A 2006;76(2):431-8.

63. Ghosh P. Natural fibres. In: Ghosh P, editor. Fibre Science and technology. Tata McGraw-Hill Education. 2003:36-102.

64. Xia Z, Triffitt J T. A review on macrophage responses to biomaterials. Biomed Mater 2006;1:R1-9.

65. Anderson J M, Rodriguez A, Chang D T. Foreign body response to biomaterials. Semin Immunol 2008;20:86-100.

66. Tsaryk R, Peters K, Unger R E, Scharnweber D, Kirkpatrick C J. The role of oxidative stress in the response of endothelial cells to metals. In: Antoniac I, editor. Biologically responsive materials for tissue engineering, vol. 1. Springer New York. 2013:65-88.

67. Prokopovich P, Perni S. Prediction of the frictional behavior of mammalian tissues against biomaterials. Acta Biomater 2010;6(10):4052-9.

68. Skórkowska-Telichowska K, Żuk M, Kulma A, Bugajska-Prusak A, Ratajczak K, Gąsiorowski K, Kostyn K, Szopa J. New dressing materials derived from transgenic flax products to treat long-standing venous ulcers - a pilot study. Wound Rep Reg 2010;18:168-179.

69. Kunert-Keil C, Gredes T, Meyer A, Wróbel-Kwiatkowska M, Dominiak M, Gedrange T. The survival and proliferation of fibroblasts on biocomposites containing genetically modified flax fibers: an in vitro study. Ann Anatomy 2012;194(6):513-7.

70. Gredes T, Kunert-Keil C, Dominiak M, Gedrange T, Wróbel-Kwiatkowska M, Szopa J. The influence of biocomposites containing genetically modidied flax fibers on gene expression in rat skeletal muscle. Biomed Tech 2010;55:323-9.

71. Vavřik J, Foltýnová V, Vítková I, Adámek S, Poučková P. Changes in abdominal wall after mesh implantation in rats. Med Sci Monit, 2000;6(3):476-9.

72. Cassano R, Trombino S, Ferrarelli T, Barone E, Arena V, Mancuso C, Picci N. Synthesis, characterization, and anti-inflammatory activity of diclofenac-bound cotton fibers. Biomacromolecules 2010;11:1716-20. 
73. Thorn J. The inflammatory response in humans after inhalation of bacterial endotoxin: a review. Inflamm res 2001;50:254-61.

74. Berry G, Molyneux M K B, Tombleson J B L. Relationships between dust level and byssinosis and bronchitis in Lancashire cotton mills. Brit J Ind Med 1974;31:18-27.

75. Niven R McL, Fletcher A M, Pickering C A C, Fishwick D, Warburton C J, Simpson J C G, Francis H, Oldham L A. Chronic bronchitis in textile workers. Thorax 1997;52:22-7.

76. Simpson J C G, Niven R M, Pickering C A C, Fletcher A M, Oldham L A, Francis H M. Prevalence and predictors of work related respiratory symptoms in workers exposed to organic dusts. Occup Environ Med 1998;55:668-72.

77. Lewis S, Singh D, Evans C E. Cyclic hydrostatic pressure and cotton particles stimulate synthesis by human lung macrophages of cytokines in vitro. Respir Res 2009;2:10-44.

78. Gorbet M B, Sefton M V. Endotoxin: the uninvited guest. Biomaterials 2005;26:68117.

79. For all information given in this paragraph, see website: http: / / www.bmsri.com/structures-overview/

80. Wasiak J, Cleland H, Campbell F, Spinks A. Dressings for superficial and partial thickness burns (review). Cochrane Database Syst Rev 2013;3.

81. The British Hernia Society. http://www.britishherniasociety.org

82. The National Health Service. http://www.nhs.uk

83. Matthews R D, Neumayer L. Inguinal hernia in the $21^{\text {st }}$ century: an evidence-based review. Curr Probl Surg 2008;45:261-312.

84. Kingsnorth A N, LeBlanc K A, editors. Management of Abdominal Hernias, $3^{\text {rd }}$ Ed. Springer London. 2011.

85. Read R C. Herniology, past present and future. Hernia 2009; 13(6) 577-80.

86. Sanders D L, Kingsnorth A N. From ancient to contemporary times: a concise history of incisional hernia repair. Hernia 2012;16:1-7.

87. Luijendijk R W, Hop W C, van den Tol M P, de Lange D C, Braaksma M M, Ijzermans J N, Boelhouwer R U, de Vries B C, Salu M K, Wereldsma J C, Bruijninckx C M, Jeekel J. A comparison of suture repair with mesh repair for incisional hernia. $N$ Engl J Med 2000;343(6):392-8.

88. Shankaran V, Weber D J, Reed R L, Luchette F A. A review of available prosthetics for ventral hernia repair. Ann Surg 2011;253:16-26.

89. Brown C N, Finch J G. Which mesh for hernia repair? Ann R Coll Surg Engl 2010;92:272-8.

90. Burger J W A, Halm J A, Wijsmuller A R, ten Raa S, Jeekel J. Evaluation of new prosthetic meshes for ventral hernia repair. Surg Endosc 2006;20:1320-5.

91. Emans P J, Schreinemacher M H F, Gijbels M J J, Beets G L, Greve J-W M, Koole L H, Bouvy N D. Polypropylene meshes to prevent abdominal herniation. Can stable coatings prevent adhesions in the long term? Ann Biomed Eng 2009;37(2):410-8.

92. Schreinemacher M H F, Emans P J, Gijbels M J J, Greve J-W M, Beets G L, Bouvy N D. Degradation of mesh coatings and intraperitoneal adhesion formation in an experimental model. Br J Surg 2009;96:305-13.

93. Burns N K, Jaffari M V, Rios C N, Mathur A B, Butler C E. Non-cross-linked porcine acellular derma matrices for abdominal wall reconstruction. Plast Reconstr Surg 2010;125(1):167-76. 
94. Coda A, Lamberti R, Martorana S. Classification of prosthetics used in hernia repair based on weight an biomaterial. Hernia 2012;16(1):9-20.

95. Bringman S, Conze J, Cuccurullo D, Deprest J, Junge K, Klosterhalfen B et al. Hernia repair: the search for ideal meshes. Hernia 2010;14(1):81-7.

96. Klosterhalfen B, Junge K, Klinge U. The lightweight and large pores concept for hernia repair. Expert Rev Med Devices 2005;2(1):103-17.

97. Doctor GH. Evaluation of various prosthetic materials and newer meshes for hernia repairs. J Minim Access Surg 2006;2(3):110-6.

98. Klinge U, Klosterhalfen B. Modified classification of surgical meshes for hernia repair based on the analyses of 1000 explanted meshes. Hernia 2012; 16:251-8.

99. O’Dwyer P J, Kingsnorth A N, Molloy R G, Small P K, Lammers B, Horeyseck G. Randomized clinical trial assessing impact of a lightweight or heavyweight mesh on chronic pain after inguinal hernia repair. Brit J Surg 2005;92:166-70.

100. Conze J, Rosch R, Klinge U, Weiss C, Anurov M, Titkowa S, Oettinger A, Schumpelick V. Polypropylene in the intra-abdominal position: influence of pore size and surface area. Hernia 2004;8:365-72.

101. Smart N J, Marshall M, Daniels I R. Biological meshes: a review of their use in abdominal wall hernia repairs. Surgeon 2012;10:159-71.

102. Mulier K E, Nguyen A H, Delaney J P, Marquez S. Comparison of Permacol ${ }^{\mathrm{TM}}$ and Strattice $^{\mathrm{TM}}$ for the repair of abdominal wall defects. Hernia 2011;15:315-9.

103. Klinge U, Si Z Y, Zheng H, Schumpelick V, Bhardwaj R S, Klosterhalfen B. Abnormal collagen I to III distribution in the skin of patients with incisional hernia. Eur Surg Res 2000;32:43-8.

104. Klinge U, Binnebösel M, Rosch R, Mertens P. Hernia recurrence as a problem of biology and collagen. J Minim Access Surg 2006;2(3):151-4.

105. MacNeill B D, Pomerantseva I, Lowe H C, Oesterle S N, Vacanti J P. Toward a new blood vessel. Vasc Med 2002; 7:241-6.

106. Ahrenstedt N A. Surface modification of cellulose materials from wood pulps to artificial blood vessels. PhD Thesis. KTH Royal Institute of Technology, Sweden. 2007.

107. Zhang W J, Liu W, Cui L, Cao Yilin. Tissue engineering of blood vessel. J Cell Mol Med 2007;11(5):945-57.

108. Ponticos M, Smith B D. Extracellular matrix synthesis in vascular disease: hypertension, and atherosclerosis. J Biomed Res 2014;28(1):25-39.

109. Fredman G, Spite M. Recent advances in the role of immunity in atherosclerosis. Circ Res 2013;113(12):111-4.

110. Moore K J, Sheedy F J, Fisher E A. Macrophages in atherosclerosis: a dynamic balance. Nat Rev Immunol 2013;13(10):709-21.

111. Michaels A D, Chatterjee K. Angioplasty versus bypass surgery for coronary artery disease. Circulation 2002;106:187-90.

112. Ku D N, Allen R C. Vascular grafts. In: Bronzimo J D. The biomedical engineering handbook: $2^{\text {nd }}$ edition. CRC Press. 2000.

113. Shin Y M, Lee Y B, Kim S J, Kang J K, Park J-C, Jang W, Shin H. Mussel-inspired immobilization of vascular endothelial growth factor (VEGF) for enhanced endothelialization of vascular grafts. Biomacromolecules 2012;13(7):2020-8.

114. Heyligers J M, Arts C H, Verhagen H J, de Groot P G, Mool F L. Improving smalldiameter vascular grafts: from the application of an endothelial cell lining to the construction of a tissue-engineered blood vessel. Ann Vasc Surg 2005;19(3):448-56. 
115. Rotmans J I, Heyligers J M M, Stroes E S G, Pasterkamp G. Endothelial cell-seeded grafts: rash and risky. Can J Cardiol 2006;22(13):1113-6.

116. Deutsch M, Meinhart J, Fischlein T, et al. Clinical autologous in vitro endothelialization of infrainguinal ePTFE grafts in 100 patients: a 9-year experience. Surgery 1999;126:847-55.

117. Kurobe H, Maxfield M W, Breuer C K, Shinoka T. Concise review: tissue-engineered vascular grafts for cardiac surgery: past, present, and future. Stem cells Transl Med 2012;1(7):566-71.

118. Li S, Sengupta D, Chien S. Vascular tissue engineering: from in vitro to in situ. Wiley Interdiscip Rev Syst Biol Med 2014;6:61-76.

119. Zuwei M A, He W, Yong T, Ramakrishna S. Grafting of gelatin on electrospun poly(caprolactone) nanofibers to improve endothelial cell spreading and proliferation and to control cell orientation. Tissue Eng 2005;11(7-8):1149-58.

120. Bos G W, Scharenborg N M, Poot A A, Engbers G H M, Beugeling T, van Aken W G, Feijen J. Blood compatibility of surfaces with immobilized albumin-heparin conjugate and effect of endothelial cell seeding on platelet adhesion. J Biomed Mater Res 1999;47(3):279-91.

121. Bellik Y, Boukraâ L. Honey: an Ethnomedicine. In: Boukraâ L. Honey in traditional and modern medicine. CRC Press. 2013:1-12.

122. Jones V, Grey J E, Harding K G. ABC of wound healing. Wound dressings. BMJ 2006;332:777-80.

123. Atiyeh B S, Hayek S N, Gunn S W. New technologies for burn wound closure and healing - Review of the literature. Burns 2005;31:944-56.

124. Wasiak J, Cleland H, Campbell F. Dressings for superficial and partial thickness burns (review). Cochrane database Syst Rev 2008;4.

125. Kane J B, Tompkins R G, Yarmush M L, Burke J F. Application of materials in medicine and dentistry: burn dressings. In: Ratner B D, Hoffman A S, Schoen F J, Lemons J E, editors. Biomaterials science: an introduction to materials in medecine. Academic Press. 1996:360-70.

126. Enoch S, Grey J E, Harding K G. ABC of wound healing. Non surgical and drug treatments. BMJ 2006;332:900-3.

127. Seetharaman S, Natesan S, Stowers R S, Mullens C, Baer D G, Suggs L J, Christy R J. A PEGylated fibrin-based wound dressing with antimicrobial and angiogenic activity. Acta Biomater 2011;7(7):2787-96.

128. Peršin Z, Maver U, Pivec T, Maver T, Vesel A, Mozetič M, Stana-Kleinschek K. Novel cellulose based materials for safe and efficient wound treatment. Carbohydr Polym 2014;100:55-64.

129. Poon V K M, Burd A. In vitro cytotoxicity of silver: implication for clinical wound care. Burns 2004;30:140-7.

130. Kim Y-J, Yang S I, Ryu J-C. Cytotoxicity and genotoxicity of nano-silver in mammalian cell lines. Mol Cell Toxicol 2010;6:119-25.

131. Klasen H J. Historical review of the use of silver in the treatment of burns. I. Early uses. Burns 2000;26:117-30.

132. Klasen H J. Historical review of the use of silver in the treatment of burns. II. Renewed interest for silver. Burns 2000;26:131-8.

133. Stevens K N, Crespo-Biel O, van den Bosch E E, Dias A A, Knetsch M L, Aldenhoff Y B, van der Veen F H, Maessen J G, Stobberingh E E, Koole L H. The relationship 
between the antimicrobial effect of catheter coatings containing silver nanoparticles and the coagulation of contacting blood. Biomaterials 2009;30(22):3682-90.

134. Liu J, Sonshine D A, Shervani S, Hurt R H. Controlled release of biologically active silver from nanosilver surfaces. ACS Nano 2010;4(11):6903-13.

135. Lok C-N, Ho C-M, Chen R, He Q-Y, Yu W-Y, Sun H, Tam P K-H, Chiu J-F, Che CM. Silver nanoparticles: partial oxidation and antibacterial activities. J Biol Inorg Chem 2007; 12:527-34.

136. AshaRani P V, Low Kah Mun G, Hande M P, Valiyaveettil S. Cytotoxicity and genotoxicity of silver nanoparticles in human cells. ACS Nano 2009;3(2):279-90. 


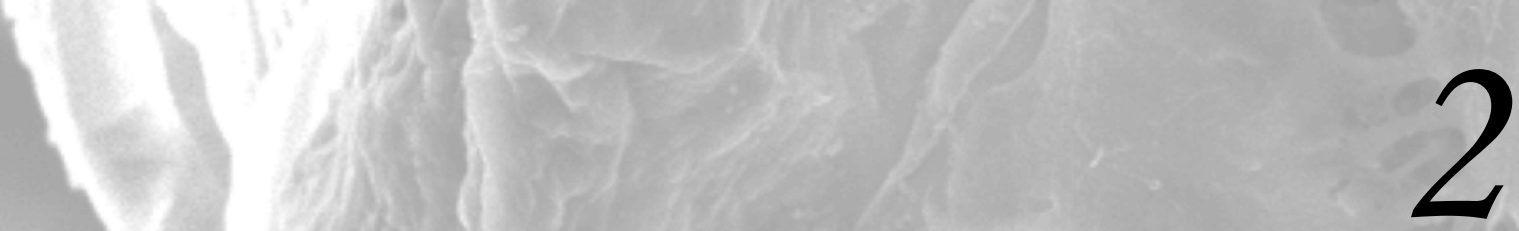

Utilization of flax fibers for biomedical applications

Sophie A A X Michel, Ruben RM Vogels, Nicole D Boury, Menno L W Knetsch, JNynke M S van den AkKer, Marion I J Gijbels, Cees van der Marel, Jan Vermeersch, Daniel G M Molin and Leo H Koole.

J Biomed Mater Res Part B 2013; doi: 10.1002/j6m.6.33025 


\section{Abstract}

Over the past decades, a large number of animal-derived materials have been introduced for several biomedical applications. Surprisingly, the use of plantbased materials has lagged behind. To study the feasibility of plant-derived biomedical materials, we chose flax (Linum usitatissimum). Flax fibers possess excellent physical-mechanical properties, are non-biodegradable, and there is extensive know-how on weaving/knitting of them. One area where they could be useful is as implantable mesh structures in surgery, in particular for the repair of incisional hernias of the abdominal wall. Starting with a bleached flax thread, a prototype mesh was specifically knitted for this study, and its cytocompatibility was studied in vitro and in vivo. The experimental data revealed that application of flax in surgery first requires a robust method to remove endotoxins and purify the flax fiber. Such a method was developed, and purified meshes did not cause loss of cell viability in vitro. In addition, endotoxins determined using LAL test were at acceptable levels. In vivo, the flax meshes showed only mild inflammation, comparable to commercial polypropylene meshes. This study revealed that plant-derived biomaterials could provide a new class of implantable materials that could be used as surgical meshes or for other biomedical applications.

\section{Introduction}

During the past two decades, there has been a clear trend towards study and use of bio-derived and bio-inspired materials for many different biomedical applications. For example, the potential of silk fiber matrices and wool keratin scaffolds for tissue engineering has been described [1-3]. In addition, chitosan was found to be very suitable in vitro and in vivo, and this material is now applied in wound dressings, drug delivery devices, and scaffold in tissue engineering [4-6]. Remarkably, only a minority of the biological materials that have been screened for in vivo applications are of plant origin. This is quite surprising since several reports describing the almost non-immunogenicity of cellulose have been published [7-15]. Bacterial cellulose implanted in rats induced a negligible foreign body response [7-12]. Cellulose acetate, cellulose sponge and cellulose phosphate also elicit non- or low-immunogenic responses [8,13-15]. The wound dressing product Dermafill $^{\circledR}$ (Cellulose solutions, LLC) is an important example of a successful commercial product that is made out of bacterial cellulose and FDA approved. 
In this study, we set out to answer the question whether plant derived fibers could be used in non-biodegradable medical devices. An obvious drawback to their use in biomedical devices may be the difficulty to obtain cellulose in sufficiently pure form, i.e. free from lignin and pectin. In this study, we specifically focused on flax (Linum usitatissimum). The physical-mechanical properties of the flax fibers have been well described - a high tensile strength $(1339 \pm 486 \mathrm{MPa})$ with low elasticity $(3.27 \pm 0.84 \%)$ - and techniques to apply flax in the production of textiles (linen) are extensively developed [16,17]. As flax fibers are predominantly composed of polysaccharides - cellulose (approximately $64 \%$ ) and hemicellulose (approximately $16.7 \%$ ) - we expected a priori that they would exhibit favorable biocompatibility [18-19]. Moreover, procedures and chemical reactions have been designed to isolate these two compounds and finally obtain pure or nearly pure cellulose [20,21].

Surgical meshes could be one especially interesting area for flax fibers. These implants are routinely used in the surgical repair of incisional hernias in the abdominal wall $[23,23]$. Implantable meshes are also used to treat pelvic organ prolapse (POP) $[24,25]$. The majority of the commercially available meshes are made out of polypropylene fibers [26,27]. Unfortunately, the use of these products lead is still associated with many complications, such as adhesions (in abdominal repair), or erosions, extrusions and contractions (in POP) [24-27]. Regarding abdominal wall repair, it is clear that the mesh techniques offer important advantages: implantation of a mesh leads to lower recurrence rates as compared to suture repair [22,23]. In POP surgery, however, the pros and contras of implantable synthetic meshes are still a matter of debate [24,27,28]. This indicates that there is an urgent need for improved structures and/or new kinds of mesh materials.

Here, we report a study on an experimental mesh that was especially knitted from a $181 \mu$ m-thick multifilament flax thread for this research project. The design of the mesh was essentially a copy of a commercial polypropylene mesh. We studied cytocompatibility of our experimental mesh in vitro, and biosafety in vivo. After some poor initial results with the mesh per se, we designed a new purification treatment based on Soxhlet automated extraction, using green (biobased, non-toxic) solvents only. The treatment removes almost completely (if not all) endotoxins, which is mandatory to obtain adequate biocompatibility. The data obtained on the experimental mesh demonstrate that flax fibers can be used for biomedical applications. 


\section{Materials and Methods}

\section{Materials}

Brown and white flax threads were obtained from the company Van der Bilt Seeds \& Flax BV, Sluiskil, the Netherlands. White flax threads were free of pectin and lignin due to additional treatment with hydrogen peroxide $[29,30]$. Dulbecco's modified eagle medium (DMEM/F-12 + Glutamax-1), Fetal bovine serum (FBS), Trypsin-EDTA, Antibiotics (penicillin, streptomycin, amphotericine), the live/dead and CyQUANT ${ }^{\circledR}$ Cell Proliferation Assay Kits were purchased from Invitrogen (Bleiswijk, The Netherlands). Thiazolyl blue tetrazolium bromide (MTT) was from Sigma (Zwijndrecht, Netherlands). All other standard chemicals were from Acros (Landsmeer, The Netherlands) and were used as received. Absorbance and fluorescence measurements were obtained using a microplate reader (SpectraMax M2, Molecular Devices, Wokingham, United Kingdom)

\section{Chemical treatment of flax fibers}

Holocellulose and cellulose II threads were prepared from brown flax yarns according to the procedures described by Bledzki [21]. After the appropriate treatments, holocellulose fibers (free from extractibles and lignin) and cellulose II fibers were dried at $70{ }^{\circ} \mathrm{C}$ and weighed.

Composition of flax fibers was obtained by comparing air-dried weight of flax before any treatment and after the appropriate treatment using the formulas:

Mass $\%$ extractables $=($ Mass before treatment - Mass after treatment $) \times 100$

Mass before treatment

Mass $\%$ cellulose $=\underline{\text { Mass after all extracting treatments }} \times 100$

Mass before treatment

Production of an experimental flax mesh

Especially for this study, the white flax thread was used to knit an experimental mesh; the design of the PROLENE ${ }^{\mathrm{TM}}$ mesh (Ethicon, Johnson \& Johnson) was reproduced (fig. 1). PROLENE ${ }^{\mathrm{TM}}$ is commonly used for abdominal hernia repair and possesses a rather dense structure, allowing maximal cell contact and population. The knitting was done by Centexbel (Verviers, Belgium). The white flax mesh was obtained as a strip with a width of approximately $8 \mathrm{~cm}$, and a 
length of several meters. Small mesh pieces could easily be cut out of the strip; such pieces were used in our further experiments in vitro and in vivo.

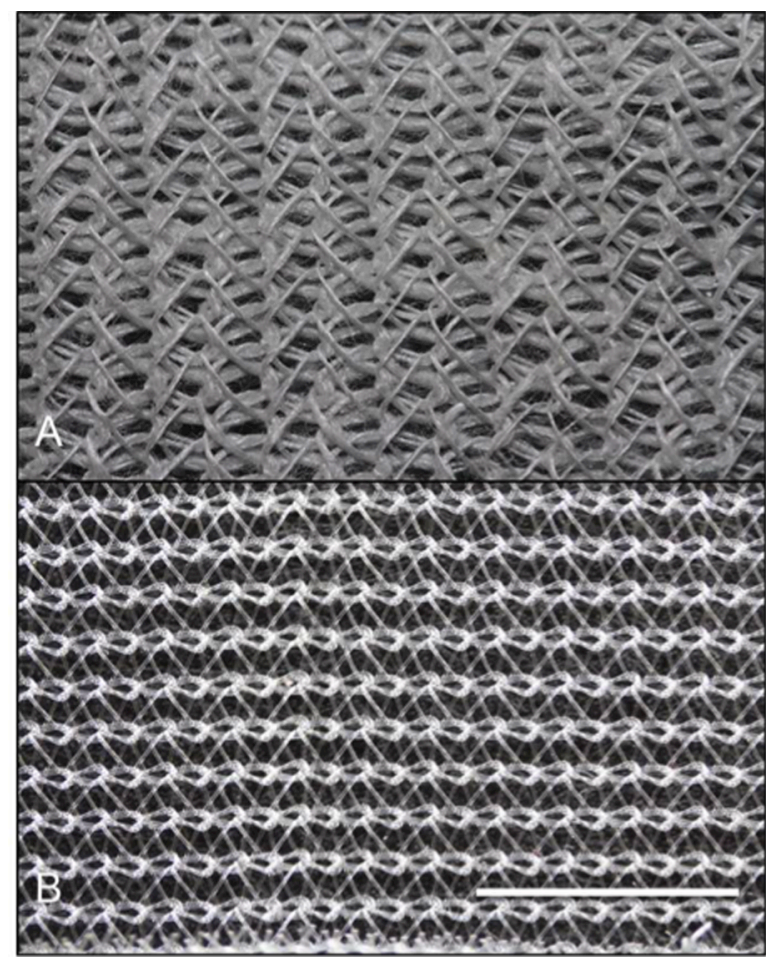

Figure 1. Detailed photographs of (A) flax and (B) polypropylene meshes. Scale bar represents 1 $\mathrm{cm}$.

Soxhlet purification of the mesh

Mesh (with dimensions of typically $20 \times 8 \mathrm{~cm}$ ) was put in a Soxhlet device without a filter for $48 \mathrm{~h}$. During the first $24 \mathrm{~h}, 5 \% \mathrm{v} / \mathrm{v}$ acetic acid and $10 \% \mathrm{wt}$ $\mathrm{NaCl}$ in doubly distilled water was used as solvent. During the last $24 \mathrm{~h}, 75 \%$ ethanol in water was used as solvent. After the procedure, the mesh was rinsed with ethanol and with excess water and dried $\left(70^{\circ} \mathrm{C}\right.$, overnight $)$.

\section{Scanning electron microscopy}

Samples of flax fibers were dried, put on carbon tape and sputter-coated with gold. Images were recorded with a scanning electron microscope (Philips XL 30, FEI, Eindhoven, The Netherlands) at an operating voltage of $15 \mathrm{kV}$. 
XPS analysis

Analyses were performed on untreated and Soxhlet treated meshes (dimensions 10 $\mathrm{x} 10 \mathrm{~mm}$ ). The measurements have been carried out in a XPS Microprobe (Quantera SXM ${ }^{\mathrm{TM}}$, ULVAC-PHI, Chigasaki, japan). The measurements have been performed using monochromatic AlKa-radiation and a spot size of 200 x $600 \mu \mathrm{m}$. By means of wide-scan measurements the elements present at the surface have been identified. Accurate narrow-scans have been measured to determine the surface concentrations. Standard sensitivity factors were used to convert peak areas to atomic concentrations.

\section{Cell culture}

Mouse fibroblasts (clone L929 cells) were grown in DMEM/F12-1 medium containing Glutamax and supplemented with $10 \%$ fetal bovine serum and antibiotics $(100 \mathrm{U} / \mathrm{mL}$ penicillin, $100 \mu \mathrm{g} / \mathrm{mL}$ streptomycin, $0.25 \mu \mathrm{g} / \mathrm{mL}$ amphotericin B) and incubated at $37{ }^{\circ} \mathrm{C}$ and $5 \% \mathrm{CO}_{2}$. Cells were harvested with $0.05 \%$ Trypsin/0.53 mM EDTA. When used in contact with cells, all flax materials were steam-sterilised at $121^{\circ} \mathrm{C}$ for 15 minutes.

\section{Indirect cytotoxicity evaluation}

Flax fibers and meshes were incubated in medium $(0.05 \mathrm{~g} / \mathrm{mL})$ for three days at $37{ }^{\circ} \mathrm{C}$ under agitation. Cells were harvested, seeded in a 96 well plate at a density of 10.000 cells per well and incubated for $16 \mathrm{~h}$. Following removal of the medium, the flax extracts were added to the cells and incubated for $48 \mathrm{~h}$. Then, concentrated MTT solution in medium was added to a final concentration of 0.25 $\mathrm{mg} / \mathrm{mL}$. The MTT was left for $2 \mathrm{~h}$ and the formed blue formazan crystals were dissolved in isopropanol. The absorbance at $570 \mathrm{~nm}$ was determined and cell viability was defined as percentage of the viable control (pure medium). Medium containing $5 \%$ DMSO was used as toxic control, and the extract of commercially available polypropylene mesh was used for comparison.

Microscopic observation of $L 929$ cells incubated with flax meshes and polypropylene meshes.

Flax mesh specimens of $10 \times 10 \mathrm{~mm}$ were put in 6-well plates, fixed to the bottom by a metal ring. L292 cells were added at a density of 150.000 cells per well. Plates were incubated for $72 \mathrm{~h}$. Morphology of cells was observed with an inverted microscope $\left(\operatorname{EVOS}_{\mathrm{xl}}\right.$, Invitrogen, Bleiswijk, The Netherlands). Medium 
was used as a viable control and latex as a toxic control; commercial PP mesh (cut to $10 \times 10 \mathrm{~mm}$ ) was used for comparison.

\section{Direct cytotoxicity evaluation}

The viability of cells seeded on flax fibers submitted to different chemical treatments was evaluated with the Live/Dead Viability/Cytotoxicity Kit. Flax fibers and commercially available polypropylene meshes of $10 \times 10 \mathrm{~mm}$ were incubated in $2.5 \mathrm{~mL}$ medium at $37^{\circ} \mathrm{C}$ for two periods of two days in refreshed medium. Meshes were put in 6 well plates, $100 \mu \mathrm{L}$ of a highly concentrated cell suspension $(\approx 1.600 .000$ cells $/ \mathrm{mL})$ was put directly on each mesh and incubated for four hours to allow adhesion of cells with flax fibers. Subsequently, $5 \mathrm{~mL}$ of medium was added to each well followed by incubation for three days at $37^{\circ} \mathrm{C}$. Subsequently, meshes were rinsed three times with $5 \mathrm{~mL}$ sterile PBS and transferred into a new 6-wells plate. $200 \mu \mathrm{L}$ of a solution of $2 \mu \mathrm{M}$ Calcein AM and $4 \mu \mathrm{M}$ of EthD-1 in sterile PBS was put on top of each mesh and the plate was incubated in the dark at room temperature for $20 \mathrm{~min}$ before observing the adhered cells using a fluorescence microscope (Nikon eclipse E800). Pictures were taken at two different wavelengths: $465-595 \mathrm{~nm}$ (excitation-emission) to visualize (green) live cells and 540-580 $\mathrm{nm}$ for (red) dead cells.

\section{Cell Growth}

Flax meshes and polypropylene meshes were cut into $10 \mathrm{x} 10 \mathrm{~mm}$ samples and put in 24-well plates. Then, $100 \mu \mathrm{L}$ of a 100.000 cells $/ \mathrm{mL}$ solution of cells suspended in medium was added on top of each mesh. Meshes were incubated for $4 \mathrm{~h}$ to allow cell adhesion. Then, $1 \mathrm{~mL}$ of medium was added in each well. Medium was changed every $48 \mathrm{~h}$ or when needed as indicated by color change of the medium, and meshes were taken out every one, two or three days to be frozen at $-80{ }^{\circ} \mathrm{C}$. At the end of the experiment the CyQUANT ${ }^{\circledR}$ Cell Proliferation Assay Kit was used to analyze the number of attached cells. Values on percentage of cells were obtained by dividing cell amount by the number of cells reached at plateau. Plateau values were of approximately 36.000 cells for Polypropylene mesh and 20.000 cells for untreated and Soxhlet treated mesh.

\section{Endotoxin analysis}

Flax meshes and polypropylene meshes were autoclaved for 15 minutes at $121{ }^{\circ} \mathrm{C}$ and tested for endotoxin using the limulus amebocyte lysate (LAL) endpoint chromogenic test (Lonza, Verviers, Belgium). Such lysate is extracted from the blood of the horseshoe crab. In this assay, the presence of endotoxins will activate 
the LAL lysate which will in turn cleave a colorless synthetic chromogenic substrate, thereby liberating p-nitroanilide (yellow). The higher the endotoxin concentration in the specimen, the faster the production of p-nitroanilide.

Meshes were cut into $10 \times 10 \mathrm{~mm}$ pieces and placed individually in the wells of a 24-well plate. $1 \mathrm{~mL}$ LPS-free water was added to each well and samples were left for overnight incubation at $37{ }^{\circ} \mathrm{C}$ under agitation. First, incubated water extracts were analyzed for endotoxins according to manufacturer's instructions. Briefly, $50 \mu \mathrm{L}$ aqueous extract was mixed with 50 $\mu \mathrm{L}$ LAL reagent and incubated for 10 minutes at $37{ }^{\circ} \mathrm{C}$. Then, $100 \mu \mathrm{L}$ chromogenic substrate was added to the mixture. Six minutes later, reaction was stopped with $25 \%$ acetic acid. The absorbance of the 96-well plate samples was analyzed at $405 \mathrm{~nm}$ and absorbance values were converted into Endotoxin Unit (EU) thanks to the reference curve. When necessary, proper dilution of the reactions was performed in the reference curve window of 0.1 to $1 \mathrm{EU} / \mathrm{mL}$.

Incubated water extracts were discarded and each mesh sample was rinsed with $3 \times 1 \mathrm{~mL}$ LPS-free water. Meshes were then put in a new 24-well plate to determine the amount of endotoxins directly present on them. The same procedure as the one described above was used with reagents volumes being multiplied by three. At the end of the assay, $300 \mu \mathrm{L}$ of each reaction mixture was transferred to a 96-well plate for absorption analysis.

\section{In vivo biocompatibility}

Male Wistar rats weighing 250-300 g were housed and cared for at the Central Animal Facilities of Maastricht University with free access to water and food, in accordance with local standards. The experimental protocol was approved by the Committee of Animal Experiments in accordance to the Dutch Animal Experimentation Act.

The two different experimental flax meshes were implanted in the dorsal subcutaneous space (group size: $\mathrm{n}=4$ with 2 meshes/rat) and compared to Polypropylene meshes $(n=4)$ (Parietene ${ }^{\mathrm{TM}}$, Sofradim Production, Trévoux, France; part of Covidien, North Haven, Connecticut, USA).

\section{Surgical procedure}

Anesthesia was induced by inhalation of Isoflurane through a small animal ventilator. The skin on the back of the rats was shaved and disinfected using $4 \%$ iodine before covering with sterile drapes. A 2-cm midline incision was made in 
the back of the rat. Two subcutaneous pockets were carefully prepared. Meshes were emerged in sterile phosphate buffered saline for one minute to allow full absorption of PBS by the flax meshes before implantation. A sterile piece of mesh $10 \times 30 \mathrm{~mm}$ was inserted into each pocket, without further fixation. The skin was closed intracutaneously with a running suture (Monocryl ${ }^{\mathrm{TM}}$; Ethicon, Johnson \& Johnson, Somerville, New Jersey, USA). No antibiotics were administered.

\section{Macroscopic and microscopic evaluation}

Rats were euthanized by an overdose of inhaled carbon dioxide after 7 days of follow-up. The incision on the back was opened and the skin over the mesh was carefully removed. Infection was defined as a clinical apparent infection with pus at the time of death. After macroscopic evaluation the mesh was excised locally with adjacent muscle tissue. Each specimen was fixed in $4 \%$ formaldehyde solution for $24 \mathrm{~h}$, after which the specimens were embedded in paraffin.

Slices of $5 \mu \mathrm{m}$ thick were stained with hematoxylin and eosin (H\&E) using standard histological techniques. Histologic assessments were performed by an experienced pathologist, blinded to the study groups.

\section{Results}

Characterization of untreated and treated flax threads

The brown and white flax threads were first examined by scanning electron microscopy. Figure 2(A) shows the brown flax yarn, as received from the manufacturer. The filaments partially stick together, presumably due to the presence of pectin [31]. Treatment of this brown flax thread with glacial acetic

Table I. Chemical composition of brown flax fibers

*Experiments were done in triplo.

\begin{tabular}{lc}
\hline & Amount of compound (in percentage) \\
\hline Extractibles and lignin & $3.5 \pm 0.2^{*}$ \\
Hemicellulose & $8.1 \pm 2.2^{*}$ \\
Cellulose & $88.5 \pm 2.0^{*}$ \\
\hline
\end{tabular}


acid yielded a holocellulose yarn (fig. 2(B)) [21], which clearly has weakened adhesions between the filaments, resulting in a more open bundle. Additional treatment with $17.5 \% \mathrm{NaOH}$ afforded cellulose II threads (fig. 2(C)) [21,32]. This severe treatment at high $\mathrm{NaOH}$ concentration destroys the mechanical properties of the yarn, and therefore cannot be used to purify the flax [33,34]. Interestingly, the two-step purification (first acetic acid, then $\mathrm{NaOH}$ ) provided information about extractibles such as pectin and lignin (both removed in the first step), and hemi-cellulose (removed in the second step; Table 1). Both steps together led to $\approx 12 \%$ mass reduction. Figure $2(\mathrm{D})$ shows the white flax thread, as it was received from the manufacturer; this material received a bleach treatment with $\mathrm{H}_{2} \mathrm{O}_{2}$. The yarns in figures 2(A) and (D) look similar, while cleansing effect of the $\mathrm{H}_{2} \mathrm{O}_{2}$ treatment can be noted. Figure 2(E,F) again show

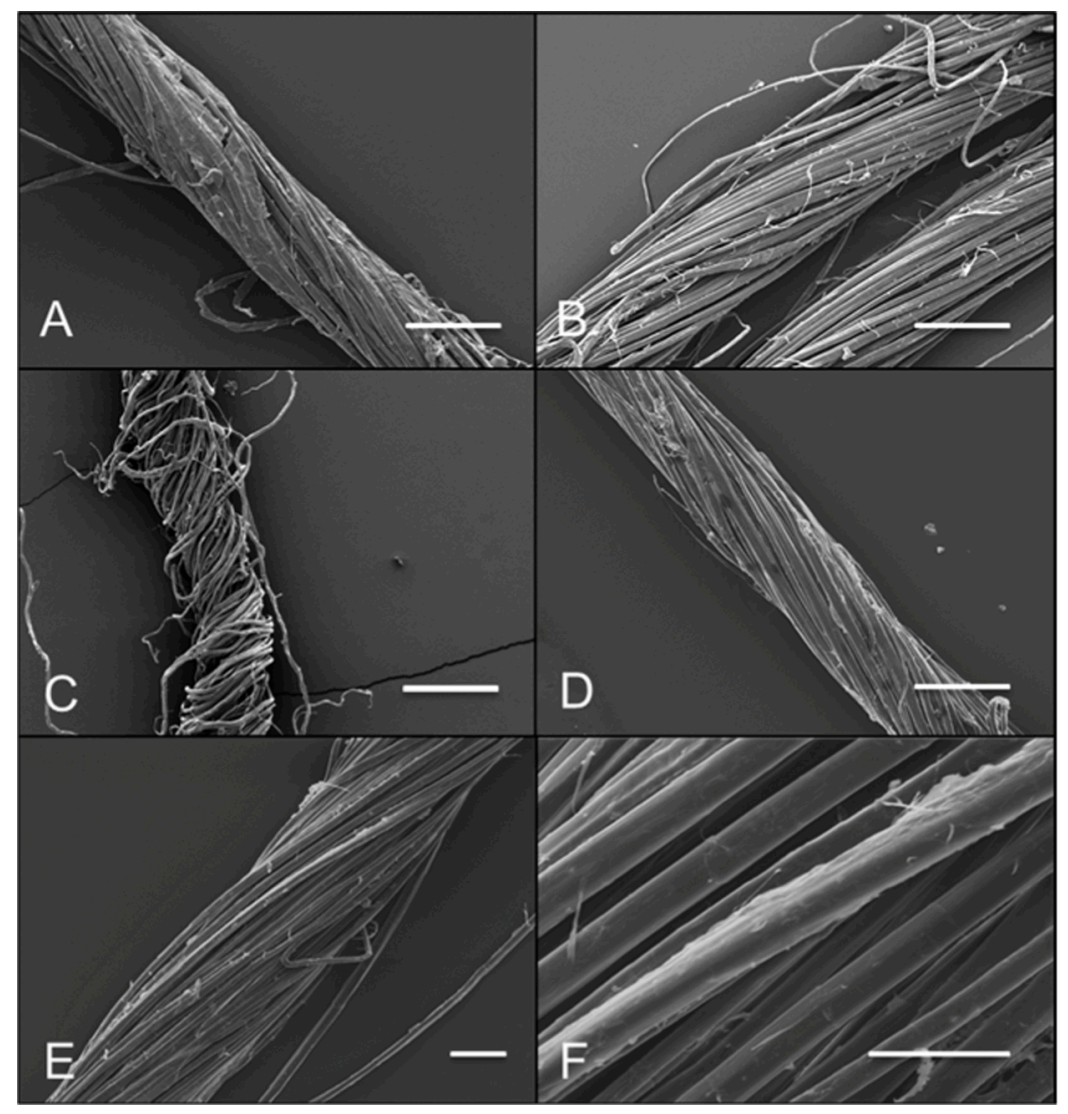

Figure 2. SEM images of various flax threads. Scale bars represent (A-E) $200 \mu \mathrm{m}$, (F) $50 \mu \mathrm{m}$. (A) Thread of brown flax, (B) Two holocellulose threads, (C) Cellulose II thread, (D) White flax thread, (E-F) White flax thread after Soxhlet treatment at different magnifications. 
the white flax thread, but now after Soxhlet treatment (vide supra). Note the resemblance between the Soxhlet-treated yarn (fig. 2(E)) and the holocellulose one (fig. 2(B)): the filaments in both threads are uniformly loose and clean. Observation of the Soxhlet treated yarn at a higher magnification (fig. 2(E)) confirms the cleaning effect of this treatment while no damage (cracks or cavities) of the individual fiber surface can be seen.

In vitro cytotoxicity analysis of flax materials and effect of Soxhlet treatment

To analyse the potential cytotoxicity of the flax meshes in vitro, an MTT cytotoxicity assay on mesh extracts was applied (fig. 3). Extracts of the brown flax were cytotoxic, showing only $48.5 \% \pm 6.5 \%$ survival of the cells that were incubated with the extracts. Treatment of the brown flax with acetic acid markedly decreased this cytotoxic response (holocellulose), and this further improved up to approximately $100 \%$ cell survival after treatment with $\mathrm{NaOH}$ (Cellulose II). Extracts from white flax were also highly cytotoxic $(41.8 \% \pm 3.1$ $\%$ survival), even exceeding brown flax. Soxhlet treatment also completely abolished cytotoxicity $(99.5 \% \pm 4.6 \%)$ from these white flax meshes. The PP mesh extracts did not induce any cytotoxicity $(101.1 \% \pm 4.3 \%)$.

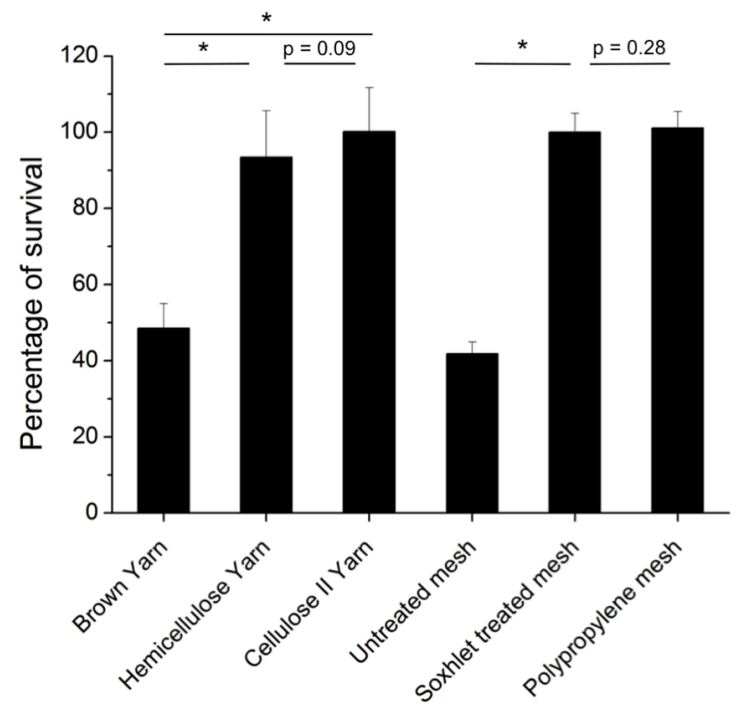

Figure 3. Histogram of MTT test performed on mouse fibroblast L929 cells and cultured on 96well plates for 48 hours. Cells were seeded at 10.000 cells/well and cell viability is defined as percentage of the viable control (pure medium). * indicates statistical difference with $\mathrm{p}<0.05$. 
Cytotoxicity of white flax was further investigated through a direct contact experiment, in which mouse L929 fibroblast cells were allowed to grow in contact with the respective materials. After $72 \mathrm{~h}$ of incubation, the specimens were evaluated through light microscopy (fig. 4). Fibroblasts grown in close proximity conditions for untreated flax mesh (fig. 4(A)) and Soxhlet-treated meshes (fig. 4(B)) showed a marked difference in cell appearance. Untreated flax meshes (fig. 4(A)) presented an interrupted cell layer, in which the cells were distorted and non-viable, whereas for the Soxhlet-treated meshes a confluent layer of apparently healthy cells was found (fig. 4(B)). Note that the cells in figure 4(A) show a close resemblance to the cells in figure 4(D), which were grown under identical circumstances in contact with latex (cytotoxic control material). On the contrary, cells in figure 4(B) have a similar appearance to cells in figure 4(E), where cells were incubated in pure medium only (viable control). Figure 4(C) shows the fibroblasts growing in contact with the benchmark PP mesh. These cells also form a healthy confluent monolayer, resembling figure 4(B) and figure 4(E).

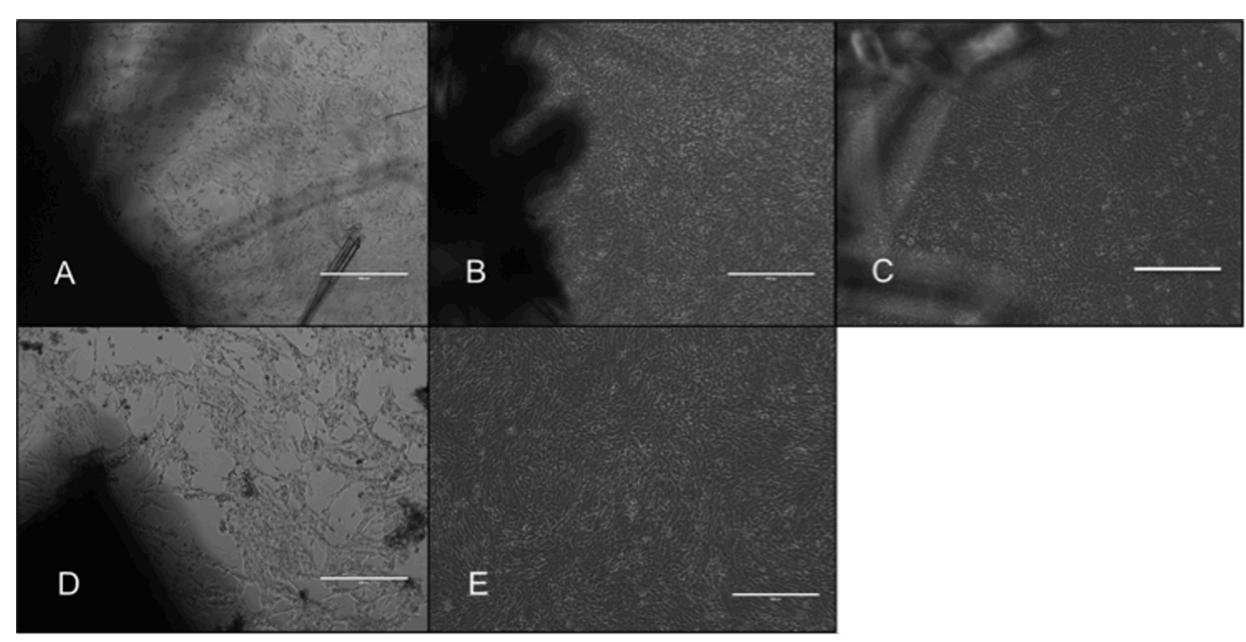

Figure 4. Microscopic bright field images of the appearance of cells placed in close proximity of materials. All scale bars represent $400 \mu \mathrm{m}$. (A) Untreated mesh, (B) Soxhlet treated mesh, (C) Polypropylene mesh, (D) Latex, (E) Medium only.

Mesh-cell cultures were also subjected to the Live-Dead assay (fig. 5). Inspection of the adherent cells by fluorescence microscopy confirmed the inherent non-toxic nature of the Soxhlet-treated white flax mesh (fig. 5(B,E)) and the PP control (fig. 5(C,F)). Significantly less adherent cells were found on the surface of the untreated white flax mesh (fig. 5(A,D)), even though the mesh had been previously washed several times before the experiment. 


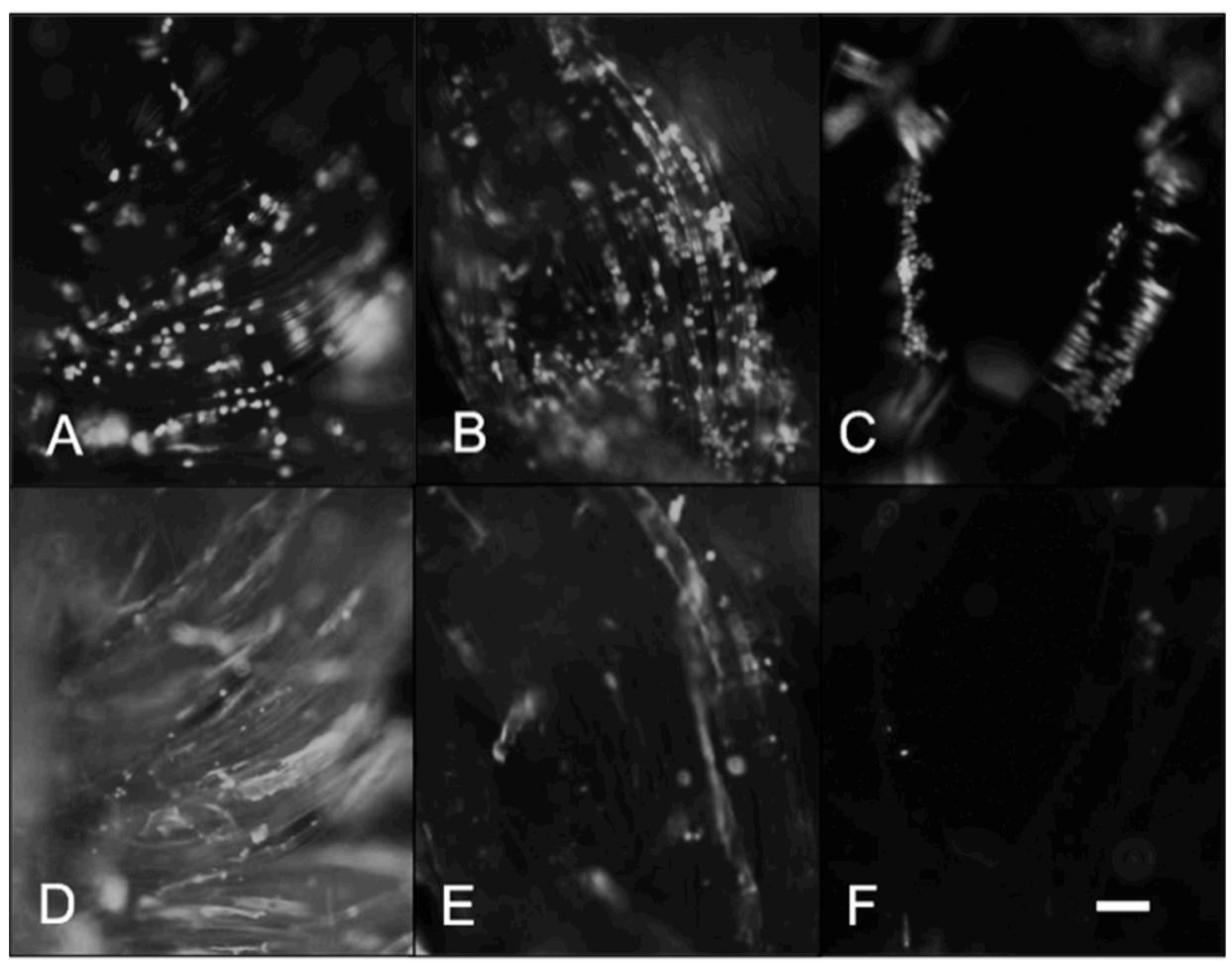

Figure 5. Live/dead images of cells on materials. All scale bars represent $100 \mu \mathrm{m}$. Pictures (AC) show viable cells; pictures (D-F) show dead cells. (A, D) Untreated mesh, (B, E) Soxhlet treated mesh, (C, F) Polypropylene mesh.

Furthermore, we monitored growth of mouse L929 fibroblasts after adherence to one of the three meshes. After initial adhesion of the cells, growth in contact with PP was observed after a lag phase of approximately 2 days (fig. 6). A more delayed growth curve (lag phase approximately 4 days) was found for the cells that were grown in contact with the Soxhlet-treated white flax mesh. After this delay the rate of proliferation [35] was comparable for both meshes: on the polypropylene meshes and Soxhlet treated flax meshes, cell numbers doubled every 58 and 42 hours respectively. For both meshes, cell numbers reached a plateau after approximately 2 weeks. A much longer lag phase (approximately 12 days) preceded the growth of cells that were in contact with the untreated white flax mesh. In this case the cell number doubling time was of 146 hours. 


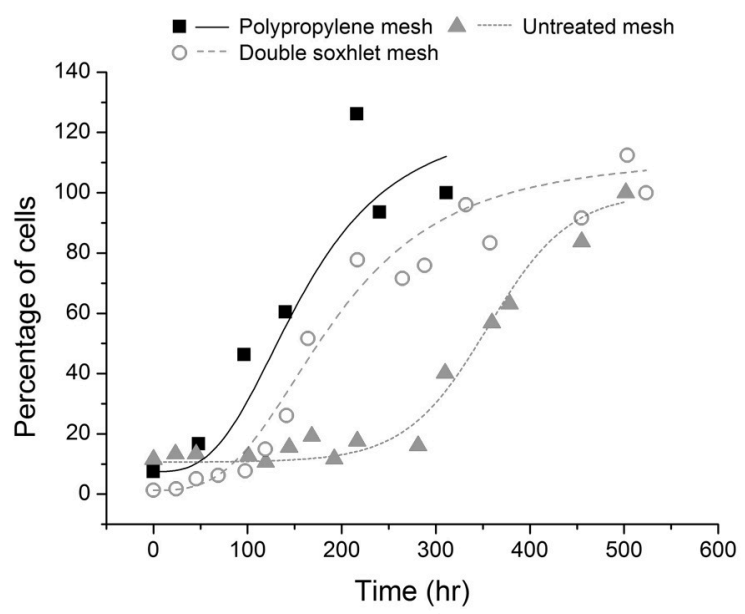

Figure 6. Cell growth curves of cells adhered to the meshes. After two weeks, cells on the polypropylene mesh reached plateau value (100\%) and cells on the wells started dying.

Analysis of endotoxins levels of the flax levels

To assess the amount of endotoxins on our meshes, we performed two different experiments. Firstly, we subjected the three (untreated - treated white flax, and PP) mesh materials to the LAL assay (Table 2). In this assay, the amount of extractable endotoxins present in the incubated water is first determined. Absorbance values can be converted into Endotoxin Unit (EU) thanks to the reference curve. Then, incubated water is removed and the amount of endotoxins directly present on the mesh is determined. Calibration was not

Table II. Amount of endotoxins present in a $10 \times 10 \mathrm{~mm}$ mesh and expressed in EU (Endotoxin unit)

\begin{tabular}{lccc}
\hline & $\begin{array}{c}\text { Extractable endotoxins } \\
\text { (absorbance) }\end{array}$ & $\begin{array}{c}\text { Extractable endotoxins } \\
\text { (EU) }\end{array}$ & $\begin{array}{c}\text { Adherent endotoxins } \\
\text { (absorbance) }\end{array}$ \\
\hline Untreated mesh & $6.98 \pm 0.49$ & $7.0 \pm 0.7$ & $2.18 \pm 0.41$ \\
Double soxhlet mesh & $0.38 \pm 0.04$ & $0.5 \pm 0.06$ & $0.97 \pm 0.16$ \\
PP mesh & $\mathrm{n} / \mathrm{d}^{\mathrm{c}}$ & $\mathrm{n} / \mathrm{d}^{\mathrm{c}}$ & $0.07 \pm 0.05$
\end{tabular}

${ }^{a}$ Amount of endotoxins in $1 \mathrm{~mL}$ LPS-free extracted water was checked and then, after several rinsing, blevel of endotoxins directly present on the mesh was analysed. 'In the polypropylene mesh, the extracted amount was non-detectable (n/d) for below the detection limit of 0.10 EU. For each material, calculations were done on four independent meshes, each of them being analysed in duplo $(\mathrm{ns}=8)$. In each column, results were significantly different from each other $(\mathrm{p}<0.05)$ 
possible for this second part of the test because the activity of attached endotoxins does not necessarily correspond to the activity of endotoxins in solution (which is the method used for calibration). Finally the total amount of endotoxins present on the mesh was obtained by adding the two absorbance values (i.e. absorbance values due to extractable and adherent endotoxins). The untreated flax mesh had a substantial load of endotoxins: it led to a total absorbance value of 9.16 . Approximately $70 \%$ of these were extractable. The Soxhlet treatment apparently removed most of these endotoxins; a total absorbance value of 1.35 was obtained and $39 \%$ of these endotoxins were extractable. The amount of endotoxins on the PP mesh was still lower: absorbance value was of $0.07 \pm 0.05$; these endotoxins were not extractable.

Secondly, we used X-ray photo-electron spectroscopy (XPS) to study the effect of the Soxhlet treatment on endotoxins levels. A small measurement spot was used, which enabled us to analyze the surface of one single thread in the flax meshes. Surface measurements were conducted at 4-different positions for each material. No significant differences were obtained between these measurements. XPS spectra are shown in figures 7(A) (survey) and 7(B) (narrow scan) and the
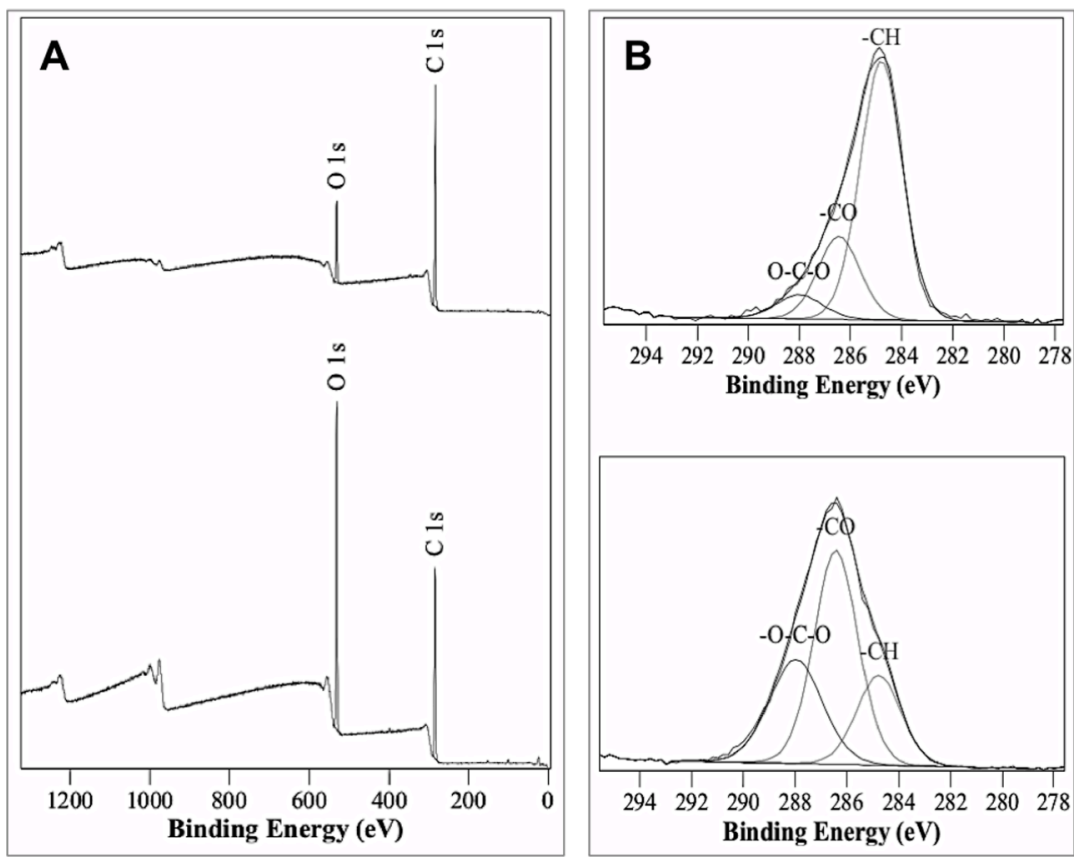

Figure 7. XPS spectra for untreated (top) and Soxhlet treated mesh (down). (A) XPS survey spectra showing that the relative intensities of the $\mathrm{C} 1 \mathrm{~s}$ or O1s revert as a result of the Soxhlet treatment. (B) Narrow-scan XPS spectra with decomposition into components. Contribution of $\mathrm{C}-\mathrm{H}$ is decreasing substantially in accordance with the removal of endotoxins. 


\begin{tabular}{llllll}
\hline & C 1s & O 1s & N 1s & Ca 2p & Si 2p \\
\hline Untreated & 83 & 16 & 0.4 & 0.1 & 0.7 \\
Flax mesh & 87 & 14 & 0.1 & - & 0.4 \\
\hline \multirow{2}{*}{ Soxhlet treated Flax mesh } & 61 & 36 & 0.4 & - & 1.8 \\
& 60 & 38 & 0.3 & 0.1 & 1.7 \\
\hline
\end{tabular}

Table III. Atomic concentrations at the surface of the untreated and Soxhlet treated white flax meshes as obtained from XPS survey spectra

results of the measurements are compiled in Table 3. Several conclusions can be drawn on the basis of these data. The outer surface of the two materials consists almost exclusively of carbon and oxygen. Other elements (including silicon) are found in very low concentrations, indicating the high level of purity of the materials. Additionally, the Soxhlet treatment leads to a considerable decrease of the carbon content at the surface (from $85 \pm 2 \%$ to $61 \pm 1 \%$ ), and a rise of the oxygen content (from $15 \pm 2 \%$ to $37 \pm 1 \%$; see table 3 ). In other words, the $\mathrm{O} / \mathrm{C}$ ratio increased from $0.18 \pm 0.03$ to $0.61 \pm 0.03$.

Table IV. Data from narrow-scan XPS.

\begin{tabular}{lcccccc}
\hline & & & & $\begin{array}{c}\mathrm{C} 1(\mathrm{C}-\mathrm{C}) \\
284.8 \mathrm{eV}\end{array}$ & $\begin{array}{c}\mathrm{C} 2(\mathrm{C}-\mathrm{O}) \\
286.5 \mathrm{eV}\end{array}$ & $\begin{array}{c}\mathrm{C} 3(\mathrm{O}-\mathrm{C}-\mathrm{O}) \\
288.0 \mathrm{eV}\end{array}$ \\
\cline { 5 - 6 } & $\mathrm{C} 1 \mathrm{~s}$ at. $\%$ & $\mathrm{O} 1 \mathrm{~s}$ at. $\%$ & $\mathrm{O} / \mathrm{C}$ & $\%$ & $\%$ & $\% \pm 1$ \\
\hline Untreated mesh & $85 \pm 2^{\mathrm{a}}$ & $15 \pm 2^{\mathrm{a}}$ & $0.18 \pm 0.03$ & $70 \pm 3$ & $22 \pm 1$ & $7 \pm \pm 2$ \\
Soxhlet treated mesh & $62 \pm 1^{\mathrm{a}}$ & $38 \pm 1^{\mathrm{a}}$ & $0.61 \pm 0.03$ & $25 \pm 4$ & $49 \pm 2$ & $26 \pm 2$ \\
Pure Cellulose & 54.5 & 45.5 & 0.83 & 0 & 83 & 17
\end{tabular}

$\overline{\mathrm{a}}$ Data measured in quadruplo; mean and standard deviation are compiled here. ${ }^{\mathrm{b}}$ For comparison, XPS data of pure cellulose were added [42,43]. In each column, results between untreated and Soxhlet treated mesh were significantly different from each other $(\mathrm{p}<0.05)$

Narrow-scan analysis made it possible to decompose the carbon signal into three sub-signals due to $\mathrm{C}-\mathrm{C} / \mathrm{C}-\mathrm{H}, \mathrm{C}-\mathrm{O}$, and O-C-O (fig. 8, Table 4). The Soxhlet treatment causes a decrease of the fraction of $\mathrm{C}$-atoms that are engaged in $\mathrm{C}$ - $\mathrm{C}$ bonding (from $70 \pm 3 \%$ to $25 \pm 4 \%$ ) and an increase of the relative content of $\mathrm{C}$-atoms in $\mathrm{C}$-O bonds and O-C-O bonds (from $22 \pm 1 \%$ to $49 \pm 2$ $\%$, and from $7 \pm 1$ to $26 \pm 2 \%$, respectively). 
In vivo analyses and histopathology of white flax and PP meshes

The flax meshes tested in vitro were all knitted from the white flax threads, of which one group remained untreated and a second group was subsequently treated with the Soxhlet protocol to remove endotoxins from the meshes. PP meshes were taken along as control. All animals survived the experimental treatment and quickly recovered from anesthesia and were thriving during the 7 days experiment. No clear general signs of infection or discomfort were noticed for any of the animals used.

Macroscopically, the polypropylene (PP) group showed no inflammation, although low to mild fibrous tissue generation was apparent. In contrast, untreated flax showed a severe inflammatory reaction with pus formation that was still apparent after 7 days of implantation. This excessive tissue reaction was also reflected by overt foreign body reaction, showing massive fibrotic tissue at sites the meshes were implanted. The meshes prepared with Soxhlet treatment presented a markedly lower inflammation, with mild fibrotic tissue formation and absence of pus around the meshes (data not shown).

Microscopic analysis of the subcutaneous tissue surrounding the meshes underlined the macroscopic observations for the different groups (fig. 8). Minimal inflammation and foreign body reaction was seen in the PP (control) group, with few macrophages observed in the fibrotic tissue surrounding the PP fibers, which showed signs of granuloma formation (fig. 8(A-C)). Untreated flax meshes showed a massive inflammatory reaction with high numbers of granulocytes, macrophages, foreign body giant cells and fibrosis (fig. 8(D-F)). Substantial cell death (necrosis) was apparent for cells in close proximity to the individual fibers of the mesh bundles, as well as for the surrounding tissue (fig. $8(\mathrm{E}, \mathrm{F})$ ). No signs of bacterial infection were found for these meshes. For the Soxhlet treated meshes, low inflammatory and foreign body reaction were seen (fig. 8(G-L)), with low numbers of granulocytes and macrophages. In some occasions giant cells were found at the transition zone between the mesh-fibers and the fibrotic tissue (fig. 8(K,L)). No massive inflammation and necrosis was apparent for the fibrotic tissue surrounding the treated flax mesh bundles (fig. $8(\mathrm{G}, \mathrm{I}-\mathrm{K}))$. 

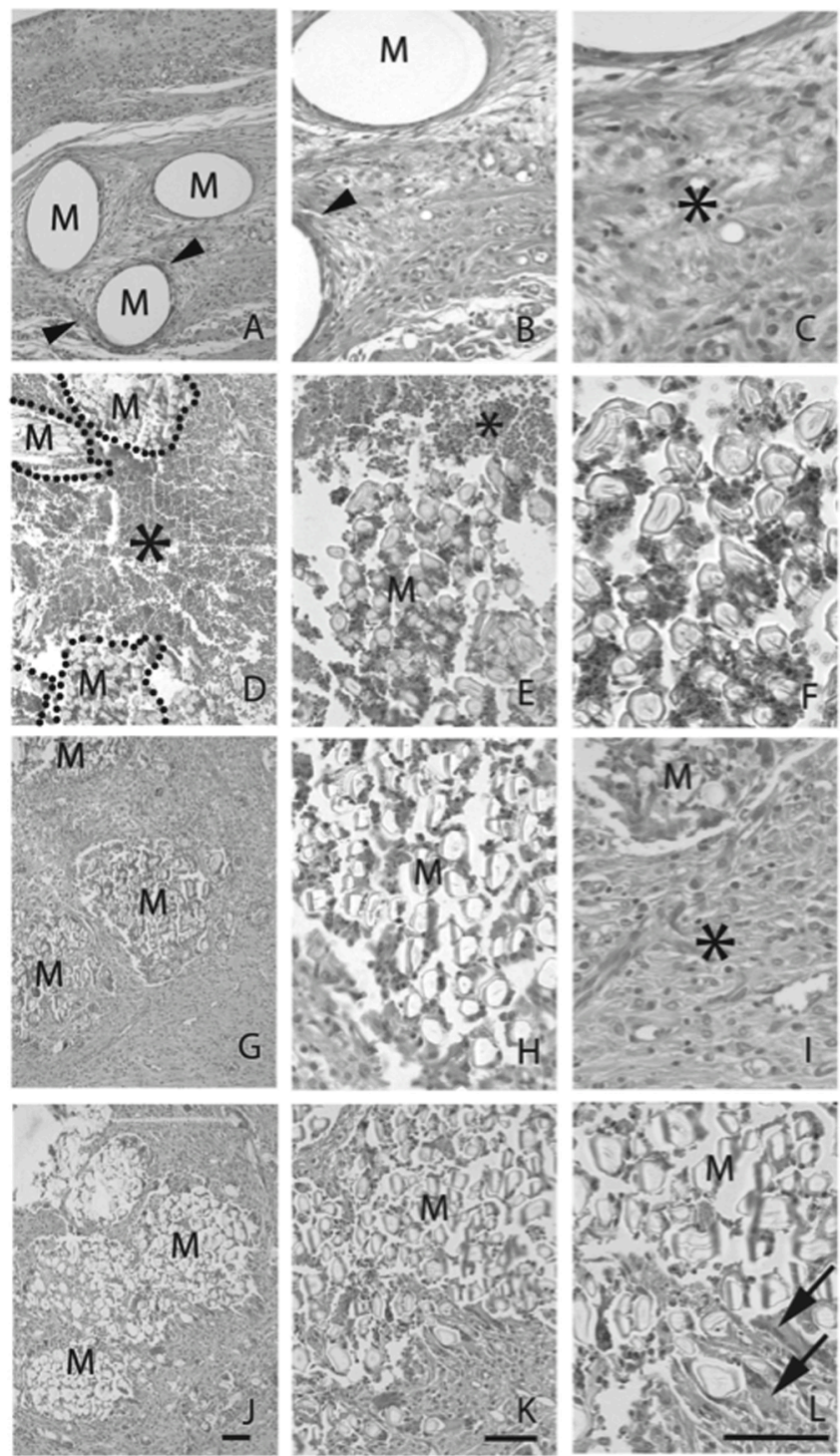

Figure 8. Representative histological of $\mathrm{H} \& \mathrm{E}$ stained skin-mesh sections from in vivo experiments after 7 days follow-up. (A-C) PP controls with foreign body granuloma tissue surrounding the fibers of the mesh ( $\mathrm{M}$; arrowheads $\mathrm{A}$ and $\mathrm{B})$. A few inflammatory cells are present in the fibrous tissue (asterisk, C). (D-F) Untreated flax meshes with necrosis and inflammation around the mesh (asterisk D and E) and within the mesh bundle (E and F). (G-L) Soxhlet treated mesh showing great improvement with lower foreign body reaction, and inflammatory cells (predominantly) present inside the flax bundles ( $\mathrm{H}, \mathrm{K}$ and $\mathrm{L}$ ), and occasionally giant cells in the transition zone between flax fibers and fibrotic tissue (arrows, L). Note the comparable tissue reaction and inflammatory response for the fibrotic tissue surrounding the PP and treated flax fibers (asterisk C and I). Scale bar J applies for (A), (D), (G) and (J); K applies for (B), (E) and (K); and L for $(\mathrm{C}),(\mathrm{F}),(\mathrm{H}),(\mathrm{I})$ and $(\mathrm{L})$. All scale bars represent $50 \mu \mathrm{m}$. 


\section{Discussion}

In this study, we analyzed the cytocompatibility of flax fibers in vitro, their biosafety in vivo, and their applicability for biomedical applications. Brown flax threads are obtained after heckling and spinning of flax fibers. White flax yarns are obtained when brown flax threads are submitted to another additional treatments to remove pectin, lignin and wax compounds [29,30]. In our case, brown flax yarns were submitted to bleaching with hydrogen peroxide to obtain white flax threads. These yarns were then knitted into a mesh, called later untreated mesh. Primary in vitro experiments with MTT show that these two materials exhibit pronounced toxicity when put in contact with fibroblasts cells. Interestingly, when brown flax yarns were treated with acetic acid to obtain holocellulose fibers, this toxicity was removed. Additional treatment with sodium hydroxide to obtain cellulose II yarn did not lead to significant improvement of cytocompatibility. These experiments confirm that cellulose per se is not toxic to fibroblast cells. This is in accordance with the literature since biocompatibility of "pure" cellulose is well assessed in vitro [7-15]. It also shows that presence of hemicellulose in flax fibers does not result in increased toxicity on cells. Hemicellulose is another polysaccharide present in flax fibers and it is generally considered as being biocompatible [36].

As the white flax yarn had been knitted in the form of a mesh, its toxicity could be assessed better. All other in vitro experiments confirmed the toxicity of the untreated mesh to fibroblasts cells. Moreover, once implanted subcutaneously in rats for 7 days, massive inflammatory response and loss of flax mesh structure was observed in vivo. Such a pronounced inflammatory reaction was also reported by Vavrik \& Al in rats for hernia repair. They also observed strong inflammatory reaction with large fibrosis and extensive adhesions, although no detail on the biochemical composition of the flax was provided [37].

Such a pronounced inflammatory response is not necessarily only due to the toxicity of the white flax itself, and we wondered if part of it could originate from the presence of endotoxins on the mesh. The presence of endotoxins on flax would be logical, as bacterial fermentation (retting) plays a key role in the production of flax $[38,39]$. Moreover, it is well known that endotoxins are difficult to remove from contaminated materials [40], meaning that even after treatment with hydrogen peroxide and steam sterilization, we might have an appreciable amount of them back in the untreated mesh. Indeed, our LAL data prove the presence of endotoxins in the untreated white flax mesh (total absorbance of approx. 9.16 per $\mathrm{cm}^{2}$ mesh). Comparatively, an absorbance of 
only 0.07 was obtained on $10 \times 10 \mathrm{~mm}$ PP mesh. This high level endotoxins is most probably the cause of the strong inflammatory response in vivo.

To suppress the toxicity of the untreated mesh and to eliminate most of the endotoxins present on it, we submitted it to two purification steps. We first chose to treat it with acetic acid, since primarily experiments had shown that it suppressed in vitro toxicity of flax. Then, we aimed at removing endotoxins. According to the literature, many different chemical treatments can be used to remove most of the endotoxins [41-44]. We chose to use $75 \%$ ethanol. We reasoned that ethanol can easily be removed after the treatment, and that possible remnants of traces of ethanol cannot give rise to toxicity effects in subsequent experiments. A Soxhlet apparatus (continuous automated extraction) was used.

In vitro experiments show that this purification method is very efficient to remove the toxicity of the untreated mesh. Yet, before implantation of this double Soxhlet mesh in rats, it was of critical importance to check the remaining level of endotoxins present on it. LAL assay showed that Soxhlet treatment removed most of the endotoxins, but a residual content remained (total absorbance value of approximately 1.35 per $\mathrm{cm}^{2}$ mesh). This residual amount obtained can be due to highly stable and unextractable endotoxins, or to the presence of interfering chemical compounds. In particular, it is known that $(1,3)$ $\beta$-D-glucans interfere with the LAL test and can lead to false positive [45]. Moreover, the fact that all our flax material have proven to be exhibitory (i.e. leading to higher LAL signal as compared to expected) seems to confirm that part of the LAL signal is due to interferences, and that the real amount of endotoxins present on fibers is even smaller.

XPS analyses of the surface of the threads corroborate the idea that our protocol can largely eliminate endotoxins from the surface of the meshes. The Soxhlet treatment led to a marked change of the $\mathrm{O} / \mathrm{C}$ ratio and $\mathrm{C}$-peak deconvolution, showing a drop in $\mathrm{C}$ - $\mathrm{C}$ bonding, while increased fractions of carbon in $\mathrm{C}-\mathrm{O}$ and $\mathrm{O}-\mathrm{C}-\mathrm{O}$ bonds were apparent. These changes are consistent with the assumed removal of endotoxin from the flax materials, but also -we realize- with removal of waxy contaminants from the mesh's surface. Endotoxins are lipopolysaccharides, which owe their amphiphilic nature to the presence of long aliphatic side chains with a $\left(\mathrm{CH}_{2}\right)_{\mathrm{n}}$ structure. Removal of these structures from the mesh surface would expose more of flax's polysaccharide structure and, consequently, will lead to a drop of C- and a rise in O-content. After Soxhlet treatment, the $\mathrm{O} / \mathrm{C}$ ratio remained below that of pure polysaccharide surface $(0.61 \pm 0.03$ versus 0.83$)[46,47]$ with some aliphatic carbons $-\mathrm{C}-\mathrm{H}$ bounds still present on the fibers. Hence, even after Soxhlet treatment, the mesh is not free 
from all impurities. This is not much of a surprise as complete removal of endotoxins from natural products is notoriously difficult $[40,43,44]$.

Finally, Soxhlet-treated mesh was implanted subcutaneously in rats for 7 days in the same conditions as described above for the untreated mesh. Macroscopic observation showed no severe inflammatory reaction with absence of pus and only mild fibrosis comparable to the PP control meshes. Histological evaluation confirmed this milder inflammatory response with less fibrosis. Macrophages and granulocytes were still present, predominantly within the flax bundles, whereas for the surrounding fibrotic tissue only few inflammatory cells were apparent. Hence, although for some flax bundles giant cells and necrosis were still apparent, the foreign body reaction was much milder as compared with untreated flax meshes. Macroscopically, after 7 days implantation, the treated flax mesh had kept its original appearance and shape.

Subcutaneous implantation in rats confirms that the elimination of the toxicity and of most of the endotoxins present on the untreated mesh led to a more biocompatible mesh in vivo. Yet, implantation of the Soxhlet treated mesh still provides some degree of necrosis and inflammation that was predominantly found within the flax bundles of the meshes. We believe that this is related to the high density of the mesh itself $\left(175 \mathrm{~g} / \mathrm{m}^{2}\right)$ and the potential endotoxin residues that remain present on the treated fibers. Hence, macrophages and granulocytes that migrate into the flax bundles could be trapped and exposed to endotoxins present on the flax fibers. Presumably, by decreasing the diameter of the white yarns and designing a more open mesh, we can obtain a further improved in vivo response [48]. This hypothesis will be subject of studies in the immediate future.

\section{Conclusion}

The abundance and affordability of flax threads, their excellent physicalmechanical properties and their suitability for use in different knitted designs make them promising materials for biomedical applications. The present data, derived from knitted flax meshes, show that adequate levels of cytocompatibility and biosafety can be achieved by using a purification method that is based on a combination of two green (biobased, non-toxic) solvents. Acetic acid washing is necessary to extract toxic compounds initially present in flax fibers; ethanol extraction allows to remove endotoxins effectively.

After these Soxhlet based purification steps, flax meshes feature good cytocompatibility in vitro and mild inflammation in vivo, and these results are in 
line with the data obtained for polypropylene meshes. From our data it can be concluded that flax-derived fibers could be used to manufacture surgical meshes or other medical devices, provided that the necrosis present inside flax bundles can be suppressed.

\section{Acknowledgments}

This study is a part of the Interreg IV-A project "BioMiMedics" (www.biomimedics.org). The Universities of Maastricht (The Netherlands), Liege (Belgium), Hasselt (Belgium) and Aachen (Germany; RWTH and Fachhochschule), as well as several regional biotechnological enterprises cooperate in "BioMiMedics". This particular study was financed through generous contributions of the EU (through Interreg IV-A), the government of the Province Dutch Limburg, the Dutch National Ministery of Economic Affairs, Agriculture \& Innovation, Maastricht University, the Limburg Bank for Industry Innovation (LIOF), and the company INterface BIOmaterials BV in Geleen, Netherlands.

\section{References}

1. Mandal B M, Kundu S C. Cell proliferation and migration in silk fibroin 3D scaffolds. Biomaterials 2009;30:2956-65.

2. Mandal B M, Ghosh B, Kundu S C. Non-mulberry silk sericin/poly(vinyl alcohol) hydrogel matrices for potential biotechnological applications. Int J of Biol Macromol 2011;49:125-33.

3. Tachibana A, Furuta Y, Takeshima H, Tanabe T, Yamauchi K. Fabrication of wool keratin sponge scaffolds for long-term cell cultivation. J of Biotech 2002;93:165-70.

4. Dash M, Chiellini F, Ottenbrite R M, Chiellini E. Chitosan-A versatile semi-synthetic polymer in biomedical applications. Prog Polym Sci 2011;36:981-1014.

5. Elsabee M Z, Naguib H F, Elsayed Morsi R. Chitosan based nanofibers, review. Mater Sci Eng C 2012;32:1711-26.

6. Kean T, Thanou M. Biodegradation, biodistribution and toxicity of chitosan. Adv Drug Deliv Rev 2010;62:3-11.

7. Czaja W, Krystynowicz A, Bielecki S, Brown Jr M R. Microbial cellulose - the natural power to heal wounds. Biomaterials 2006;27:145-51.

8. Helenius G, Bäckdahl H, Bodin A, Nannmark U, Gatenholm P, Risberg B. In vivo biocompatibility of bacterial cellulose. J Biomed Mater Res 2005;76A(2):431-8.

9. Teeri T T, Brumer H I I I, Daniel G, Gatenholm P. Biomimetic engineering of cellulose-based materials. Trends in Biotechnology 2007;25(7):299-306.

10. Oliveira J T, Reis R L. Polysaccharide-based materials for cartilage tissue engineering applications. J Tissue Eng Regen Med 2010;5(6):421-36. 
11. Svensson A, Nicklasson E, Harrah T, Panilaitis B, Kaplan D L, Brittberg M, Gatenholm P. Bacterial cellulose as a potential scaffold for tissue engineering of cartilage. Biomaterials 2005;26(4):419-31.

12. Pértile R A, Moreira S, Costa R M, Correia A, Guardão L, Gartner F, Vilanova M, Gama M. Bacterial Cellulose: Long-Term Biocompatibility Studies. J Biomater Sci Polym Ed 2012;23(10):1339-54.

13. Miyamoto $\mathrm{T}$, Takahashi $\mathrm{S}$, Ito $\mathrm{H}$, Inagaki $\mathrm{H}$, Noishiki $\mathrm{Y}$. Tissue biocompatibility of cellulose and its derivatives. J Biomed Mater Res 1989;23:125-33.

14. Märtson M, Viljanto J, Hurme T, Saukko P. Biocompatibility of cellulose sponge with bone. Eur Surg Res 1998;30:426-32.

15. Martson M, Viljanto J, Hurme T, Laippala P, Saukko P. Is cellulose sponge degradable or stable as implantation material? An in vivo subcutaneous study in the rat. Biomaterials 1999;20(21):1989-95.

16. Baley C. Analysis of the flax fibres tensile behavior and analysis of the tensile stiffness increase. Composites Part A 2002;33:939-48

17. Stamboulis A, Baillie C A, Peijs T. Effects of environmental conditions on mechanical and physical properties of flax fibers. Composites Part A: Appl Sci Manuf 2001;32:110515 .

18. Nilsson T, Gustafsson P J. Influence of dislocations and plasticity on the tensile behaviour of flax and hemp fibres. Composites Part A 2007;38: 722-8.

19. Structural formulas of the different cellulose variants can be found in: The McGrawHill Dictionary of Scientific and Technical Terms, vol 6, McGraw-Hill Professional; 2002.

20. Van de Weyenberg I, Ivens J, De Coster A, Kino B, Baetens E, Verpoest I. Influence of processing and chemical treatment of flax fibres on their composites. Compos Sci Tech 2003;63(9):1241-6.

21. Bledzki A K, Mamun A A, Lucka-Gabor M, Gutowski V S. The effects of acetylation on properties of flax fibre and its polypropylene composites. Express Polym Lett 2008;2(6):413-22.

22. Burger J W, Luijendijk R W, Hop W C, Halm J A, Verdaasdonk E G, Jeekel J. Long term follow-up of a randomized controlled trial of suture versus mesh repair of incisional hernia. Ann Surg 2004;240(4):578-83.

23. Peralta R, Latifi R. Long-term outcomes of abdominal wall reconstruction. What are the real numbers? World J Surg 2012;36(3):534-8.

24. Patel B N, Lucioni A, Kobashi K C. Anterior pelvic organ prolapse repair using synthetic mesh. Curr Urol Rep 2012;13:211-5.

25. Chermansky C J, Winters J C. Complications of vaginal mesh surgery. Curr Opin Urol 2012;22:287-91.

26. Elliot S. Con: mesh on vaginal surgery: do the risks outweigh the benefit? Curr Opin Urol 2012:22;276-81.

27. Emans P J, Schreinemacher M H, Gijbels M J, Beets G L, Greve J W, Koole L H, Bouvy N D. Polypropylene meshes to prevent abdominal herniation. Can stable coatings prevent adhesions in the long term? Ann Biomed Eng 2009;37(2):410-8.

28. FDA, U.S. FDA Safety Communication: UPDATE on Serious Complications Associated with Transvaginal Placement of Surgical Mesh for Pelvic Organ Prolapse. 2011 [cited 202 2012-03-15]; Available from:

http://www.fda.gov/MedicalDevices/Safety/AlertsandNotices/ucm262435.htm. 
29. Csiszár E, Urbánszki K, Szakács G. Biotreatment of desized cotton fabric by commercial cellulase and xylanase enzymes. J Mol Catal B: Enzym 2001;11:1065-72.

30. Topalovic T, Nierstrasz V A, Bautista L, Jocic D, Navarro A, Warmoeskerken M M C G. XPS and contact angle study of cotton surface oxidation by catalytic bleaching. Colloids Surf, A 2007;296:76-85.

31. Morvan C, Andème-Onzighi C, Girault R, Himmelsbach D S, Driouich A, Akin D E. Building flax fibres: more than one brick in the walls. Plant Phys and Biochem 2003;41:935-44.

32. Jähn A, Schröder M W, Füting M, Schenzel K, Diepenbrock W. Characterisation of alkali treated flax fibres by means of FT Raman spectroscopy and environmental scanning electron microscopy. Spectrochim Acta A Mol Biomol Spectrosc 2002;58(10):2271-9

33. Raj G, Balnois E, Baley C, Grohens Y. Role of polysaccharides on mechanical and adhesion properties of flax fibres in flax/PLA biocomposites. International Journal of Polymer Science 2011:Article ID 503940.

34. Arbelaiz A, Cantero G, Fernandez B, Mondragon I. Flax fiber surface modifications: effects on fiber physic mechanical and flax/polypropylene interface properties. Polymer Compos 2005;26(3):324-32

35. Sherley J L, Stadler P B, Stadler J S. A quantitative method for the analysis of mammalian cell proliferatio in culture in terms of dividing and non-dividing cells. Cell Prolif 1995;28(3):137-44

36. Hansen N M L, Plackett D. Sustainable films and coatings from hemicelluloses: a review. Biomacromolecules 2008;9(6):1493-505.

37. Vavrik J, Foltýnová V, Vitková I, Adámek S, Poucková P. Changes in abdominal wall after mesh implantation in rats. Med Sci Monit 2000;6(3):476-9.

38. Mooney C, Stolle-Smits T, Schols H, de Jong E. Analysis of retted and non retted flax fibres by chemical and enzymatic means. J Biotechnol 2001;89(2-3):205-16.

39. Meijer W, Vertregt N, Rutgers B, van de Waart M. The pectin content as a measure of the retting and rettability of flax. Ind Crops and Prod 1995;4(4):273-84.

40. Magalhães P O, Lopes A M, Mazzola P G, Rangel-Yagui C, Penna T C V, Pessoa Jr A. Methods of Endotoxin Removal from Biological Preparations: a Review. J Pharm Pharmaceut Sci 2007;10(3):388-404.

41. Hitchins V M, Merritt K. Decontaminating particles exposed to bacterial endotoxin (LPS). J Biomed Mater Res 1999;46(3):434-7.

42. Cho D R, Shandhag A S, Hong C Y, Baran G R, Goldring S R. The role of adsorbed endotoxin in particle-induced stimulation of cytokine released. J of Orthop Res 2002;20:704-13.

43. Ragab A A, Van de Motter R, Lavish S A, Goldberg V M, Ninomiya J T, Carlin C R, Greenfield E M. Measurement and Removal of Adherent Endotoxin from Titanium Particles and Implant Surfaces. J Orthop Res 1999;17(6):803-9.

44. Gorbet M B, Sefton M V. Endotoxin: the uninvited guest. Biomaterials 2005;26:68117.

45. Dawson M E. Interferences with the LAL test and how to address it. LAL Update 2005;22(3)

46. Zafeiropoulos N E, Watts J F. An experimental investigation of modified and unmodified flax fibres with XPS, ToF-SIMS and ATR-FTIR. J of Mater Sci 2003;38:3903-14. 
47. Johansson L S, Campbell J M. Reproducible XPS on biopolymers: cellulose studies. Surf Interface Anal 2004;36:1018-22.

48. Conze J, Rosch R, Klinge U, Weiss C, Anurov M, Titkowa S, Oettinger, Schumpelick V. Polypropylene in the intra-abdominal position: Influence of pore size and surface area. Hernia 2004;8:365-72. 



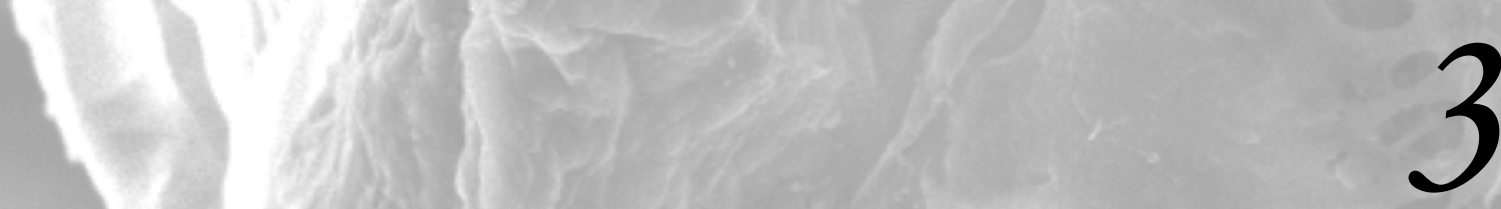

Treatment of flax mesh and fibers with dopamine. Aspects of cytocompatibility, immunogenicity and limited self-polymerisation.

Sophie $\mathcal{A}$ A X Michel, Nynke $\mathcal{M} S$ van den Akker, Menno $\mathcal{L} W$ Knetsch, Mick Gagliardi, Daniel G M Molin and Leo HH Koole.

Submitted for publication 


\section{Abstract}

Flax yarns are strong, hydrophilic and hollow, which makes it an interesting material to manufacture various biomedical devices as surgical meshes for hernia repair. Recent studies revealed that extensive purification of flax is mandatory to remove as much adherent endotoxins as possible and achieve cell compatibility in vitro, although the final flax material induces limited cell adhesion and proliferation. This study addresses the hypothesis whether poly(dopamine) surface coatings can be used to enhance cell affinity for purified flax further. A wealth of literature data on poly(dopamine) led to this expectation. Applying a standard coating protocol, and using a customized knitted flax mesh as the substrate, it was found, however, that the poly(dopamine)-coated mesh was markedly cytotoxic. Extensive purification of the mesh was needed to recover an acceptable level of cytocompatibility. Yet, a specially developed monocyteendothelial cell bioassay proved that the purified poly(dopamine)-coated mesh exhibited a pronounced immunogenicity in vitro. This current observation for flax can be ascribed to unreacted dopamine. It was observed that flax, due to its porous/hollow structure, readily absorbs dopamine (monomer), thus interfering with the polymerization reaction. This effect is not seen with common substrates, as these are non-porous and hydrophobic. It is concluded that (i), poly(dopamine) is not useful to improve biocompatibility of flax, and (ii), poly(dopamine) must be used with caution to coat hydrophilic/porous substrates.

\section{Introduction}

In biomaterials science as well as in the medical device industry, there is a growing interest in the replacement of synthetic-polymer biomaterials by biological materials [1,2]. Important examples are silk, which can be used as a surgical suture material, or to build porous scaffold structures for use in regenerative medicine [3], and decellularized bovine skin, which is commercialised as an implantable mesh material in the treatment of incisional inguinal hernias $[4,5]$.

During the past few years, we have explored the potential utility of flax fibers in biomedical applications. This was motivated by several factors, e.g. (i), flax fibers are strong and hydrophilic [6]; (ii), much is known about textile processing of flax (weaving, knitting), so it would be possible to generate sophisticated two- and three-dimensional porous structures [6,7]; (iii), flax 
filaments consist mainly of cellulose [8], which was expected a priori to have a high level of biocompatibility (iv), the microfilaments in flax are hollow tubular structures, and the lumens of these fibers could be utilized as temporary drug reservoirs in the context of controlled local delivery of drugs.

We observed, however, that flax threads are highly cytotoxic in vitro and in vivo, and this was attributed to the presence of endotoxins, which are firmly attached to the surface of the flax filaments [9]. This was reported by others as well [10]. We found cytotoxicity both for the brown (non-bleached) and white (peroxide-bleached) flax fibers. We developed a procedure to purify the flax from most of the endotoxins; the procedure is a two-step continuous extraction (Soxhlet treatment), first $24 \mathrm{~h}$ using acetic acid as the extracting fluid, then $24 \mathrm{~h}$ using ethanol as the extracting fluid. Purified white flax mesh specimens, implanted subcutaneously in rats for 7 days led to a similar histological response as for polypropylene (PP) meshes. Although these results were promising, we noticed limited cell adhesion and proliferation on flax fibers. In vitro, twice as many mouse L929 fibroblast cells adhered to PP, as compared to flax. Moreover, the residual amount of endotoxins still present on flax after the purification process remains a concern for implantable medical devices.

Herein, we address the question whether the application of a polydopamine (pDA) coating on flax' surface would promote cell adhesion. Dopamine polymerization occurs on virtually any kind of surfaces [11], and numerous papers have shown that a pDA coating promotes cell adhesion, spreading and proliferation on surfaces which usually resist to it [12-14]. Dopamine polymerization can be considered green chemistry with mild reaction conditions and absence of toxic solvents offering, theoretically, a coating process to functionalize flax fibers with minimal environmental impact $[14,15]$. These beneficial characteristics made $\mathrm{pDA}$ an ideal candidate for enhancing the biocompatibility of our flax materials.

In this paper, we report on polymerization of dopamine on flax fiber meshes. The mesh in this study used is identical to the one we utilized earlier [9]. After standard rinsing method, as described previously [11,13,14,16,17], pDAcoated flax mesh appeared to be highly cytotoxic to cells. A stringent purification method was required to recover cell compatibility in vitro. Still, cell adhesion was not considerably improved by the pDA coating. Furthermore, we tested the immunogenicity of the coated mesh in vitro as dopamine has proven inflammatory capacity [18]. The pDA-coated flax showed a pronounced immunogenic response, whereas a commercial monofilament PP mesh coated with pDA was without any overt effect. The observations are explained by the 
porous and hollow nature of flax. This leads to rapid absorption of dopamine in the substrate, which hampers the polymerization reaction through diffusion inhibition. The study reveals that pDA coating does not lead to the desired improvement of cell biocompatibility of flax. The new data show that pDA coating must applied with caution, in the case of porous hydrophilic substrates, such as flax.

\section{Materials and Methods}

\section{Materials}

White flax thread used to manufacture our knitted mesh was provided by the flax company Van der Bilt Seeds \& Flax BV (Sluiskil, the Netherlands). The same mesh as the one described in our previous work was used in this study [9]. It was especially knitted for our research project by Centexbel (Verviers, Belgium). Dulbecco's modified eagle medium (DMEM/F-12 + Glutamax-1), antibiotics (penicillin, amphotericine, streptomycin), fetal bovine serum (FBS), the CyQUANT $^{\circledR}$ Cell Proliferation Assay Kit, NuPage 4-12 \% Bis-Tris Protein Gels and the SilverQuest ${ }^{\mathrm{TM}}$ staining kit were acquired from Invitrogen (Bleiswijk, the Netherlands). Dopamine hydrochloride, Tris Base, albumin bovine, glutaraldehyde, hexamethyldisilazane, sodium dodecyl sulfate (SDS), EDTA and thiazolyl blue bromide (MTT) were from Sigma (Zwijndrecht, the Netherlands). Ethanol absolute was from VWR (Amsterdam, the Netherlands). Sodium chloride, acetic acid and methyl sulfoxide were from Acros Organics (Landsmeer, the Netherlands). A fluorometer (SpectraMax M2, Molecular Devices, Wokingham, UK) was used for the absorbance and fluorescence measurements.

Soxhlet purification of the experimental flax mesh

To purify flax meshes, Soxhlet procedure as previously described was used [9]. Briefly, the mesh was placed in a Soxhlet device for first extraction with $5 \%$ acetic acid (v/v) and $10 \mathrm{wt} \% \mathrm{NaCl}$ in double distilled water for $24 \mathrm{~h}$ (Soxhlet 1), and second extraction with $75 \%$ ethanol for $24 \mathrm{~h}$ (Soxhlet 2). At the end of the process, mesh was rinsed with ethanol, water and dried $\left(70^{\circ} \mathrm{C}\right)$. 
pDA coating

Meshes of purified flax meshes were cut in $10 \times 10 \mathrm{~mm}$ before being immersed in $5 \mathrm{~mL}$ dopamine solution $(0.2$ or $2.0 \mathrm{mg} / \mathrm{mL}, 10 \mathrm{mM}$ tris buffer, $\mathrm{pH}=8.5)$. For the micro- $\mathrm{BCA}^{\circledR}$ experiments, coatings were performed for $10 \mathrm{~min}, 20 \mathrm{~min}$, $30 \mathrm{~min}, 1 \mathrm{~h}, 2 \mathrm{~h}, 4 \mathrm{~h}, 8 \mathrm{~h}, 16 \mathrm{~h}$, or $24 \mathrm{~h}$. For other experiments, coatings were performed for $2 \mathrm{~h}$ or $24 \mathrm{~h}$. If Soxhlet washing was not performed on the meshes, they were rinsed with deionized water following procedure described in previous papers $[11,13,14,16,17]$. A commercial mesh was also coated for $24 \mathrm{~h}$ with 2.0 $\mathrm{mg} / \mathrm{mL}$ dopamine solution (Parieten $\mathrm{e}^{\mathrm{TM}}$, Sofradim production, Trevoux, France)

Soxhlet washing of the pDA-coated meshes

To achieve cell compatibility in vitro, flax meshes needed to be treated in Soxhlet with double distilled water for $24 \mathrm{~h}$ (Soxhlet 3). At the end of the process, meshes were rinsed with water and dried at $70{ }^{\circ} \mathrm{C}$. The same treatment was given to the polydopamine-coated polypropylene commercial mesh.

Albumin deposition on pDA-coated flax meshes ( $P D A C F M)$

pDA-coated flax mesh was cut in $10 \times 10 \mathrm{~mm}$ specimens. These were steam sterilized at $121{ }^{\circ} \mathrm{C}$ for 15 minutes. Then, a $2.0 \mathrm{~g} / \mathrm{L}$ albumin solution was prepared by dissolving bovine albumin in sterile PBS $(\mathrm{pH}=7.4)$. To ensure sterility, solution was passed through sterile filters. Meshes were immerged into $5 \mathrm{~mL}$ of this albumin solution for $24 \mathrm{~h}$ at $37^{\circ} \mathrm{C}$. Finally, meshes were rinsed with sterile PBS and dried.

Quantification of the amount of PDA coated on flax and PP meshes

A micro-BCA ${ }^{\circledR}$ assay (Thermo Fisher Scientific, Etten-Leur, the Netherlands) was used to quantify the amount of polydopamine deposited on our flax mesh depending on the dopamine concentration, coating time and rinsing method. This procedure was adapted from the work of Slocum who showed that the bicinchoninic acid present in the micro- $B C A^{\circledR}$ test reacted linearly with catecholamines in the 10 to $1000 \mu \mathrm{M}$ range [19]. In brief, $10 \times 10 \mathrm{~mm}$ meshes were put in $1 \mathrm{~mL}$ Tris solution $(10 \mathrm{mM}, \mathrm{pH}=8.5)$ and $1 \mathrm{~mL}$ working solution and incubated for $1 \mathrm{~h}$ at $60{ }^{\circ} \mathrm{C}$. Absorbance was measured at $562 \mathrm{~nm}$ and values were compared to the reference curve to obtain the final amount of polydopamine deposited on the meshes. Reference curve was obtained by following the same protocol as before, but this time $1 \mathrm{~mL}$ of reagent was mixed 
with $1 \mathrm{~mL}$ of dopamine solution of different concentrations (from 0 to $40 \mu \mathrm{g} / \mathrm{mL}$ $(261 \mu \mathrm{M})$ dopamine in $10 \mathrm{mM}$ Tris solution, $\mathrm{pH}=8.5)$.

\section{$X$-Ray Photoelectron spectroscopy analysis}

$10 \times 10 \mathrm{~mm}$ uncoated and polydopamine coated flax meshes were analysed with a X-Ray photoelectron spectroscopy (XPS) Microprobe (Quantera SXM ${ }^{\mathrm{TM}}$, ULVAC-PHI, Chigasaki, Japan). A monochromatic AlKa-radiation with a spot size of $200 \mu \mathrm{m} \times 600 \mu \mathrm{m}$ was used to carry out the analysis. Elements composing the surface of the meshes were determined by averages of wide-scan measurements. Concentration of each element was obtained by precise narrowscans. Peak areas were converted into atomic concentrations by using standard sensitivity factors.

\section{Cell culture}

Mouse fibroblasts (clone L929 cells) were grown in DMEM/F-12 + Glutamax-1 medium complemented with antibiotics $(100 \mathrm{U} / \mathrm{mL}$ penicillin, $0.25 \mu \mathrm{g} / \mathrm{mL}$ amphotericin B and $100 \mu \mathrm{g} / \mathrm{mL}$ streptomycin) and $10 \%$ FBS. Human coronary aortic endothelial cells (HCAEC) were grown in EGM-2MV medium (Lonza, Verviers, Belgium). Cells were harvested with $0.05 \%$ Trypsin/0.53 mM EDTA. Both cells were incubated at $37{ }^{\circ} \mathrm{C}$ and $5 \% \mathrm{CO}_{2}$. All materials were steam sterilized at $121{ }^{\circ} \mathrm{C}$ for 15 minutes before being incubated with cells or cell media.

\section{Indirect cytotoxicity evaluation}

Uncoated and polydopamine coated meshes were incubated in L929 cell medium $(0.05 \mathrm{~g} / \mathrm{mL})$ for $72 \mathrm{~h}$ at $37^{\circ} \mathrm{C}$. L929 cells were seeded in 96-well plates at a density of 10.000 cells/mesh and let to adhere overnight. Next day, cell medium was replaced by medium incubated with the meshes, and cells were further incubated for $48 \mathrm{~h}$. MTT solution was added to a final concentration of 0.25 $\mathrm{mg} / \mathrm{mL}$. Next, plates were incubated for $2 \mathrm{~h}$. After this, medium was carefully withdrawn and replaced by isopropanol to dissolve the formed formazan crystals. Absorbance of the plates was read at $570 \mathrm{~nm}$ and cell viability was defined as ratio of the viable control (blank medium incubated for $72 \mathrm{~h}$ at $37^{\circ} \mathrm{C}$ ) that was set at $100 \%$ cell viability. In each plate, medium supplemented with $5 \%$ dimethylsulfoxide was used as toxic control. 
Microscopic evaluation of L929 cells incubated with uncoated and PDCFM

$10 \times 10 \mathrm{~mm}$ meshes were put in a 6-well plate and bottom-fixed with metal rings. Then, 150.000 cells were added in each well, before the plate being incubated for $72 \mathrm{~h}$. Cell morphology was observed with an inverted microscope $\left(\operatorname{Evos}_{\mathrm{xl}}\right.$, Invitrogen, Bleiswijk, the Netherlands) and compared to the morphology of cells incubated with viable control (pure medium) or toxic control (latex).

\section{Cell adhesion}

To test cell dynamic adhesion, $10 \times 10 \mathrm{~mm}$ meshes, placed in 2-mL Eppendorf tubes, were co-incubated with 250.000 cells $/ \mathrm{mL}$ into $20 \mathrm{mM}$ HEPES buffered cell medium. Tubes were fixed on a vertical rotator $(50 \mathrm{rpm})$ and incubated overnight at $37^{\circ} \mathrm{C}$. Next day, meshes were rinsed with PBS and frozen at $-80^{\circ} \mathrm{C}$. They were later analyzed with the CyQUANT ${ }^{\mathbb{B}}$ kit.

\section{Scanning electron microscopy (SEM)}

Mesh specimens, prepared according to protocol described in cell adhesion paragraph were kept unfrozen SEM observation. Directly after overnight adhesion, meshes were rinsed in PBS, immerged in $2.5 \%$ glutaraldehyde in cold PBS solution and stored in cold room for at least $24 \mathrm{~h}$. Then, samples were dehydrated by successive immersions in $50 \%, 70 \%, 80 \%, 90 \%$ and 2 times $100 \%$ ethanol for 15 minutes each. Meshes were then treated with hexamethyldisilazane for 4 minutes and placed in a desiccator for $24 \mathrm{~h}$. Later, meshes were put on a carbon tape and sputter-coated with gold. Images were taken with a SEM (Philips XL 30, FEI, Eindhoven, the Netherlands) at an operating voltage of $10 \mathrm{kV}$.

\section{Immunogenicity assay and ICAM-1 staining}

Human coronary artery endothelial cells (HCAECs) were seeded with a density of $21.000 \mathrm{cell} / \mathrm{cm}^{2}$ on Ibidi m-slide VI 0.4 culture flow slides (Ibidi $\mathrm{GmbH}$, Martinsried, Germany) and cultured overnight $(\mathrm{o} / \mathrm{n})$ in EGM-2MV medium (Lonza, Verviers, Belgium). Monocyte cell line THP-1 $\left(2.5 \times 10^{6}\right.$ cells $/ \mathrm{mL}$; ATTC, LGC Standards GmbH, Wesel, Germany) were incubated with different biomaterials (i.e. $20 \times 10 \mathrm{~mm}^{2}$ flax mesh specimens) that were cut in small pieces in EGM-2MV medium without serum and growth supplements o/n. Next day, supernatants were collected from the THP-1-biomaterial co-incubated samples or from biomaterials incubated in blank medium. As positive control 
HCAECs were incubated o/n with $80 \mathrm{ng} / \mathrm{mL}$ TNF-alpha (Sigma-Aldrich, Zwijndrecht, the Netherlands). Subsequently, medium samples were added to the HCAEC Ibidi slides and subcultured for another $24 \mathrm{~h}$ before being subjected to THP-1 adhesion analysis or immunohistochemical staining for ICAM-1.

For THP-1 adhesion analysis, HCAEC Ibidi slides were first washed 0.22 $\mathrm{mL} / \mathrm{min}$ for $1 \mathrm{~min}$ with blank EGM-2MV to fill and pre-wash cells. Next, $1.2 \times$ $10^{6}$ calcein $(5 \mathrm{mg} / \mathrm{mL}$; Life technologies, Carlsbad, CA, US) labeled THP1 were flowed $0.44 \mathrm{~mL} / \mathrm{min}$ for $5 \mathrm{~min}$, which was followed by a second wash step of $0.22 \mathrm{~mL} / \mathrm{min}$ for $2.5 \mathrm{~min}$ with blank EGM-2MV. Number of adherent THP-1 cells was assessed fully-automated by using a BD Pathway 855 (BD, Heidelberg, Germany) with $4 x$ objective and montage of $11 \times 3$ pictures covering $80 \%$ of the slide channel, excluding entrance and exit region of the Ibidi side. Numbers of adherent THP-1 cells were quantified with BD Attovision software (BD Attovision 1.6) masking for calcein positive cells and exporting number of positive regions of interest representing number of individual cells adhering to the HCAECs per slide. All experiments were executed at least in triplicate and mean numbers of adherent THP-1 cells were normalized for positive control (TNF-alpha) which was set at 100\%. t-Test analysis with bonferroni-correction was used to define statistical differences between samples, $\mathrm{p}<0.05$ was considered significantly different.

For ICAM-1 staining endothelial cells were fixed with $4 \%$ PFA for 5 minutes at room temperature and washed twice with PBS. Anti-ICAM (1:50; clone IM0726U; Beckman Coulter, Woerden, the Netherlands) was added and incubated $\mathrm{o} / \mathrm{n}$. Next day, samples were washed with PBS and PBS/0.05\%Tween twice and incubated at room temperature with Alexa647 labeled secondaryantibody (2 mg/mL gout-anti-mouse AF647, Life technologies) for 1 hour. Slides were automatically imaged with the BD Pathway $(20 \times$ magnification and montage of $4 \times 4$ images). Image-J was used to define the fluorescence intensity per view for all conditions analyzed. Average ICAM-1 intensity of at least 3 independent samples were obtained and average intensity was plotted against ICAM-1 intensity of the blank (set at $100 \%$ ). t-Test analysis with bonferronicorrection was used to define statistical differences between samples, $\mathrm{p}<0.05$ was considered significantly different. 


\section{Results}

Figure 1 summarizes the consecutive treatments that were given to the flax mesh specimens.

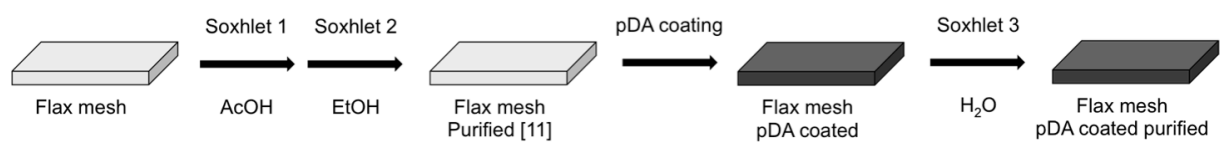

Figure 1. Overview of the successive treatments of the flax mesh specimens in this study. Treatments $1 \& 2$ (described as Soxhlet 1 and Soxhlet 2) were described previously.

All experiments in this study were conducted with flax mesh samples that already received the tandem Soxhlet treatment (Soxhlet $1 \& 2$ ) as described previously [9]. Then, flax meshes were coated with polydopamine. Different coating parameters were employed (dopamine concentration, incubation time, rinsing method). Table 1 provides a comprehensive overview of the main coating conditions used throughout this paper.

Table 1. Overview of the main coating conditions used throughout this study.

\begin{tabular}{lccc}
\hline & $\begin{array}{c}\text { Dopamine concentration } \\
(\mathbf{m g} / \mathbf{m L})\end{array}$ & $\begin{array}{c}\text { Time of incubation in } \\
\text { the dopamine solution } \\
\text { (hours) }\end{array}$ & $\begin{array}{c}\text { Soxhlet 3 washing after the } \\
\text { polydopamine coating }\end{array}$ \\
\hline Condition 0 & 0 & 0 & No \\
Condition 1 & 2 & 2 & No \\
Condition 2 & 2 & 24 & No \\
Condition 3 & 2 & 2 & Yes \\
Condition 4 & 2 & 24 & Yes \\
\hline
\end{tabular}

Condition 0 refers to the flax mesh before dopamine coating as obtained after Soxhlet treatment 1 $\& 2$.

In particular, condition 0 refers to the flax mesh before pDA coating. The uncoated flax mesh was further incubated with dopamine solution $(2 \mathrm{mg} / \mathrm{mL})$ for respectively 2 and $24 \mathrm{~h}$ in conditions 1 and 2. In conditions 3 and 4, polydopamine flax meshes (respectively conditions 1 and 2) were extensively purified with Soxhlet treatment 3. 


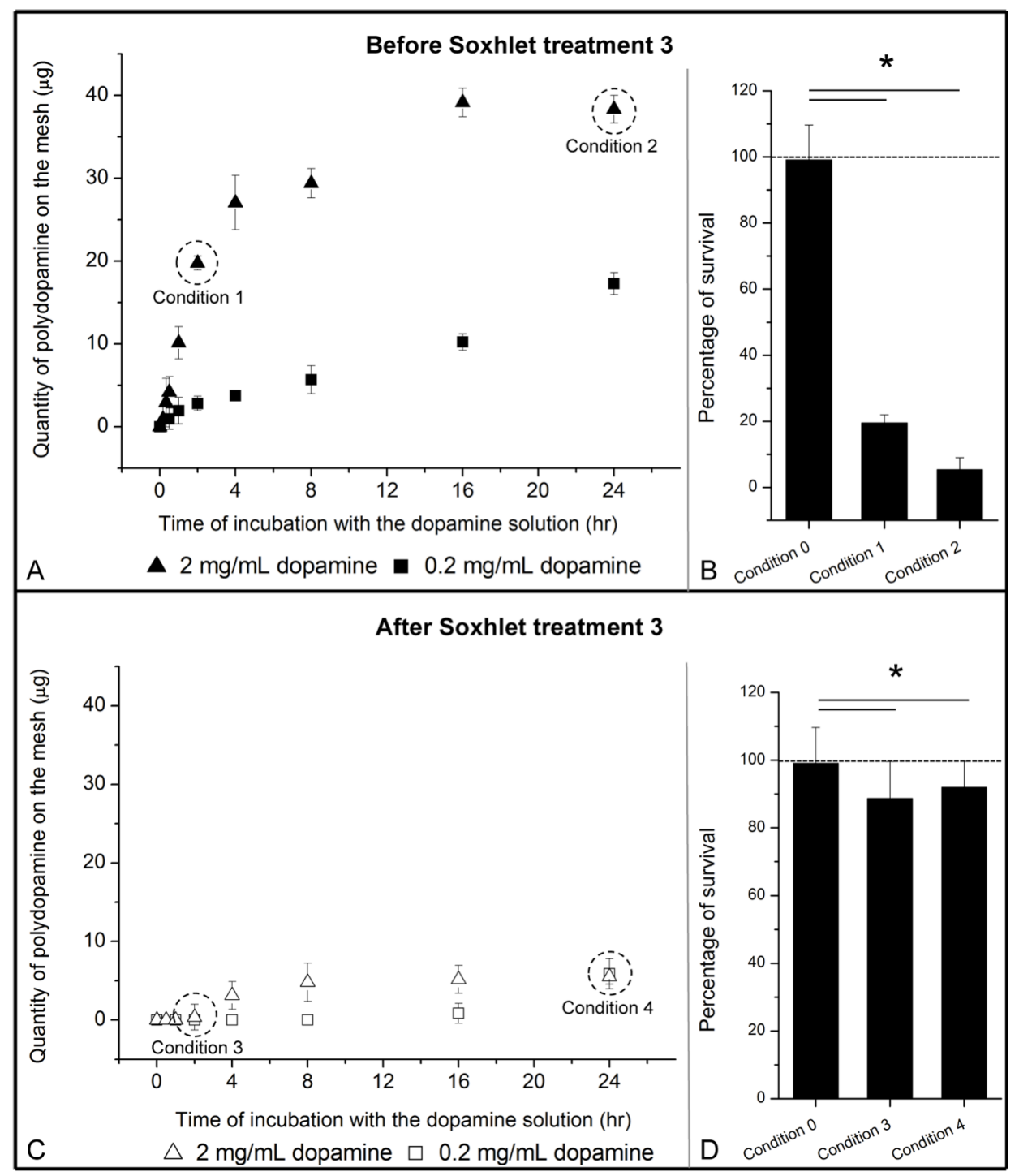

Figure 2. Relationship between the amount of adhered polydopamine (dependent on the Soxhlet treatment 3) and the level of cytotoxicity. (A,C) Quantity of pDA coated on flax mesh, values were obtained with a micro- $B C A^{\circledR}$ Protein assay reagent test, which is also sensible to the catechol amines as dopamine. (B,D) Cell survival determined by MTT test. Condition 0 refers to the uncoated flax mesh as obtained after Soxhlet $1 \& 2$. The uncoated flax mesh was further incubated with dopamine solution $(2 \mathrm{mg} / \mathrm{mL})$ for respectively 2 and $24 \mathrm{~h}$ in conditions 1 and 2 (encircled filled triangles). In conditions 3 and 4 (encircled open triangles), pDA-coated flax meshes (respectively conditions 1 and 2) were extensively washed with Soxhlet treatment 3. 
Compromised cytocompatibility of pDA-coated flax meshes

Two different concentrations of dopamine $(0.2 \mathrm{mg} / \mathrm{mL}$ and $2.0 \mathrm{mg} / \mathrm{mL}$, with the latter corresponding to the dopamine concentration commonly used $[11,12,14,15])$, and 9 different time intervals of immersion (10 min, $20 \mathrm{~min}, 30$ min, $1 \mathrm{~h}, 2 \mathrm{~h}, 4 \mathrm{~h}, 6 \mathrm{~h}, 16 \mathrm{~h}$ and $24 \mathrm{~h}$ ) were tested for coating efficiency using the micro-BCA assay. First, flax meshes were rinsed according to procedure described in literature $[11,13,14,16,17]$. Coating efficiency results are shown in figure 2(A).

An appreciable amount of $\mathrm{pDA}$ is already present on the meshes $(3.4 \pm$ $0.2 \mu \mathrm{g} / \mathrm{cm}^{2}$ ) after $30 \mathrm{~min}$ of incubation with the $2 \mathrm{mg} / \mathrm{mL}$ dopamine solution. For the $2 \mathrm{mg} / \mathrm{mL}$ dopamine concentration (filled triangles) a polymerization plateau was observed after approximately $16 \mathrm{~h}$, reaching roughly $40 \mu \mathrm{g} \mathrm{pDA} / \mathrm{cm}^{2}$ mesh. No plateau was found for specimens that were immersed in the 0.2 $\mathrm{mg} / \mathrm{mL}$ dopamine solution (closed squares). Dynamic deposition of polydopamine on PP meshes was also analyzed with the $2 \mathrm{mg} / \mathrm{mL}$ dopamine solution (fig. 3). For this biomaterial no plateau was reached and maximal amount of $\mathrm{pDA}$ attached to the polypropylene (PP) mesh $\left(28.3 \pm 2.7 \mu \mathrm{g} / \mathrm{cm}^{2}\right)$ was considerably lower than what was obtained on flax.

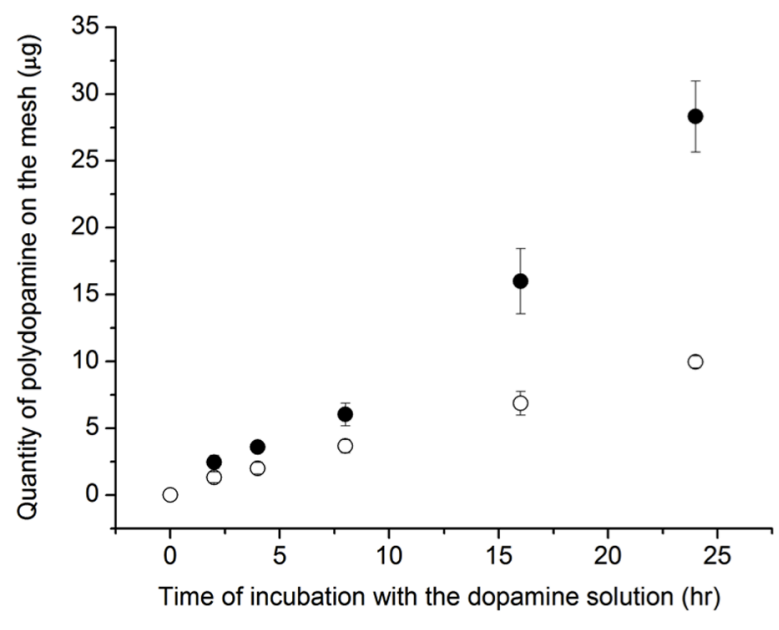

- Before Soxhlet treatment $\bigcirc$ After Soxhlet treatment

Figure 3. Quantity of polydopamine coated on a PP mesh using a $2 \mathrm{mg} / \mathrm{mL}$ dopamine solution. Values were obtained with a micro-BCA ${ }^{\circledR}$ Protein assay reagent test, which is also sensible to catecholamines as dopamine. 
Biocompatibility of the materials obtained after conditions 1 \& 2 was tested with the MTT assay. As expected uncoated flax mesh (condition 0) showed high cell survival (99\%). However, the flax specimens coated with pDA (conditions 1 and 2) showed pronounced cytotoxicity (fig. 2(B)).

Purification of the pDA-coated flax meshes

The strong cytotoxicity of pDA-coated flax meshes prompted us to introduce another purification step. For this, meshes were Soxhlet treated using water as an extracting fluid (24 $\mathrm{h}$ treatment time). BCA-analysis revealed that a substantial portion of pDA was removed from the meshes after Soxhlet treatment (open squares and triangles; fig. 2(C)). For Soxhlet treated flax meshes that were coated for $24 \mathrm{~h}$ in 0.2 and $2.0 \mathrm{mg} / \mathrm{mL}$ dopamine solution, respectively $5.89 \pm$ $1.91 \mu \mathrm{g} / \mathrm{cm}^{2}$ and $5.53 \pm 0.98 \mu \mathrm{g} / \mathrm{cm}^{2}$ PDA remained present on each mesh, representing a total average loss of $65 \%$ and $85 \%$ pDA. This loss is proportional for all conditions as the trend characterizing pDA polymerization on flax before Soxhlet wash is globally preserved after the purification treatment (i.e. a polymerization plateau is reached with the $2 \mathrm{mg} / \mathrm{mL}$ dopamine concentration). Considering that the amounts of pDA obtained on flax meshes are similar with both dopamine concentrations, we decided to discard the $0.2 \mathrm{mg} / \mathrm{mL}$ condition for further analysis. Also Soxhlet purification of PP meshes gave a high decrease in PDA coated concentration with $9.96 \pm 0.45 \mu \mathrm{g} / \mathrm{cm}^{2}$ PDA after $24 \mathrm{~h}$, being approx. $64 \%$ less than for the unpurified condition (fig. 3). This concentration is significantly higher compared to the coated flax, potentially reflecting a difference in coating caused by variable polymerization efficiency for both biomaterials.

To confirm the presence of polydopamine on the surface of coated and Soxhlet treated specimens (conditions 3 and 4), X-ray photoelectron spectroscopy (XPS) was performed. These data are compiled in Table 2.

Table 2. Atomic concentrations at the surface of the untreated and polydopamine coated flax meshes as obtained from XPS survey spectra.

\begin{tabular}{lccccc}
\hline & $\begin{array}{c}\text { C 1s at. } \\
\%\end{array}$ & $\begin{array}{c}\text { O 1s at. } \\
\%\end{array}$ & O/C & $\begin{array}{c}\text { N 1s at. } \\
\text { O=C-NH } \\
\mathbf{4 0 0 . 1} \text { eV } \\
\%\end{array}$ & N/C \\
\hline Condition 1 & 61 & 31 & 0.51 & 0.45 & 0.01 \\
Condition 3 & 66 & 27 & 0.41 & 1.25 & 0.02 \\
Condition 4 & 68 & 27.5 & 0.40 & 1.35 & 0.02 \\
\hline
\end{tabular}


The presence or absence of $\mathrm{pDA}$ is clearly indicated by the N1s peak in XPS. Prior to pDA coating, a small N1s peak was observed (0.45\%) (condition 0), whereas after pDA coating and Soxhlet treatment the concentration of Nitrogen reaches respectively $1.25 \%$ and $1.35 \%$.

Improved cell compatibility of pDA-coated flax meshes after third Soxhlet treatment.

The third Soxhlet treatment on pDA coated meshes (conditions $3 \& 4$; fig 2(D)) restored cell biocompatibility of the materials with cell survival after $2 \mathrm{~h}$ and $24 \mathrm{~h}$ coating increasing from $19.5 \%$ (condition 1) to $88.7 \%$ (condition 3), and $5.3 \%$ (condition 2) to $92.0 \%$ (condition 4), respectively. Cell survival rates between pDACFM and uncoated flax mesh can be considered almost comparable.

Incubation of L929 cells with pDA-coated flax specimens under static conditions further confirmed the non-cytotoxic nature of these Soxhlet purified biomaterials (fig. 4). After 3 days of incubation, a monolayer of confluent and healthy cells was observed in close proximity to flax specimens prepared according to conditions 0,3 and 4 . The appearance of the cells was similar to reference condition (blank medium only). In contrast, cells incubated next to latex (control toxic material) showed a distorted morphology characteristic of dying cells.

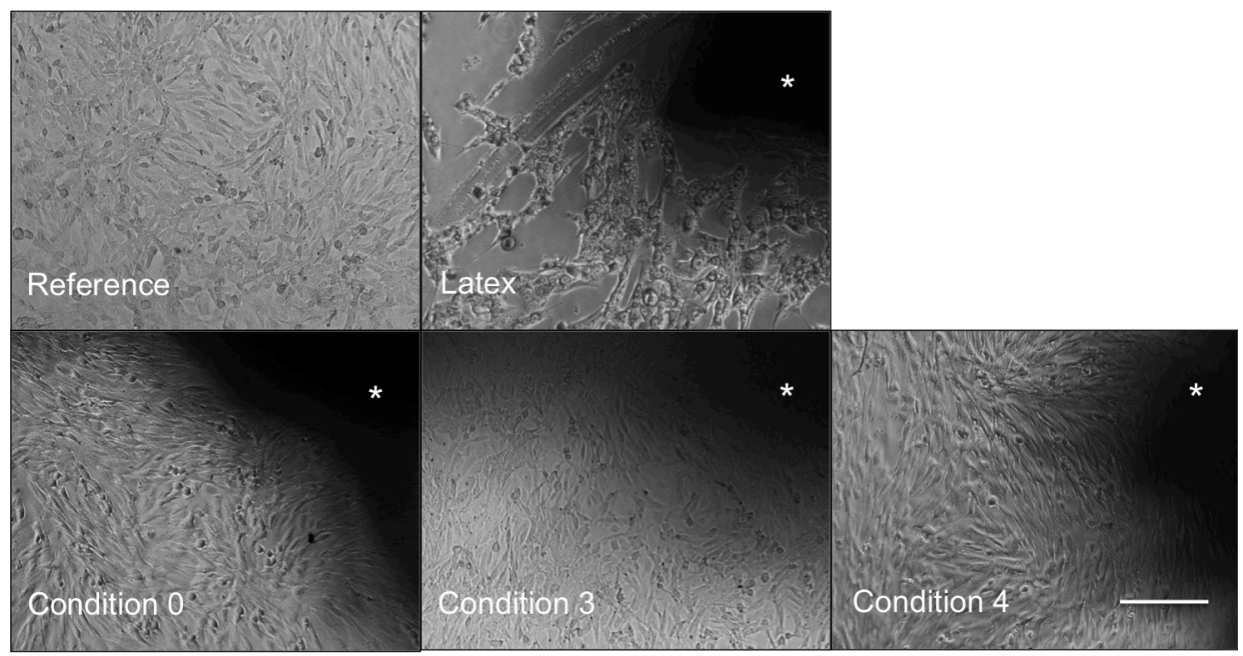

Figure 4. Microscopic bright field images of the appearance of L929 cells placed in close proximity of different materials. Condition 0 refers to the uncoated flax mesh as obtained after Soxhlet $1 \& 2$. The uncoated flax mesh was further incubated with dopamine solution $(2 \mathrm{mg} / \mathrm{mL})$ for respectively 2 and $24 \mathrm{~h}$ in conditions 3 and 4 , and meshes were extensively washed with Soxhlet treatment 3. All scale bars represent $200 \mu \mathrm{m}$ and $*$ shows material. 
Cell adhesion to samples of conditions 0,3 and 4 was also studied under dynamic conditions; both mouse fibroblast cells (L929) and human endothelial cells (HCAECs) were used. A priori, it was expected that the pDA coating would facilitate adhesion and spreading of cells $[12,13,15]$. However, for cell adhesion, an opposite trend was observed (fig. 5): the number of adhered cells per $\mathrm{cm}^{2}$ mesh appeared to decrease after the application of the pDA coating.
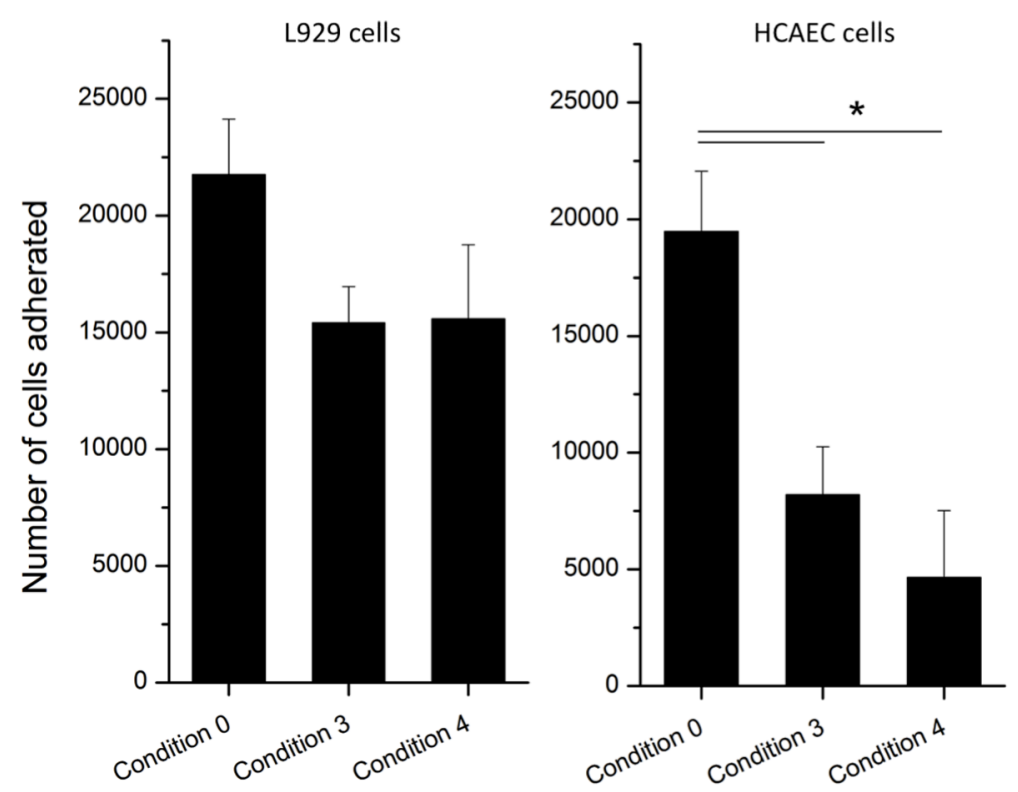

Figure 5. Overnight cell dynamic adhesion of 250.000 cells (left: L929 fibroblast cells; right: HCAEC endothelial cells) on different flax meshes. Condition 0 refers to the uncoated flax mesh as obtained after Soxhlet $1 \& 2$. The uncoated flax mesh was further incubated with dopamine solution $(2 \mathrm{mg} / \mathrm{mL})$ for respectively 2 and $24 \mathrm{~h}$ in conditions 3 and 4 , and meshes were extensively washed with Soxhlet treatment $3 . *$ denotes statistical difference $(\mathrm{p}<0.05)$.

Samples overnight incubated with L929 cells were also analyzed by SEM (fig. 6). We observed that the presence of a pDA coating had a clear effect on cell spreading. Cells were obviously more spread (elongated) once pDA was deposited on flax fibers, with increased average L929 cell length along flax fibers from $27 \pm 10 \mu \mathrm{m}$ without pDA coating (condition 0) to $57 \pm 19 \mu \mathrm{m}$ after $2 \mathrm{~h}$ pDA coating (condition 3). This cell spreading did not significantly increased further from condition 3 to 4 . 


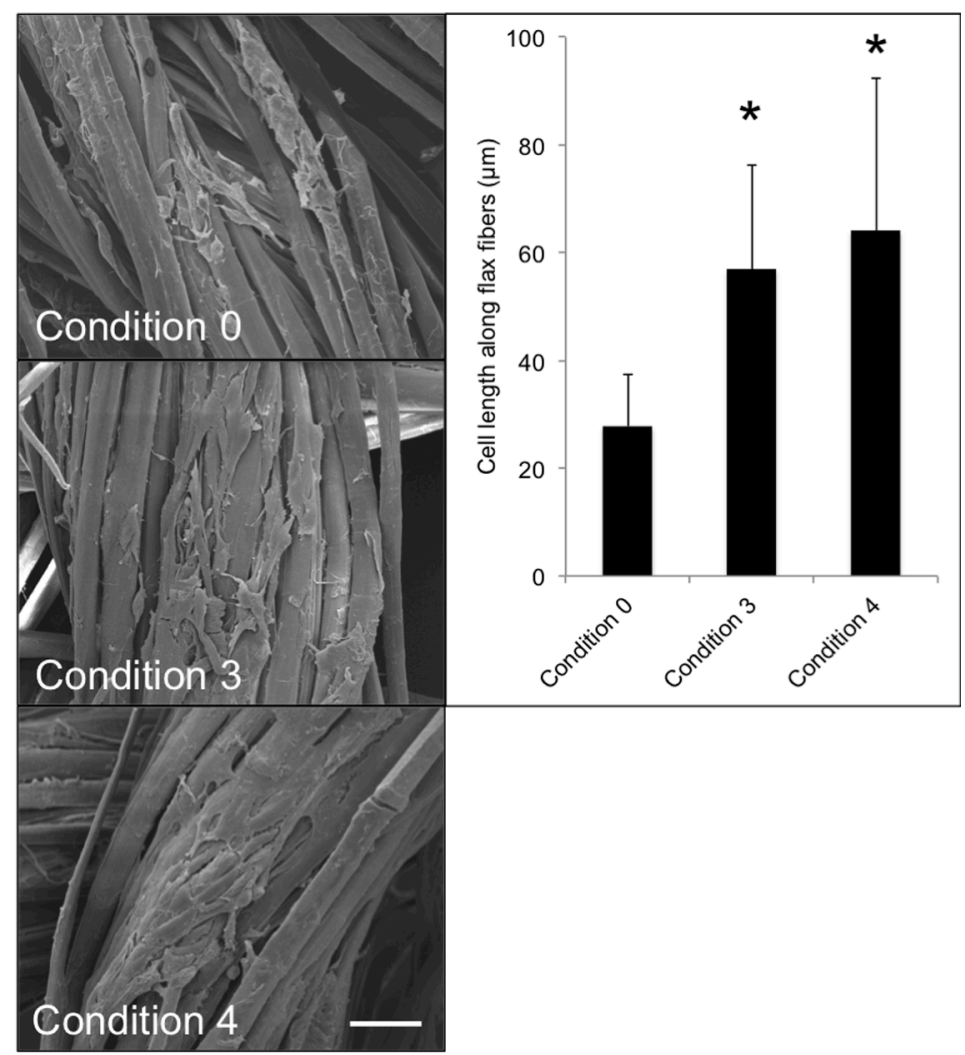

Figure 6. Effect of the pDA coating on L929 cell spreading. Left: SEM images showing the morphology of adhered cells on flax fibers with and without pDA coating. Condition 0 refers to the uncoated flax mesh as obtained after Soxhlet $1 \& 2$. The uncoated flax mesh was further incubated with dopamine solution $(2 \mathrm{mg} / \mathrm{mL})$ for respectively 2 and $24 \mathrm{~h}$ in conditions 3 and 4 , and meshes were extensively washed with Soxhlet treatment 3. Scale bar represents $10 \mu \mathrm{m}$. Right: For each condition, more than five SEM images were analyzed and length of at least 50 cells was measured to obtain mean \pm S.D. * Denotes statistical difference between cell length with condition 0 and conditions $3 \& 4$.

\section{pDA-coated flax is highly immunogenic and acts via ICAM-1}

The immunogenic response of polydopamine coated biomaterials was evaluated by quantifying the number of monocytes (THP-1) that adhere to an endothelial monolayer that has been stimulated with supernatant of monocytes co-incubated with the biomaterial. As comparison and to exclude any direct effect of soluble factors from the biomaterial on the immunogenic response, supernatants from corresponding biomaterial samples incubated in blank medium were used as negative control. In this assay, higher numbers of adherent THP-1 cells indicate 
for high immunogenicity of the biomaterial tested. pDA-coated flax showed a significantly increased immunogenic response as compared to non-coated flax, reflected by a high number of adherent THP-1 cells (fig. 7(A,B)). The supernatant of the biomaterials incubated in blank medium presented an immunogenic response comparable to blank medium only, excluding a direct immunogenic effect of the biomaterial itself. Intriguingly, co-incubation of pDAcoated flax with albumin abolished the immunogenic response (fig. 7(B)). The unfavorable immunogenic response of $\mathrm{pDA}$ was only shown for flax and not for pDA coated polypropylene biomaterial (fig. $7(\mathrm{C})$ ) and could reflect incompatibility of pDA coating with flax.

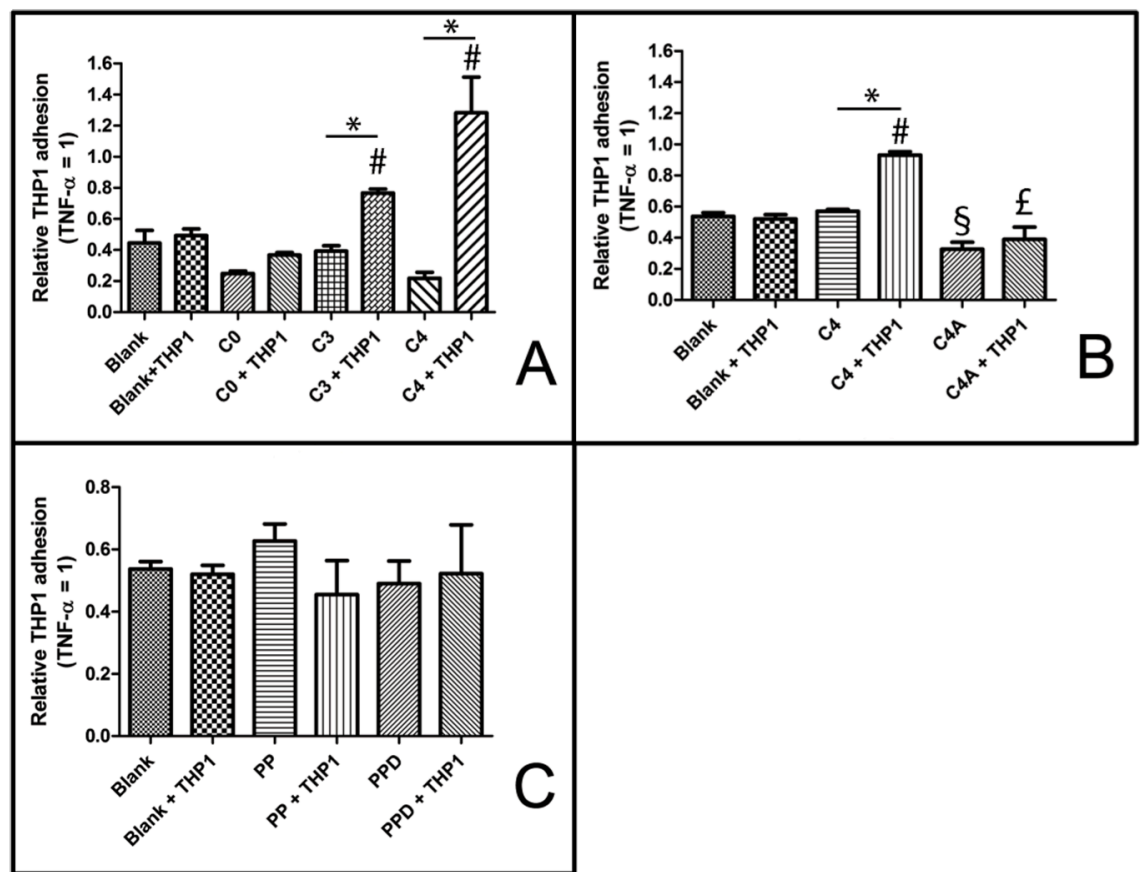

Figure 7. (A-C) Overview of the immunogenic responses of polydopamine coated and noncoated biomaterials. The biomaterials with + THP1 relate to immunogenic response of endothelial cell cultured with THP1-biomaterial conditioned medium. (A,B) Only the polydopamine coated flax (Condition 3 and Condition 4) give a significantly increased immunogenic response for the supernatants of biomaterial incubated with THP-1 compared both to corresponding supernatants of biomaterials cultured in blank medium (*, $\mathrm{p}<0.05, \mathrm{n}=3-4)$ and blank + THP-1 condition (\#, $\mathrm{p}<0.05, \mathrm{n}=3-4)$. (B) Immunogenic effect was dampened by adding albumin to the polydopamine coated materials (C4A and C4A + THP1; §, compared to bank; £ compared to C4 + THP1; both $\mathrm{p}<0.05, \mathrm{n}=3-4$ ). (C) All polydopamine coated polypropylene (PP) biomaterials were without increased immunogenic response. Abbreviations: $\mathrm{C} 0$, treated flax; $\mathrm{C} 3$, treated flax dopamine coated 2 hours; C4, treated flax dopamine coated 24 hours; C4A, treated flax dopamine-albumin coated. Immunogenic response outlined by relative THP1 adhesion with positive control $(\mathrm{TNF} \alpha)$ set at one. 

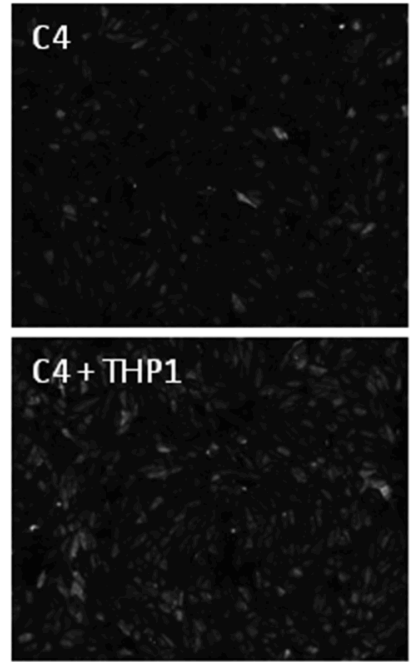
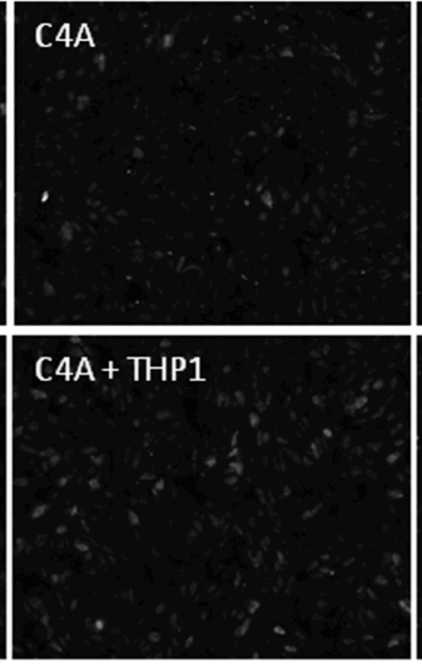

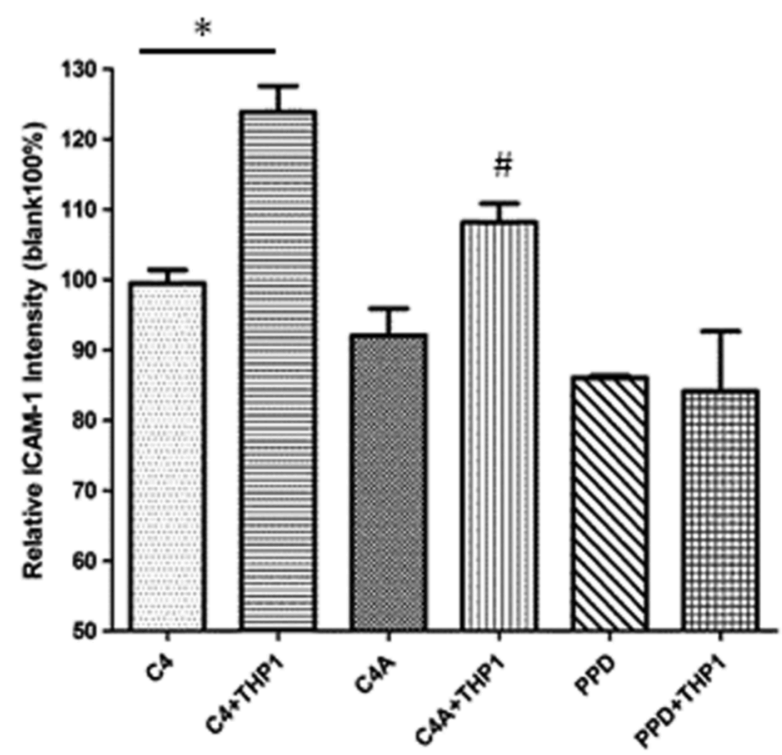

Figure 8. Immunohistochemical analysis of ICAM-1 expression by endothelial cell treated with medium incubated with treated flax coated with polydopamine (TFD; C4), TFD with albumin (C4A) or polypropylene coated with dopamine (PPD) only or +THP-1 conditioned medium. Images of ICAM-1 stained endothelial cells (left-side) show ICAM expression (grey ICAM-1 signal cells) for the different conditions with increased signal for THP-1 conditioned media compared to $\mathrm{C} 4$ or $\mathrm{C} 4 \mathrm{~A}$ condition only, with highest signal present for $\mathrm{C} 4+$ THP- 1 . Quantification of relative ICAM-1 intensity for three replicates (right side) confirms highest expression for $\mathrm{C} 4+$ THP1 condition and to be significantly higher compared to medium incubated with $\mathrm{C} 4$ only $(*, \mathrm{p}<0.05, \mathrm{n}=3)$. C4A + THP1 condition shows a significant lower expression of ICAM-1 compared to the C4 + THP1 (\#, $\mathrm{p}<0.05, \mathrm{n}=3)$. ICAM-1 expression was lowest for PPD conditions analyzed. 
As ICAM-1 is considered a prime candidate that facilitates binding of monocytes to the endothelial monolayer and as its expression and presentation at the cell surface is highly increased by inflammatory responses including TNFalpha [25], we hypothesized a positive correlation between the number of adherent monocytes and ICAM-1 expression by endothelial cells that were treated with supernatants of pDA-coated flax, providing that a high ICAM-1 expression correlates with a high number of adherent monocytes, and vice versa. To show this positive relation endothelial cells cultured with supernatant of the different samples were immuno-histochemically stained for ICAM-1 and quantified. Fluorescence intensity of the cell cultures was defined by fluorescence microscope and image analysis revealed the hypothesized positive correlation for ICAM-1 expression and monocyte adherence for pDA-coated flax samples, that was not found for other low immunogenic pDA-coated biomaterials tested (fig. $8)$.

\section{Discussion}

The apparent cytotoxicity of pDA-coated flax is a surprising outcome; it is well documented that pDA coatings actually promote cell adhesion, spreading and proliferation. We considered structural differences between flax as the substrate for $\mathrm{pDA}$ coating on one hand, and other materials that were used as substrates for pDA coating in the literature. Flax is hydrophilic and porous/hollow, whereas most other substrates are hydrophobic and non-porous [12-14,20,21]. It must be noted that pDA coating of cellulose has been described. However, cell compatibility of these materials was not reported [7,22-24].

From a chemical point of view, the pDA coating method is facile and versatile. The substrate is immersed in dopamine solution, under basic conditions, and in the presence of oxygen. Then, dopamine undergoes selfpolymerization, yielding the macromolecular coating which tightly adheres to the surface like mussel glue. The mechanism of polymerization has been the subject of intense research. It is now generally accepted that the reactive monomer is 5,6-dihydroxyindole, and that this molecule is generated from dopamine in situ, through 4 consecutive chemical reactions: oxidation, cyclization, oxidation and rearrangement (fig. 9) [25-30].

The bonding between the pDA layer and the substrate includes covalent and non-covalent interactions, such as hydrogen bonding, electrostatic interactions and $\pi-\pi$ interactions. pDA coatings are remarkably stable and durable, except in strongly alkaline solutions $(\mathrm{pH}>13)$. We could easily apply a 

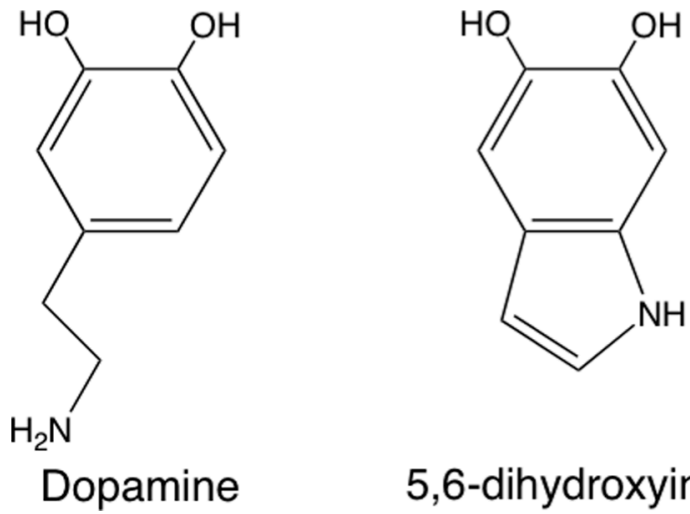

\section{5,6-dihydroxyindole}

Figure 9. Structural formulas of dopamine and 5,6-dihydroxyindole. The latter compound is the reactive monomer in the self-polymerization reaction leading to biocompatible adherent $\mathrm{pDA}$ surface coatings.

biocompatible pDA coating onto a PP mesh material, but we failed when we tried the same with flax. Our explanation for this is that dopamine is absorbed by the flax which is cellulose in a multifilament form; the filaments are hollow. We observed that the material readily absorbs dopamine. Hence, dopamine molecules are not confined to the flax' surface, they are embedded in the flax material. Clearly, this will hamper the polymerization reaction via diffusion limitation. In other words: the terminus of a growing polymer chain cannot collide easily with the next monomer molecule. Consequently, chemical conversion of dopamine on/in flax is relatively slow, and flax still contains many unreacted dopamine molecules when the "normal" protocol for pDA coating is finished. This explains why flax threads, after having received the double Soxhlet treatment, become cytotoxic after the treatment with dopamine. It also explains why cytocompatibility is improved when the material is subjected to a third Soxhlet treatment with water. Evidently, the last treatment will remove unreacted dopamine.

Interestingly, dopamine is a catecholamine which can cause immune responses [18]. Considering this risk for in vivo application we analyzed the immunogenicity of $\mathrm{pDA}$ coated flax. To test the immunoreactivity of biomaterials, we have developed a monocyte-endothelial cell bioassay. In this assay the biomaterial is incubated for 24 hours with a humane monocyte cell line (THP1 cells). Upon the event of an immunoresponse these THP1 cells will be triggered and, subsequently, will secrete pro-inflammatory factors (e.g. IL-6, TNF $\alpha$ ). Next, the supernatant is collected and added to immuno-quiescent endothelial cells, cultured as monolayer. When a pro-inflammatory factor is 
present in the THP1 derived supernatant, endothelial cells will become proinflammatory as well. During an inflammatory response, endothelial cells expose a repertoire of pro-inflammatory cell adhesion proteins (e.g. ICAM-1) at their surface [31], and eventually this will facilitate binding of monocytes. By flowing fluorescent-labeled THP1 cells under standardized conditions over these endothelial cells their pro-inflammatory status can be estimated by defining the number of adherent THP-1 cells per surface area. In this assay, the number of adherent THP1 cells is proportional to the immunoreactivity of the biomaterial.

From our data we can conclude that supernatant from THP1-cells coincubated with pDA-coated flax induced a potent inflammatory response in endothelial cells. This effect is most likely related to a dopamine induced proinflammatory response of THP1 cells that acts as a paracrine factor on endothelial cells. In contrast, Soxhlet treated flax induced no ascertainable inflammatory response, with or without THP-1 co-incubation, indicating that the flax mesh itself is low-immunogenic and that the inflammatory response is directly attributed by $\mathrm{pDA}$ coating. This phenomenon is restricted to flax as, in agreement with literature $[12,14]$, we show low immunogenicity for common biomaterial like PP coated with pDA. Interestingly the overt immunogenic response of $\mathrm{pDA}$ coated flax could be reduced by adding albumin after $\mathrm{pDA}$ coating. Likely the albumin dampens the immunoresponse by binding to free dopamine or polydopamine, thereby hampering interaction of the ligand with its cognate dopaminergic receptor on THP-1 cells. It has been reported that dopamine can bind to BSA, forming a stabile complex by interaction with both tyrosine and tryptophan residues on BSA $[32,33]$. BSA might also have inhibited paracrine signaling of THP-1 to endothelial cells, as albumin has been reported to act as an anti-inflammatory agent towards endothelial cells, inhibiting the inflammatory response of the strong inflammatory factor TNF $\alpha$ in a dosedependent manner [34].

ICAM-1 expression and presentation at the surface of the cell is increased by inflammatory responses and its expression is positively correlated with monocyte adherence [31]. Providing that a high ICAM-1 expression correlates with a high number of adherent monocytes, and vice versa, we could show a positive relation between increased monocytes adherence and ICAM-1 expression for endothelial cells that were treated with supernatant of THP-1 cells co-cultured with pDA coated flax. In agreement with the low immunogenic response of $\mathrm{pDA}$-coated $\mathrm{PP}$ and $\mathrm{pDA}+$ albumin-coated flax, no significant increase in ICAM-1 expression was apparent. This data show that dopamine coating on flax could compromise biocompatibility of the biomaterials by activating monocytes. It has previously been shown that dopamine can activate 
the expression of IL-6 and CCL2. Both IL-6 [35] and CCL2 [36] are secreted by monocytes and have been reported to increase expression of ICAM-1 in endothelial cells. Based on these general activities of IL-6 and CCL2 in upregulating ICAM-1, we consider a comparable mode of paracrine activation to have occurred in our setting as well.

\section{Conclusion}

Application of flax as a biomedical material is problematic, due to the presence of adherent endotoxins as contaminants. Although continuous extraction can purify flax to a large extent, quantitative removal of endotoxins could not be achieved so far. This study has explored the idea of using polydopamine surface coating to enhance the biocompatibility of flax; polydopamine coatings are known for their excellent sticking to numerous substrates (mussel glue effect), and for their excellent cell compatibility. Unfortunately, application of polydopamine surface coating on flax meshes did not produce the desired effect. The resulting specimens were found to be cytotoxic and immunogenic, which could be attributed to the presence of unreacted dopamine. To the best of our knowledge, this reveals for the first time that polydopamine surface coatings must be applied with caution, whenever one deals with porous and/or hydrophilic substrates.

\section{Acknowledgement}

This study is a part of the Interreg IV-A project "BioMiMedics" (www.biomimedics.org). The Universities of Maastricht (The Netherlands), Liege (Belgium), Hasselt (Belgium) and Aachen (Germany; RWTH and Fachhochschule), as well as several regional biotechnological enterprises cooperate in "BioMiMedics". This particular study was financed through generous contributions of the EU (through Interreg IV-A), the government of the Province Dutch Limburg, the Dutch National Ministery of Economic Affairs, Agriculture \& Innovation, Maastricht University, the Limburg Bank for Industry Innovation (LIOF), and the company INterface BIOmaterials BV in Geleen, Netherlands. We are grateful to the company Van der Bilt Seeds \& Flax BV (Sluiskil, The Netherlands) for expert advice and generous gift of flax yarns. 


\section{References}

1. Elsabee M Z, Abdou E S. Chitosan Based Edible Films and Coatings: A Review. Mater Sci Eng C 2013;33:1819-41.

2. Fernandes E M, Pires R A, Mano J F, Reis R L. Bionanocomposites from lignocellulosic resources: Properties, applications and future trends for their use in the biomedical field. Prog Polym Sci 2013;38:1415-41.

3. Altman G H, Diaz F, Jakuba C, Calabro T, Horan R L, Chen J, Lu H, Richmond J, Kaplan D L. Silk-based biomaterials. Biomaterials 2003;24(3):401-16.

4. Shankaran V, Weber D J, Reed R L, Luchette F A. A review of available prosthetics for ventral hernia repair. Ann Surg 2011;253:16-26.

5. Smart N J, Marshall M, Daniels I R. Biological meshes: a review of their use in abdominal wall hernia repairs. Surgeon 2012;10:159-71.

6. Kromer K-H. Physical properties of flax fibre for non-textile-use. Res Agr Eng 2009;55:52-61.

7. Goutianos S, Peijs T, Nystrom B, Skrifvars M. Development of flax fibre based textile rein- forcements for composite applications. Appl Compos Mater 2006;13:199-215.

8. Nilsson T, Gustafsson P J. Influence of dislocations and plasticity on the tensile behaviour of flax and hemp fibres. Compos Part A 2007;38:1722-8

9. Michel S A A X, Vogels R R, Bouvy N D, Knetsch M L, van den Akker N M, Gijbels M J, van der Marel C, Vermeersch J, Molin D G, Koole L H. Utilisation of flax fibers for biomedical applications. J Biomed Mater Res Part B 2013;doi: 10.1002/jbm.b.33025.

10. Vavrik J, Foltýnová V, Vitková I, Adámek S, Poucková P. Changes in abdominal wall after mesh implantation in rats. Med Sci Monit 2000;6(3):476-9.

11. Lee H, Dellatore S M, Miller W M, Messersmith P B. Mussel-inspired surface chemistry for multifunctional coatings. Science 2007;318:426-30.

12. Ku S H, Ryu J, Hong S K, Lee H, Park C B. General functionalization route for cell adhesion on non-wetting surfaces. Biomaterials 2010;31:2535-41.

13. Rim N G, Kin S J, Shin Y M, Jun I, Lim D W, Park J H, Shin H. Mussel-inspired surface modification of poly(L-lactide) electrospun fibers for modulation of osteogenic differentiation of human mesenchymal stem cells. Colloids Surf B Biointerfaces 2012;91:189-97.

14. Tsai W B, Chen W T, Chien H W, Kuo W H, Wang M J. Poly(dopamine) coating of scaffolds for articular cartilage tissue engineering. Acta Biomater 2011;7(12):4187-94.

15. Sureshkumar M, Siswanto D Y, Lee C-K. Magnetic antimicrobial nanocomposite based on bacterial cellulose and silver nanoparticles. J Mater Chem 2010;20:6948-55.

16. Shin Y M, Lee Y B, Shin H. Time-dependant mussel-inspired functionalization of poly(L-lactide- $\varepsilon$-caprolactone) substrates for tunable cell behaviors. Colloids Surf B Biointerfaces 2011;87:79-87.

17. Shin Y M, Lee Y B, Kim S J, Kang J K, Park J C, Jang W, Shin H. Mussel-inspired immobilization of vascular endothelial growth factor (VEGF) for enhanced endothelialization of vascular grafts. Biomacromolecules 2012;13(7):2020-8.

18. Gaskill P J, Calderon T M, Coley J S, Berman J W. Drug induced increases in CNS dopamine alter monocyte, macrophage and T cell functions: implications for HAND. $J$ Neuroimmune Pharmacol 2013;8:621-42. 
19. Slocum T L, Deupree J D. Interference of biogenic amines with the measurement of proteins using bicinchonic acid. Anal Biochem 1991;195:14-7.

20. Jiang J, Zhu L, Zhu L, Zhu B, Xu Y. Surface characteristics of a self-polymerised dopamine coating deposited on hydrophobic polymer films. Langmuir 2011;27:141807.

21. Zhu L P, Jiang J H, Zhu B K, Xu Y Y. Immobilisation of bovine serum albumin onto porous polyethylene membranes using strongly attached polydopamine as a spacer. Colloids Surf B Biointerfaces 2011;86(1):111-8.

22. Xu H, Shi X, Ma H, Lv Y, Zhang L, Mao Z. The preparation and antibacterial effects of dopa-cotton/AgNPs. Appl Surf Sci 2011;257:6799-803.

23. Wei Q, Li B, Yi N, Su B, Yin Z, Zhang F, Li J, Zhao C. Improving the blood compatibility of material surfaces via biomolecule-immobilized mussel inspired coatings. J Biomed Mater Res Part A 2011;96A:38-45.

24. Lee H, Rho J, Messersmith P B. Facile conjugation of biomolecules onto surfaces via mussel adhesive protein inspired coatings. Adv Mater 2009;21(4):431-4.

25. Lee H, Dellatore S M, Miller W M, Messersmith P B. Mussel-inspired surface chemistry for multifunctional coatings. Science 2007;318:426-30.

26. Lee H, Lee B P, Messersmith P B. A reversible wet/dry adhesive inspired by mussels and geckos. Nature 2007;448:338-41.

27. Bernsmann F, Ball V, Addiego F, Ponche A, Michel M, Gracio J J, Toniazzo V, Ruch D. Dopamine-melanin deposition depends on the used oxidant and buffer solution. Langmuir 2011;27:2819-25.

28. Lynge M E, van der Westen R, Postma A, Staedler B. Polydopamine - a natureinspired polymer coating for biomedical science. Nanoscale 2011;3:4916-28.

29. Jiang J, Zhu L, Zhu L, Zhu B, Xu Y. Surface Characteristics of self-polymerized dopamine coating deposited on hydrophobic polymer films. Langmuir 2011;27:141807.

30. Kim H W, McCloskey B D, Choi T H, Lee C, Kim M-J, Freeman B, Park H B. Oxygen concentration control of dopamine-induced high uniformity surface coating chemistry. ACS Appl Mater Interfaces 2013;5:233-8.

31. Kevil C G, Patel R P, Bullard D C Essential role of ICAM-1 in mediating monocyte adhesion to aortic endothelial cells. Am J Physiol Cell Physiol 2001;281:C1442-7.

32. Li J, Duan H, Wei W, Shenglian L. Spectrometric investigations on the binding of dopamine to bovine serum albumin. Phys Chem Liq 2012;50:453-64.

33. Zhang Q, Ni Y, Kokot S. Binding interaction of dopamine with bovine serum albumin: a biochemical study. Spectrosc Lett 2012;45:85-92.

34. Zhang W J, Frei B. Albumin selectively inhibits TNF alpha-induced expression of vascular cell adhesion molecule-1 in human aortic endothelial cells. Cardiovasc Res 2002;55:820-9.

35. Wung B S, Ni C W, Wang D L. ICAM-1 induction by TNFalpha and IL-6 is mediated by distinct pathways via Rac in endothelial cells. J Biomed Sci 2005;12:91-101.

36. Kawai Y, Kaidoh M, Yokoyama Y, Sano K, Ohhashi T. Chemokine CCL2 facilitates ICAM-1-mediated interactions of cancer cells and lymphatic endothelial cells in sentinel lymph nodes. Cancer Sci 2009;100:419-28. 



\section{4}

Flax as a 6lood-contacting material. Effect of an albumin coating in vitro and in vivo

Sophie A A X Michel, Ruben RM Vogels, Nicole D Bouvy, Menno L W Knetsch and Leo H Koole.

Adapted from $\mathcal{I}$ Biomater Sci, Polym Ed 2014; doi: 10.1080/09205063.2014.896633 


\section{Abstract}

The physical/chemical properties of flax (linen) are attractive from the perspective of biomaterials science and engineering. Flax textiles uniquely combine hydrophilicity and strength, with the technical know-how to produce precisely engineered two- and three-dimensional knitted or woven structures. It is, however, extremely difficult to completely remove endotoxins from the flax, and this essentially precludes the use of linen for implant purposes. Herein, the potential utility of flax textiles for blood-contacting applications is investigated, using purified two-dimensional mesh specimens, with and without an albumin surface coating. It was hypothesized that the albumin coating will abolish the effect of adherent endotoxins at the flax' surface. In vitro cell viability assays showed that the flax mesh +/- albumin is not cytotoxic. The albumin coating reduced (but not abolished) the effect of surface-exposed endotoxins (LAL test). Under dynamic conditions, the albumin coating favors coverage with endothelial cells. Experiments with fresh human blood plasma (platelet-rich and plateletfree) showed that the albumin coating reduces the thrombogenicity in vitro. Platelets adhered to the albumin-coated flax mesh showed a less flattened structure. Subcutaneous implantation in rats of Soxhlet purified flax fibers of four different diameters was performed. For three of these diameters, albumin coated fibers were also implanted. Histological analysis showed that the severity of the inflammatory response was related to the diameter of the fiber, i.e. in vivo results were better with smaller threads. The presence of an albumin coating also led to a smaller immune response (i.e. reduced inflammation and less giant cells and necrosis inside the flax bundles), although results are not good enough to allow standard use and commercialisation.

\section{Introduction}

During the last few years, we have become intrigued by linen, which is the generic name for knitted or woven textiles stemming from the flax plant (Linum usitatissimum). Linen belongs to the oldest textiles in the world [1]. The material is soft and strong, and capable of absorbing relatively large amounts of water. Linens can be produced in a large variety of different shapes, sizes, patterns, thickness, and densities. For example, many different knitting or weaving patterns can be used, and the thickness of the flax yarns can be varied [2,3]. From the perspective of biomaterials science, this offers interesting perspectives. We have asked ourselves the question whether linen could provide the basis for improved implantable textiles. One rationale behind this was that flax consists 
primarily of cellulose. Pure cellulose is biocompatible and non-immunogenic $[4,5]$. Another consideration was that linen links hydrophilicity and the capacity to imbibe water, to a high level of strength; this combination is difficult to achieve with synthetic (fiber) materials [3]. Initially, we examined the potential use of linen textiles in abdominal wall surgery, particularly for the repair of inguinal hernias [6]. That work has shown that it is essential for flax fibers to be purified extensively, due to the presence of endotoxins on their surface. Endotoxins are remnants of the wall of Gram-negative bacteria, and these molecules are well known for their pyrogenic nature [7,8]. Their presence on flax fibers is logical, as bacteria are widely involved in the obtaining of flax fibers $[9,10]$. After maturation, flax plant is retted, meaning it is laid down in fields for one month to allow bacteria to digest the inner part of the plant. Retting isolates flax fibers from the stem of the plant. To remove these endotoxins, which is a notoriously difficult task $[11,12]$, we developed a two-step purification protocol (Soxhlet, 2 x $24 \mathrm{~h}$ ) in a previous study [6]. This led to removal of most (but not all) of the adherent endotoxins.

Herein, we report a study in which we further explored the possible use of flax textiles in biomedicine. Now, we focused on applications in bloodcontacting medical devices, such as vascular grafts. Recently, we found that vascular grafts with a hydrophilic luminal surface have better performance (in vivo patency rates) in comparison with identical grafts that have a hydrophobic luminal surface [13]. The know-how for weaving or knitting strong tubular structures from hydrophilic flax threads is available, and all essential parameters such as inner/outer diameter and porosity can be varied easily [14]. As a first step into this direction, we examined specimens of a knitted flax mesh that was manufactured especially for this study. The yarn had a diameter of 160 microns. The study comprised: (i), knitted flax textile specimens $(15 \times 15 \mathrm{~mm})$ that passed the purification protocol, and (ii), same specimens after the application of an albumin surface coating. It was anticipated that the presence of an albumin coating would improve hemocompatibility and cover the endotoxins present at the surface of the meshes. Albumin is the most abundant protein in blood plasma, and is well known for its tendency to adsorb readily to polymer biomaterials [1517].

In this study, the two mesh types (with or without albumin) were subjected to X-ray photo-electron spectrometry, LAL test, and in vitro assays for cytocompatibility. Adhesion of endothelial cells to our meshes was studied under static and dynamic conditions. Moreover, in vitro thrombogenicity was determined (using fresh human blood plasma). Interactions of human blood 
platelets with the two mesh types were studied as well. Finally, in vivo biocompatibility was evaluated subcutaneously in rats.

\section{Materials and Methods}

\section{Materials}

White flax threads were generously provided by the company Van der Bilt Seeds \& Flax BV (Sluiskil, The Netherlands). Bovine albumin, hexamethyldisilazane, glutaraldehyde, thiazolyl blue tetrazolium bromide (MTT) and hydrocortisone was purchased from Sigma (Zwijndrecht, The Netherlands). HEPES, acetic acid and $\mathrm{CaCl}_{2}$ were from Acros Organics (Landsmeer, The Netherlands). Dulbecco's modified eagle medium (DMEM/F-12 + Glutamax-1), MCDB 131 medium, sterile HEPES, antibiotics (amphotericine, penicillin, streptomycin), fetal bovine serum (FBS), L-glutamine, hydrocortisone, epidermal growth factor, trypsin and the live/dead and CyQUANT ${ }^{\circledR}$ Cell Proliferation Assay Kits were from Invitrogen (Bleiswijk, The Netherlands). Ethanol was from VWR (Amsterdam, The Netherlands). Fluorescence and absorbance measurements were performed using a microplate reader (SpectraMax M2, Molecular Devices, Wokingham, United Kingdom).

\section{Mesh production and purification}

Knitting of the white flax thread was performed by Centexbel (Verviers, Belgium). An open mesh was produced, using the commercial Parietene ${ }^{\circledR}$ mesh (Sofradim production, Trevoux, France; part of Covidien, North Haven, Connecticut, USA) as the design example. The mesh was obtained as a long strip of roughly $12 \mathrm{~cm}$ wide and several meters length. Soxhlet purification was made following the procedure described earlier [6].

\section{Albumin coating}

Pieces of mesh $(15 \times 15 \mathrm{~mm})$ were cut and steam-sterilized for 15 minutes at $121{ }^{\circ} \mathrm{C}$. Then, a solution of $2.0 \mathrm{~g} / \mathrm{L}$ albumin was prepared by dissolving bovine albumin in a sterile HEPES solution (25 mM HEPES, $150 \mathrm{mM} \mathrm{NaCl}-\mathrm{pH} 7.4$ ). Then the solution was filtered to ensure sterility using a $0.22 \mu \mathrm{m}$ filter (Whatman, Zwjindrecht, The Netherlands). Meshes were then incubated for 24 $\mathrm{h}\left(37^{\circ} \mathrm{C}\right)$ either in the pure HEPES solution (used as a control), or in the $2.0 \mathrm{~g} / \mathrm{L}$ albumin solution. 


\section{X-Ray Photoelectron Spectroscopy analysis}

Analysis of the meshes +/- albumin was performed. A XPS microprobe

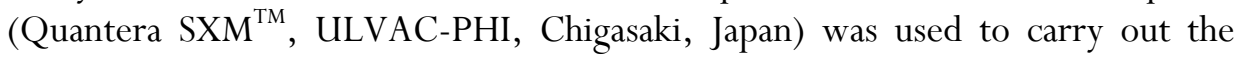
measurements using a monochromatic AlKa-radiation with a spot size of $200 \mu \mathrm{m}$ $\times 600 \mu \mathrm{m}$. Wide-scan measurements were performed to determine the general composition at the surface of the meshes. Precise narrow-scan measurements were made to determine the exact concentration of each element composing the surface of the meshes. Standard sensitivity factors were employed to transform peak areas into atomic concentrations.

\section{Endotoxin analysis}

Endotoxins were analyzed with in vitro Limulus amebocyte lysate (LAL) test. The lysate is an aqueous blood cell extract from the horse-shoe crab. Endotoxinactivated LAL will cleave a colorless synthetic chromogenic substrate, thereby liberating p-nitroanilide (yellow). The higher the endotoxin concentration in the specimen, the faster the production of p-nitroanilide [18]. Since albumin is known as an inhibiting compound $[19,20]$, the ability of the $2.0 \mathrm{~g} / \mathrm{L}$ albumin solution to inhibit the LAL reaction was checked. Results showed that the albumin solution totally inhibited the LAL reaction, but that once steam sterilized (and so albumin denatured), inhibition was suppressed (data not shown). As a result, $15 \times 15 \mathrm{~mm}$ meshes +/- albumin were steam sterilized before LAL analysis. The protocol described earlier was followed [6].

\section{Cell culture}

Mouse fibroblast (clone L929) and human endothelial (HMEC-1) cells were used to perform the in vitro experiments [21]. L929 cells were cultured in DMEM/F12-1 medium comprising Glutamax and supplemented with $10 \%$ FBS and antibiotics $(0.25 \mu \mathrm{g} / \mathrm{mL}$ amphotericin $\mathrm{B}, 100 \mathrm{U} / \mathrm{mL}$ penicillin and 100 $\mu \mathrm{g} / \mathrm{mL}$ streptomycin). HMEC-1 cells were grown in MCDB 131 medium complemented with $10 \%$ FBS, antibiotics (same concentration as for the L929 cells), L-Glutamax $(2 \mathrm{mM} / \mathrm{mL})$, hydrocortisone $(1 \mu \mathrm{g} / \mathrm{mL})$ and epidermal growth factor $(10 \mathrm{ng} / \mathrm{mL})$. Both cell types were incubated at $37^{\circ} \mathrm{C}$ and $5 \% \mathrm{CO}_{2}$ and harvested using $0.05 \%$ Trypsin/0.53 mM EDTA. 


\section{Indirect cytotoxicity analysis}

Mesh samples were incubated in supplemented DMEM/F12-1 medium (0.05 g material/mL medium) for 3 days at $37{ }^{\circ} \mathrm{C}$. L929 cells were seeded in a 96-well plate at 10.000 cells/well and let for overnight adhesion. $24 \mathrm{~h}$ later, cell medium was removed and replaced by the medium incubated with flax meshes. Plates were further incubated for 48 hours. Then, a MTT solution was added in each well to yield a final MTT concentration of $0.25 \mathrm{mg} / \mathrm{mL}$. Plates were incubated for 2 hours and medium was discarded and replaced by isopropanol to dissolve the newly formed formazan crystals. Absorbance of the plates was examined at $570 \mathrm{~nm}$ and cell survival was calculated as a ratio of the viable control (pure medium; set at $100 \%$ cell survival). Medium with $5 \%$ DMSO was used as a toxic control.

\section{Direct cytotoxicity analysis}

Viability of L929 cells directly deposited on flax meshes was determined by using the live/dead viability/cytotoxicity kit. $15 \times 15 \mathrm{~mm}$ meshes were put in a 6-well plate and $100 \mu \mathrm{L}$ of a L929 cell suspension ( $1.000 .000 \mathrm{cells} / \mathrm{mL})$ was added on top of each mesh. Meshes were incubated for 4 hours to allow maximum cell adhesion. Then, $5 \mathrm{~mL}$ medium was added into each well and plates were further incubated for 7 days. Meshes were rinsed 3 times with 5 -mL PBS and $250 \mu \mathrm{L}$ of a solution containing $2 \mu \mathrm{M}$ Calcein and $4 \mu \mathrm{M}$ EthD-1 in PBS was added on top of them. Meshes were let in dark at room temperature, once rinsed with PBS, and observed with a fluorescence microscope. Pictures consist of two superposed images: one taken at a wavelength of 465-595 nm (excitation-emission) allowing us to see the green (live) cells - and one taken at a wavelength of 540$580 \mathrm{~nm}$ showing the red (dead) cells.

\section{Cell growth}

$100 \mu \mathrm{L}$ of a HMEC-1 cell suspension $(1.000 .000$ cells $/ \mathrm{mL}$ ) was put onto each 15 $\times 15 \mathrm{~mm}$ mesh set in 24-well plates. Meshes were incubated for 4 hours to allow maximum cell adhesion under static conditions, and 1-mL medium was added into each well. Then, meshes were either immediately rinsed twice in HEPES solution and frozen at $-80^{\circ} \mathrm{C}$ (corresponding to $\mathrm{t}=0 \mathrm{~h}$ ), or rinsed twice and frozen after 24 h, 3 days, 5 days, and 7 days. During the growth experiment, cell medium was changed every $48 \mathrm{~h}$ or when needed as indicated by color change of the medium. Once all samples frozen for at least $24 \mathrm{~h}$, number of cells present on the meshes was determined using the CyQUANT ${ }^{\circledR}$ kit. 


\section{Cell adhesion under dynamic conditions}

$15 \times 15 \mathrm{~mm}$ meshes were placed in 2-mL Eppendorf tubes. 1-mL of a HMEC-1 cell suspension $(20.000$ cells $/ \mathrm{mL}, 50.000$ cells $/ \mathrm{mL}, 100.000$ cells $/ \mathrm{mL}$ or $250.000 \mathrm{cells} / \mathrm{mL})$ in buffered medium $(20 \mathrm{mM}$ sterile HEPES - $\mathrm{pH}=7.4)$ was put in each tube. Tubes were closed and incubated overnight at $37{ }^{\circ} \mathrm{C}$ on a rotating device $(50 \mathrm{rpm})$. Next day, meshes were twice rinsed with HEPES solution and frozen at $-80{ }^{\circ} \mathrm{C}$. The amount of adhered cells was determined by using the CyQUANT ${ }^{\circledR}$ kit.

\section{Thrombin generation}

Circular mesh specimens were cut such that they fit on the bottom of a 96-well plate (diameter of approximately $6 \mathrm{~mm}$ ). Blood from three healthy male donors was collected, discarding the first $5 \mathrm{~mL}$. Part of the blood $(15 \mathrm{ml})$ was used for leukocyte isolation using Leukosep ${ }^{\mathrm{TM}}$ tubes (Greiner Bio One, Alphen a/d Rijn, The Netherlands) according to the manufacturers instructions. Isolated leukocytes were suspended in PBS to a final concentration of roughly $5.10^{6}$ leukocytes $/ \mathrm{mL}$. $250 \mu \mathrm{L}$ of this suspension was then put on some meshes and the whole was incubated at $37{ }^{\circ} \mathrm{C}$ for one hour. Then, the other blood tubes were centrifuged at $200 \mathrm{~g}$ for 15 minutes, and platelet rich plasma (PRP) was collected. Same blood tubes were centrifuged again at $1800 \mathrm{~g}$ for 10 minutes. PFP was collected, put in 2-mL Eppendorf tubes, centrifuged again at $13.2 \mathrm{rpm}$ for 2 minutes, and finally saved in a new tube. Fluorogenic substrate (Z-Gly-GlyArg-AMC, Bachem, Bubendorf, Switzerland) was added to the PRP and PFP solutions at a final concentration of $400 \mu \mathrm{M}$. Meshes were then rinsed with HEPES solution and placed into a 96-well plate. Just before the beginning of the measurement of thrombin generation, $\mathrm{CaCl}_{2}$ was added into the PRP/PFPsubstrate solutions to a final concentration of $20 \mathrm{mM} \mathrm{CaCl}_{2}$. $200 \mu \mathrm{l}$ of these final $\mathrm{PRP} / \mathrm{PFP}$-substrate- $\mathrm{CaCl}_{2}$ solutions was added into each well. Analysis using a fluorometer pre-warmed at $37{ }^{\circ} \mathrm{C}$ was directly started. Analysis of thrombin generation was done over $90 \mathrm{~min}$. with a measurement every 30 seconds.

\section{SEM observation of adhered platelets}

Blood was collected, discarding the first $5 \mathrm{~mL}$. Blood was centrifuged at $200 \mathrm{~g}$ for 15 minutes for platelet rich plasma (PRP) isolation. Flax meshes and glass samples were wetted in PBS for 1 hour, transferred into a 6-well plate before $250 \mu \mathrm{L}$ PRP being added on top of each of them. The plate was incubated at 37 ${ }^{\circ} \mathrm{C}$ for one hour and then rinsed with $5 \mathrm{~mL}$ PBS. Meshes and glass samples were transferred into a new 6-well plate, rinsed 4 times with $5 \mathrm{~mL}$ PBS, incubated in 
$2.5 \%$ glutaraldehyde solution and stored in cold room overnight. Then, meshes were dehydrated by successive incubations in $50 \%, 70 \%, 80 \%, 90 \%$, and 2 times $100 \%$ ethanol solutions for 15 minutes each. Meshes were further incubated in hexamethyldisilazane for 4 minutes before being stored in a desiccator for at least $24 \mathrm{~h}$ [22]. Finally, meshes were placed on a carbon tape and sputter-coated with gold. Pictures were taken with a SEM (Philips XL 30, FEI, Eindhoven, the Netherlands), at an operating voltage of $10 \mathrm{kV}$.

In vivo biocompatibility

Male Wistar rats weighing 250-300 g were housed and cared for at the Central Animal Facilities of Maastricht University, with free access to water and food, and in accordance with local standards. The experimental protocol was approved by the Committee of Animal Experiments, and was in accordance to the Dutch Animal Experimentation Act.

To compare the influence of the diameter of the thread on the in vivo response, four different sizes of uncoated flax yarns (but Soxhlet purified) were implanted in the dorsal subcutaneous space (group size: $\mathrm{n}=4$ with 2 fibers/rat) and compared to polyethylene (PE) multifilament thread $(n=4)\left(\right.$ Mersilene $^{\mathrm{TM}}$, Ethicon, Johnson and Johnson, Somerville, New Jersey, USA). Flax threads are defined by their metric Number $(\mathrm{Nm})$, which represents the number of $\mathrm{km}$ of yarn necessary to obtain $1 \mathrm{~kg}$ of yarn. In this study, threads with a $\mathrm{Nm}$ of 39 (biggest diameter), 45, 52 and 58 (smallest diameter) were used, corresponding to a diameter of respectively roughly 350, 300, 250 and $200 \mu \mathrm{m}$. Mersilene yarn had a diameter of approximately $500 \mu \mathrm{m}$.

Then, influence of the albumin coating on the inflammatory response was assessed. Albumin coated threads with an $\mathrm{Nm}$ of 45, 52 and 58 were implanted in the dorsal subcutaneous space (group size: $\mathrm{n}=4$ with 2 fibers $/$ rat).

\section{Surgical procedure}

Anesthesia was induced by inhalation of Isoflurane through a small animal ventilator. The skin on the back of the rats was shaved and disinfected using $4 \%$ iodine solution before covering with sterile drapes. A 2 -cm midline incision was made in the back of the rat, and two subcutaneous pockets were carefully prepared through blunt dissection. Fibers were emerged in sterile phosphate buffered saline for one minute to allow full absorption of PBS in the flax meshes before implantation. A sterile fiber $(30 \mathrm{~mm}$ length) was inserted into each pocket, without further fixation. The skin was closed intracutaneously with a 
running suture (Monocryl ${ }^{\mathrm{TM}}$; Ethicon, Johnson \& Johnson, Somerville, New Jersey, USA). No antibiotics were administered.

\section{Macroscopic and microscopic evaluation}

Rats were euthanized by an overdose of inhaled carbon dioxide after 7 days of follow-up. The incision on the back was opened and the skin over the mesh was carefully removed. Infection was defined as a clinical apparent infection with pus at the time of death. After macroscopic evaluation the mesh was excised locally with adjacent muscle tissue. Each specimen was fixed in $4 \%$ formaldehyde solution for $24 \mathrm{~h}$, after which the specimens were embedded in paraffin.

Slices of $5 \mu \mathrm{m}$ thick were stained with hematoxylin and eosin (H\&E) using standard histological techniques. Histologic assessments were performed by an experienced pathologist, blinded to the study groups.

\section{Results and discussion}

Characterization of the flax fibers $+/$ - albumin

Figure 1 shows the knitted flax mesh that was used in this study; square specimens $(15 \times 15 \mathrm{~mm}$ ), or circula specimens (diameter $6 \mathrm{~mm}$ ) were cut out of it. The mesh was manufactured especially for this research project, starting from a white (peroxide-bleached) multi-filament flax thread with a diameter of 160 micrometer.

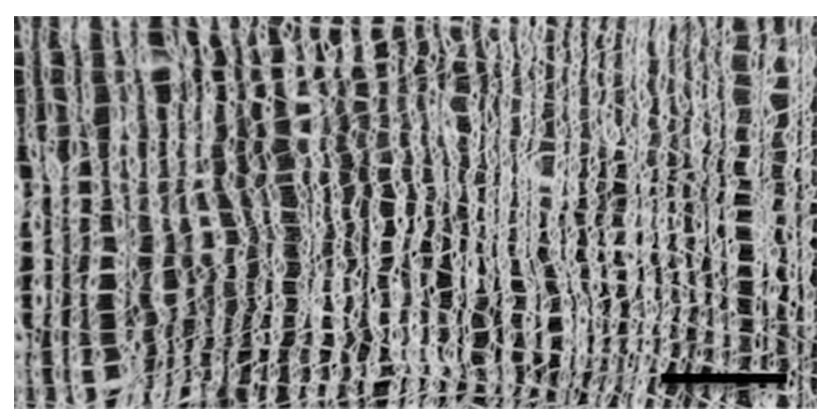

Figure 1. Typical flax mesh specimen that was used in this study. Note the multifilament structure of the yarn. Scale bar represents $1.6 \mathrm{~mm}$. 
The specimens were first studied with XPS which is a useful technique to study the presence or absence of adsorbed proteins on our meshes. Indeed, our purified flax mesh is mostly composed of polysaccharides, and so its characteristic XPS broad spectra should only reveal the presence of oxygen and carbon. In contrast, after incubation with albumin solution $(2.0 \mathrm{mg} / \mathrm{mL})$ and after subsequent washing/drying steps, the adsorption of albumin to the surface should introduce the element nitrogen. Indeed, the treatment of our specimens with albumin introduces a nitrogen peak close to $400 \mathrm{eV}$ in XPS (fig. 2). Further

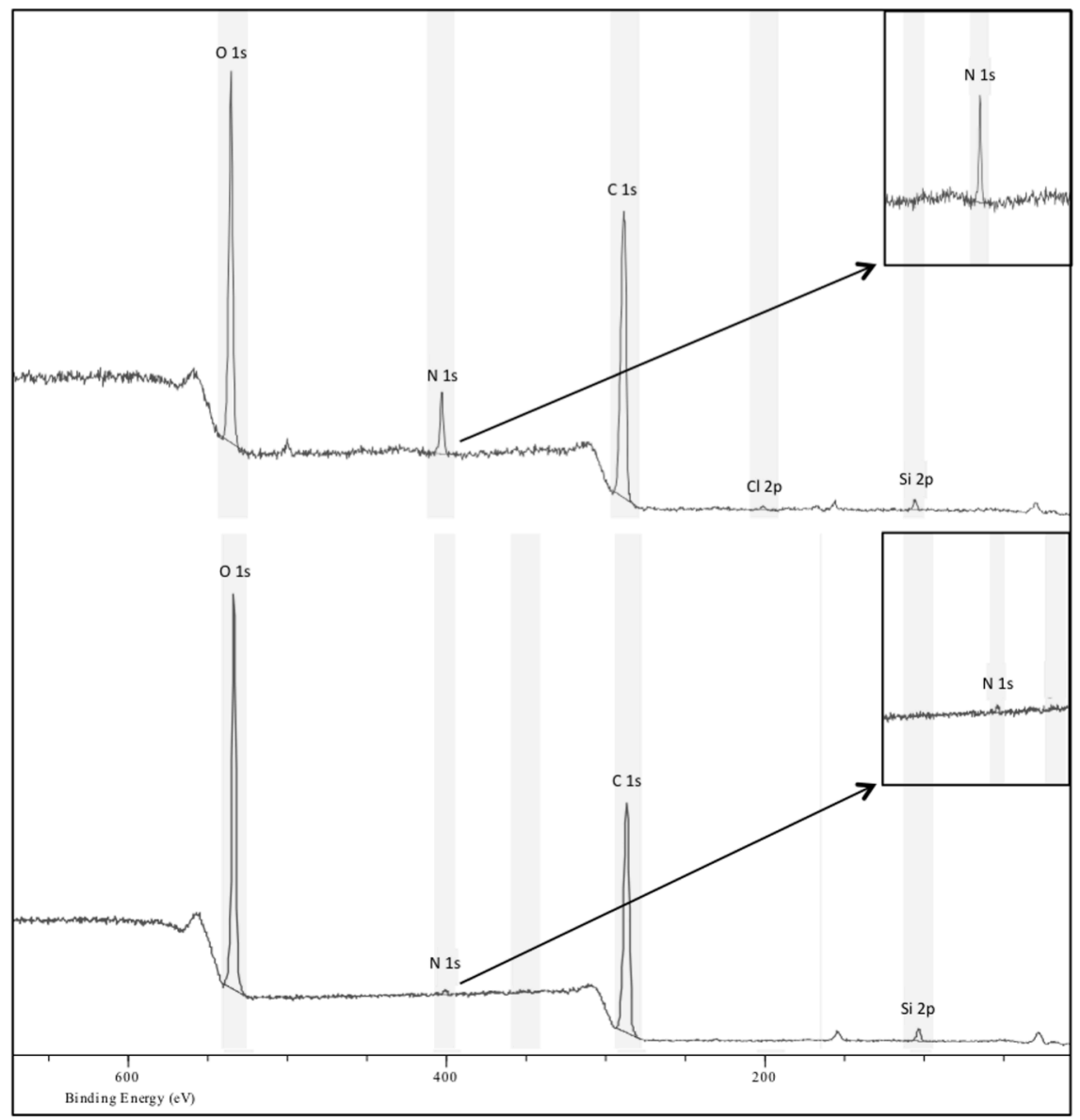

Figure 2. XPS broad spectras of the uncoated (down) and albumin coated (top) meshes. Presence of a $\mathrm{N}$ peak can be seen on the spectra of the albumin coated mesh, confirming that albumin was effectively grafted on our flax mesh. 
Table 1. Surface atomic percentages of meshes $+/$ - albumin as obtained from narrow-scans XPS. Elemental composition of pure BSA was added for comparison.

\begin{tabular}{lccc}
\hline & C 1 s & O 1s & $\begin{array}{c}\text { N 1 s } \\
(\mathbf{4 0 0 . 1 ~} \mathbf{~ V})\end{array}$ \\
\hline Uncoated mesh & 61 & 31 & 0.45 \\
Albumin coated mesh & 65 & 27 & 5.4 \\
BSA powder [24] & 67.3 & 20.5 & 11.7 \\
\hline
\end{tabular}

expansion of the peak revealed that its exact position is $400.1 \mathrm{eV}$, which confirms that we are dealing with nitrogen in the peptide bond $(-\mathrm{NH}-\mathrm{C}(\mathrm{O})-)$ [23]. Quantitatively, it was found that the atom percentage of nitrogen (N1s line) increases upon going from the uncoated to the albumin-coated meshes, i.e., from 0.5 to $5.4 \%$ (Table 1 ). In parallel, the percentage of carbon $(\mathrm{C} 1 \mathrm{~s})$ slightly increased from 61 to $65 \%$ while the percentage of oxygen $(\mathrm{O} 1 \mathrm{~s})$ decreased from 31 to $27 \%$. It is of interest to compare the experimental \% C(1s) and \% $\mathrm{O}(1 \mathrm{~s})$ values for the mesh $+/$ - albumin with literature XPS data on bovine serum albumin per se [24]. Our data for the albumin coated mesh are intermediates between the data for uncoated mesh and those for BSA per se. This suggests that the surface of the albumin coated mesh is only partially covered by albumin.

\section{Endotoxin analysis}

The limulus amebocyte lysate (LAL) test was used to measure presence or absence of Gram-negative bacterial endotoxins in or on the mesh specimens. In short, this assay uses endotoxins to activate a proenzyme that hydrolyzes the colorless chromogenic substrate Ac-Ile-Glu-Ala-Arg-pNA. p-Nitroaniline (yellow) is generated by this hydrolysis and the level of absorption (405-410 nm) is proportional to the amount of endotoxin in the sample. Table 2 compiles the resulting data. Low amounts of endotoxins were found in the water that was used for extraction of the samples ("extractable endotoxins" columns). The data on absorption could be converted to endotoxin unit (EU, with 1 EU being equivalent to $0.2 \mathrm{ng}$ endotoxin) [12] using the calibration set that was provided by the supplier. These values do not differ for the meshes +/- albumin coating, confirming that our purification process is effective at removing most of the extractable endotoxins. Note that the limit for endotoxin set by the US Food and Drug Administration (FDA) for medical devices is of $0.5 \mathrm{EU} / \mathrm{mL}$ (based on a 40 
Table 2. Final absorbance obtained when LAL test was performed on the meshes $+/$ - albumin. In this test, the absorbance level is proportional to the amount of endotoxin; results show that the presence of an albumin coating reduces the amount of active endotoxins directly present on the mesh. For each material, test was carried out on four independent meshes, each of them being tested in duplo $(\mathrm{ns}=8)$. * represents statistically significant difference $(\mathrm{p}<0.05)$.

$\begin{array}{ccc}\text { Extractable endotoxins } & \text { Extractable endotoxins } & \text { Adherent endotoxins } \\ \text { (absorbance) } & \text { (EU) } & \text { (absorbance) }\end{array}$

\begin{tabular}{lccc}
\hline Uncoated mesh & $0.29 \pm 0.06$ & $0.38 \pm 0.08$ & $1.04 \pm 0.20$ \\
Albumin coated mesh & $0.25 \pm 0.05$ & $0.32 \pm 0.07$ & $0.73 \pm 0.15 *$ \\
\hline
\end{tabular}

$\mathrm{mL}$ rinse) [25]. Our results (based on a $15 \times 15 \mathrm{~mm}$ mesh with a $1 \mathrm{~mL}$ rinse) are already below this FDA limit. Higher absorbance levels were found when the meshes themselves were submitted to the LAL reaction ("adherent endotoxins" column). Although these data could not be converted into endotoxin levels (the activity is due to immobilized endotoxin molecules for which calibration is not possible), it can be concluded that the albumin coating leads to a clear and statistically significant reduction of the signal (absorption $0.73 \pm 0.15$ for the mesh specimens with albumin coating, versus $1.04 \pm 0.20$ for the mesh specimens without albumin coating; Table 2). The signal reduction is of approximately $27 \%$. Clearly, application of the albumin coating has reduced but not abolished the effect of endotoxins. This is in agreement with our XPS data, which also indicated that the surface of the albumin coated mesh is only partially covered with albumin. It must be noted that many substances can interfere with the chromogenic LAL test [26]. For example, serine proteases (e.g. trypsin, activated blood factors) can cause false-positive results, unless they have been denatured by heat before testing. We checked the possible interference of albumin, and when we carried out the LAL test using the $2 \mathrm{~g} / \mathrm{L}$ albumin solution, we indeed found complete inhibition of the LAL reaction. After steam sterilization $\left(121{ }^{\circ} \mathrm{C}, 15 \mathrm{~min}\right)$ this inhibitory effect disappeared, presumably due to denaturation of albumin. The data in Table 2 refer to steam-sterilized specimens, i.e. the observed differences for mesh with or without albumin reflect differences in surface-exposed endotoxins.

\section{Cytocompatibility analysis}

The meshes +/- albumin coating were studied for their potential cytotoxicity using the MTT test [27]. This experiment revealed that the cell survival was 90.0 
$\pm 9.7 \%$ for the albumin-coated specimens and $91.2 \pm 9.6 \%$ for the uncoated counterparts, as compared to the positive control (pure medium incubated, set to $100 \%$ cell survival). These data show that the albumin coating does not affect the cell-compatibility of the flax meshes. Subsequently, we studied mesh-cell cultures with the Live-Dead assay. At the surface of both materials, mostly green (alive) cells were encountered (fluorescence microscopy), thus confirming that the flax meshes +/- albumin coating are non-toxic (fig. 3).

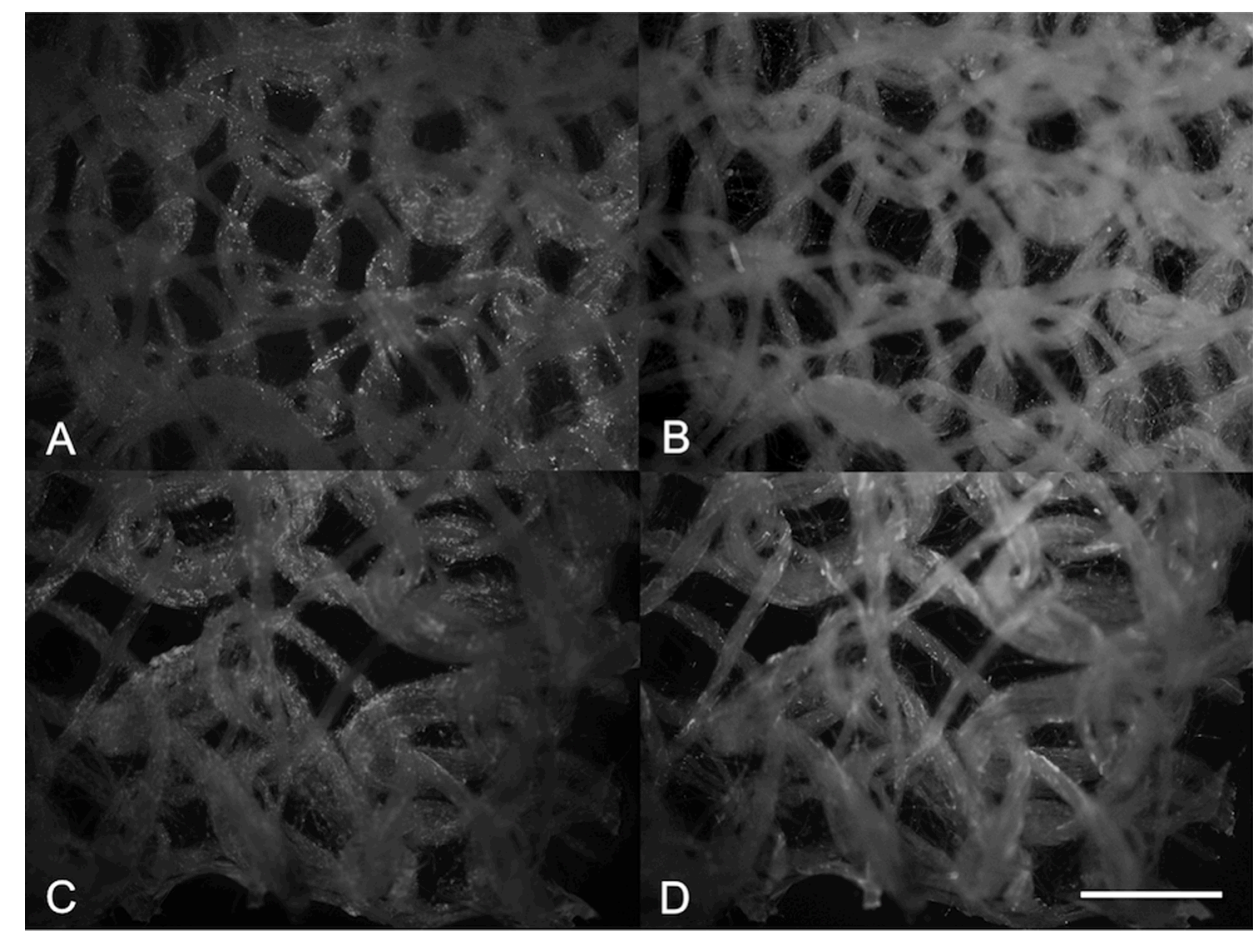

Figure 3. Representative images of alive (green) and dead (red) L929 mouse fibroblast cells on flax meshes +/- albumin coating. (A,B) uncoated mesh, (C,D) albumin coated mesh. (A,C) show live cells (green channel); (B,D) shows dead cells (red channel). Almost no red cells were observed, showing that none of the materials is cytotoxic. Scale bar represents $1 \mathrm{~mm}$.

Next, adhesion of human endothelial HMEC-1 cells to the meshes +/albumin coating was studied. The effect of the albumin coating on cell adhesion and proliferation cannot be easily predicted. On one hand, it has been shown that the presence of an albumin coating on TCPs or glass slides completely prevents fibroblast and hepatocyte cell adhesion [28-30]. For our application, such an effect of the albumin coating on HMEC-1 adhesion would be highly unfavorable, as it is well known that the ideal prosthetic graft should promote cell adhesion 
and proliferation. On the other hand, Bernards et al. showed that the presence of an albumin coating, although preventing cell adhesion, highly increased cell proliferation [31]. Similar results were found elsewhere [32].

We first analyzed the effect of our albumin coating on HMEC-1 adhesion and proliferation by performing a cell growth experiment (fig. 4). Samples were incubated up to 7 days. Adherent cells were counted immediately after $4 \mathrm{~h}$ incubation, after 24 h, 3 days, 5 days and 7 days. Clearly, significantly less cells adhered to the albumin-coated mesh after $4 \mathrm{~h}$ incubation. Moreover, the presence of an albumin had no influence on cell growth since cell doubling time was of respectively $110 \mathrm{~h}$ and $120 \mathrm{~h}$ on the uncoated and albumin coated mesh. As a consequence, after 7 days incubation, the albumin coated mesh still supported $37 \%$ less cells as compared to the uncoated one.

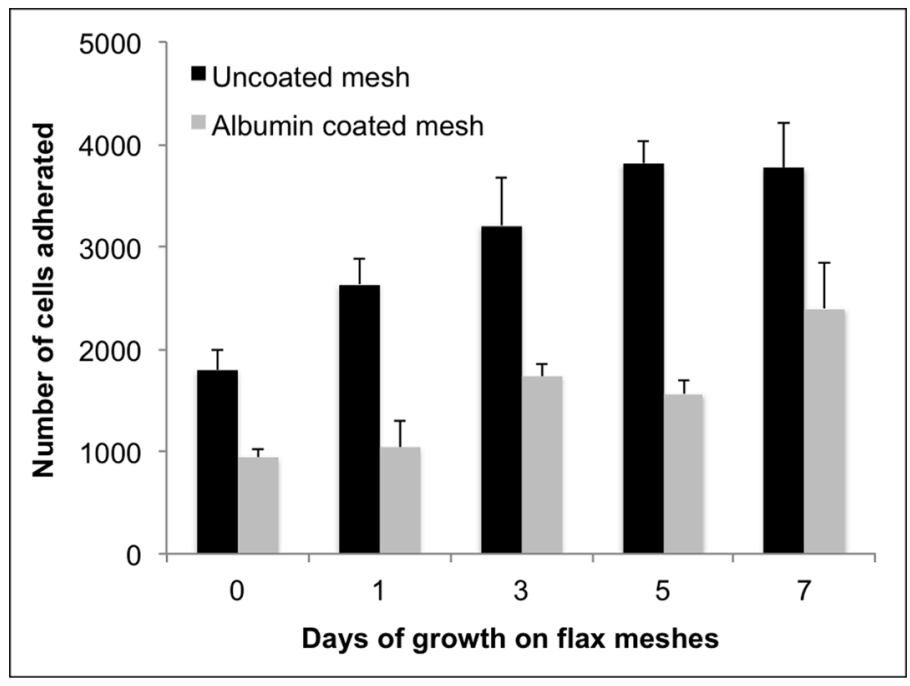

Figure 4. Cell dynamic adhesion of HMEC-1 cells on meshes +/- albumin depending on the initial cell concentration, as obtained with the CyQUANT® kit. For each condition, mean \pm S.D. were obtained from four independent mesh samples $(15 \mathrm{x} 15 \mathrm{~mm})$. For each cell concentration, number of cells present on the albumin coated mesh was statistically different from the number of cells present on the uncoated mesh $(\mathrm{p}<0.05)$.

Furthermore, we analyzed HMEC-1 cell adhesion to our meshes +/albumin under dynamic conditions (fig. 5). To do so, meshes were placed in Eppendorf tubes containing cell solutions of different concentrations, and fixed on a rotator operating at $50 \mathrm{rpm}$ for overnight dynamic adhesion at $37^{\circ} \mathrm{C}$. The number of adherent cells (counted after $16 \mathrm{~h}$ ) increases proportionally with the 
number of cells that were incubated, and surprisingly, for each cell concentration, cell number was always statistically much higher on the albumincoated mesh. With a concentration of 20.000 cells $/ \mathrm{mL}$, double amount of cells was obtained on the albumin mesh as compared to the uncoated one. With $50.000,100.000$ and 250.000 cells $/ \mathrm{mL}$, respectively $33 \%$, $53 \%$ and $60 \%$ more cells were present on the albumin-coated mesh. These data prove that flax can easily support cell adhesion, provided that this cell adhesion is performed under dynamic conditions.

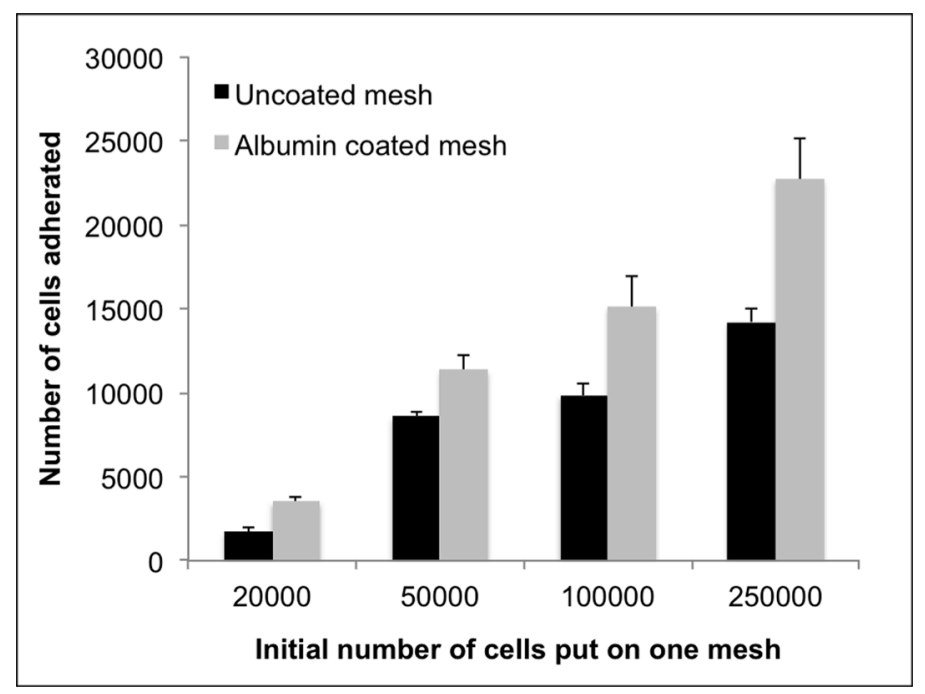

Figure 5. Cell dynamic adhesion of HMEC-1 cells on meshes $+/$ - albumin depending on the initial cell concentration, as obtained with the CyQUANT® kit. For each condition, mean \pm S.D. were obtained from four independent mesh samples $(15 \times 15 \mathrm{~mm})$. For each cell concentration, number of cells present on the albumin coated mesh was statistically different from the number of cells present on the uncoated mesh $(\mathrm{p}<0.05)$.

\section{Blood compatibility}

First, we studied the thrombogenicity levels of our two mesh types in contact with human platelet-rich blood plasma (PRP) or platelet- free plasma (PFP), anticipating that flax will have a low propensity to initiate thrombin formation due to its hydrophilic nature. Moreover, we expected that the presence of albumin at the mesh surface will further reduce the material's thrombogenicity [33]. The possible role of leukocyte activation was examined as well. All of our experiments were based on fresh human blood from three healthy volunteer donors. 
Thrombin generation was studied under 4 different conditions in vitro. These were: (i) using either PRP or PFP, and (ii), with or without pre-incubation with leukocytes. The thrombin generation curves measured with the blood sample from donor \#1 (as well as two control curves) are shown in figure 6.

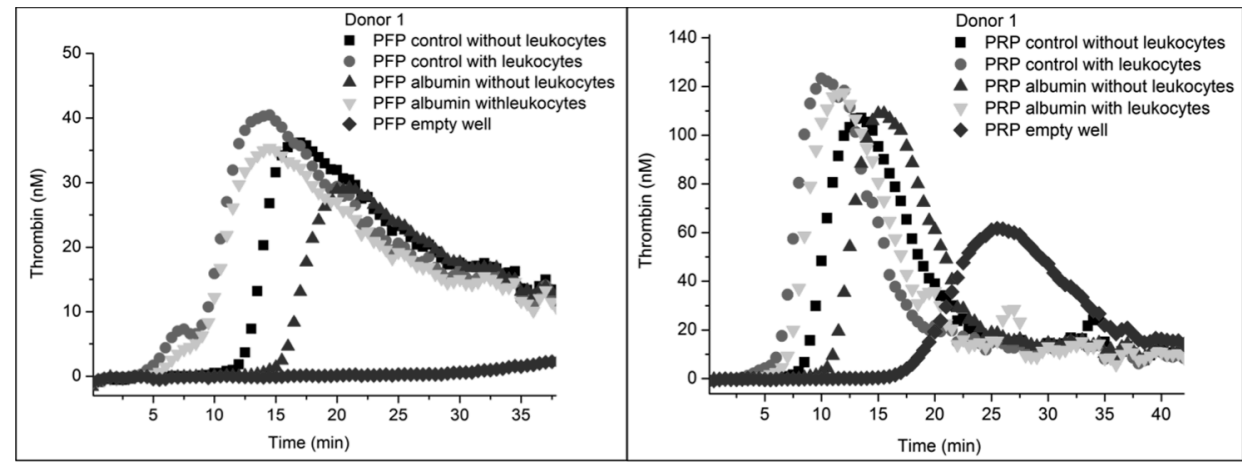

Figure 6. Thrombin generation curves obtained by using meshes + /- albumin with or without pre-incubation with leukocytes. The left curve shows the amount of thrombin generated when meshes were incubated with PFP, whereas on the right curve meshes were incubated with PRP. Each curve is the average of four individual wells.

The most important parameter that can be abstracted from each curve is the socalled thrombin generation lag time [34-36]. This is the time elapsing between the moment of re-calcification of the plasma $(t=0)$ and the moment at which a sudden increase of the thrombin concentration is observed. This is the moment at which genuine blood clotting starts. The maximum lag time (i.e. the lowest level of thrombogenicity) seen in the left graph of figure 6 (triangles) is of appr. $16 \mathrm{~min}$; the experiment refers to the albumin-coated flax mesh in contact with PFP, without pre-incubation with leukocytes. A decreased lag time (12 min) was found for the uncoated flax mesh (control), also without pre-incubation with leukocytes. Further decreased lag times (approximately $6 \mathrm{~min}$ ) were found for both types of flax meshes (i.e. +/- albumin coating), after pre-incubation with leukocytes. Note, furthermore, that practically no increase of the thrombin concentration was found when PFP was measured in the empty well, i.e. in the absence of any flax mesh.

The right graph in figure 6 shows analogous thrombin generation curves, but now for incubation with PRP. It is readily seen that all corresponding thrombin generation lag times are shorter in the presence of platelets. This reveals that the platelets are involved in thrombin generation. Platelets become activated upon contacting the both flax meshes, which is translated into faster generation of thrombin. The thrombin generation lag times decrease as follows: 
albumin coated flax mesh without pre-incubation with leukocytes (appr. $10 \mathrm{~min}$ ) $>$ uncoated flax mesh without pre-incubation with leukocytes (appr. $8 \mathrm{~min})>$ albumin coated flax mesh after pre-incubation of leukocytes (appr. 6 min) $>$ uncoated flax mesh after pre-incubation with leukocytes (appr. $4 \mathrm{~min}$ ). The same set of thrombin generation curves was measured for two other blood donors (fig. 7).
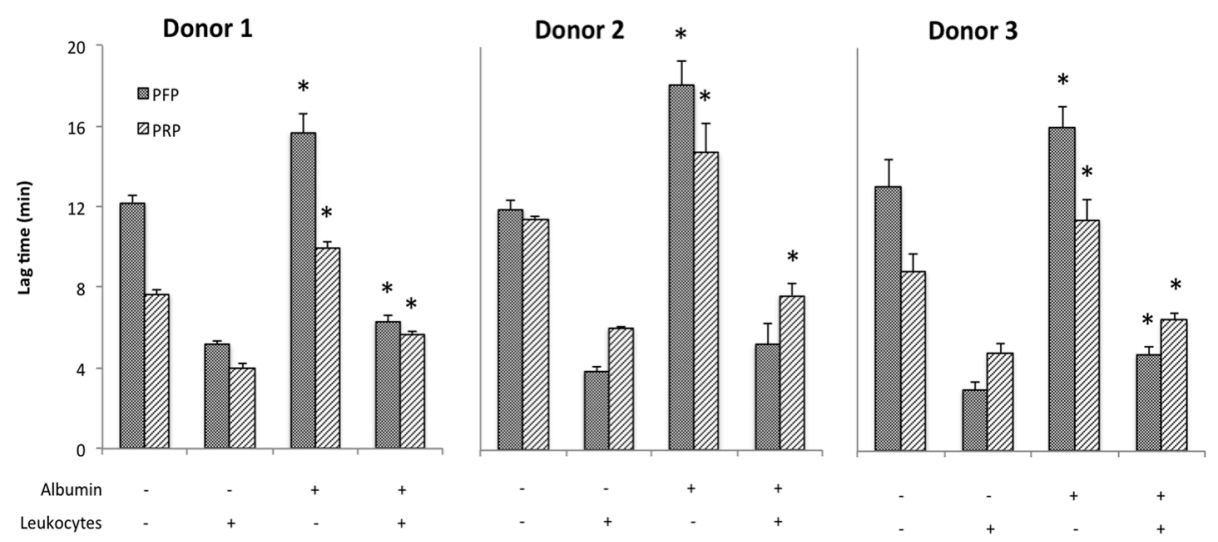

Figure 7. Thrombin generation lag times as extracted from the thrombin generation curves. For each condition, lag time average \pm S.D. were obtained from four independent wells. $*$ denotes statistical difference between meshes $+/$ - albumin, both being pre-incubated in same conditions (with or without leukocytes) and with same plasma type (PFP or PRP).

For all donors, we measured the longest lag times for the albumin coated flax meshes without pre-incubation with leukocytes. Conversely, the shortest lag times were found for the meshes without albumin coating and after preincubation with leukocytes. The effect of the albumin coating on thrombogenicity is most apparent in the absence of leukocytes (compare: triangles vs. squares in both graphs of figure 6). Pre-incubation with leukocytes accelerates thrombin formation, presumably since the cells become activated upon contacting the flax $+/$ - albumin coating. This activation can be explained by the fact that endotoxins are present at both mesh types (see data in Table 1). Results show that albumin can be effectively coated on flax fibers to reduce their thrombogenicity level.

The effect of the albumin coating on platelet spreading was also studied. Numerous studies have already shown that the presence of an albumin coating could effectively reduce platelet spreading and so, activation [23,33,36]. Figure 8(A-B) shows two representative scanning electron micrographs of blood platelets which are adhered to the flax meshes. Figure 8(A), shows adhered 
platelets attached to the flax mesh without albumin coating The platelets have extended pseudopodia, which are responsible for their adherence to the flax surface, with some of them being even fully spread on flax surface. Some platelet aggregates were also observed. Figure 8(B) analogously shows platelets that are

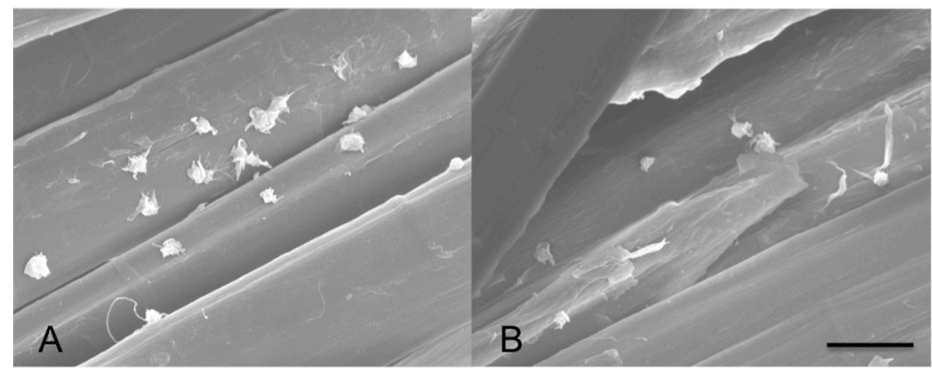

Morphology of activated platelets

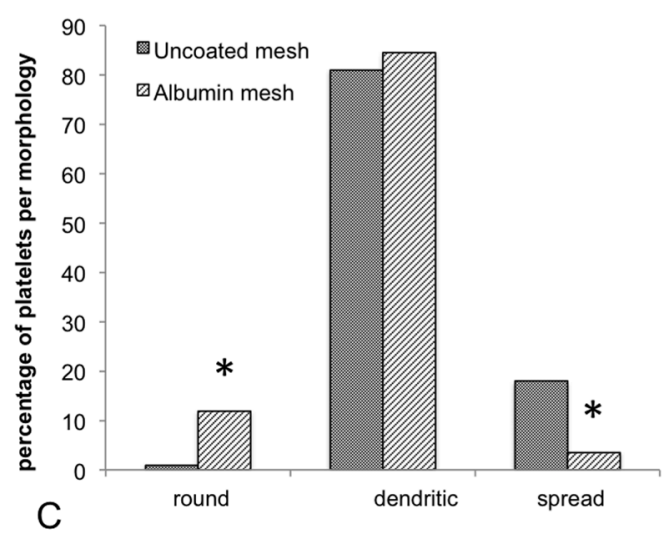

Figure 8. Effect of the albumin coating on platelet adhesion and spreading.

(A, B) SEM images showing the morphology of adhered platelets on flax meshes +/ - albumin: (A) uncoated mesh, B) albumin coated mesh. Scale bar represents $10 \mu \mathrm{m}$.

(C) For each material, more than ten SEM images were analyzed. The morphology of adhered platelets was divided into three categories: round, dendritic and spread. For each category, * denotes statistical difference between meshes $+/$ - albumin $(\mathrm{p}<0.05)$.

attached to the albumin-coated flax filaments. Platelets are well isolated from each other and show limited pseudopodia development, part of them exhibiting spherical morphologies. Finally, SEM images were analyzed, and adhered platelets were separated into three groups depending on their spreading degree (round, dendritic, spread) and so activation level (fig. 8(C)). Results show that both meshes + / - albumin contain same amount of dendritic platelets, but that a 
significantly increased number of round cells is obtained after albumin coating, while the number of spread cells significantly decreased. This is in line with the thrombin experiments, which showed a slower activation of the coagulation incubated with the albumin coated mesh. It also confirms that albumin can decrease platelet adhesion and spreading, and so finally improve blood compatibility of our flax material further.

In vivo analysis and histopathology of flax and PE fibers

To finish, in vivo analyses were performed subcutaneously in rats. All animals survived the experimental treatment, quickly recovered from anesthesia and were thriving during the 7 days experiments. No clear general sign of infection or discomfort were noticed for any of the animals used. In all cases, Soxhlet purified flax threads with or without albumin coating (maximum $350 \mu \mathrm{m}$; minimum $200 \mu \mathrm{m})$ were smaller in diameter to the Mersilene ${ }^{\mathrm{TM}}$ thread $(500 \mu \mathrm{m})$.

We first investigated the effect of flax yarn diameter on the inflammatory response (fig. 9). Flax thread with the biggest diameter ( $\mathrm{Nm} \mathrm{39}$; fig. 9(A)) showed a severe inflammatory reaction with high numbers of inflammatory cells and foreign body giant cells (FBGC) around the yarn, and substantial cell death (necrosis) apparent inside the flax threads. By reducing the diameter (Nm 45; fig. 9(B)), less inflammatory cells were present. Nevertheless, quantity of necrosis and FBGC was still high and a thick fibrotic capsule could be seen. Further

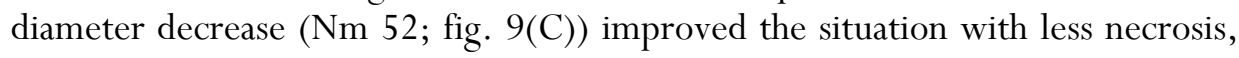
FBGC, inflammatory cells and fibrotic capsule. However, and for the three

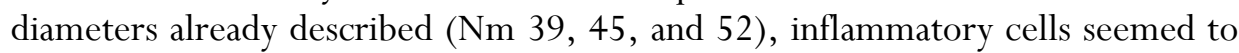
pull the individual fibers away, resulting in a physical destruction of the bundles. Smallest diameter led to the best inflammatory response (Nm 58; fig. 9(D)), since the thread kept its integrity over the 7 days implantation. Even so, the fibrotic capsule was still important around the thread and it extended over a long distance. Finally, some individual fibers pulled away over a long distance could be seen with all diameters. Commercial PE multifilament thread was also implanted for comparison (fig. 9(E,F)). It led to a moderate inflammatory reaction with small fibrotic capsule and no necrosis inside the bundle, although its diameter was much more important than the ones of flax threads.

Results show that some improvements can be obtained by reducing flax yarn diameter. This is not of a surprise, as several studies already described that the inflammatory response is dependent on the thread size, with the best response being obtained with the smallest gauge $[37,38]$. However, the thick and 

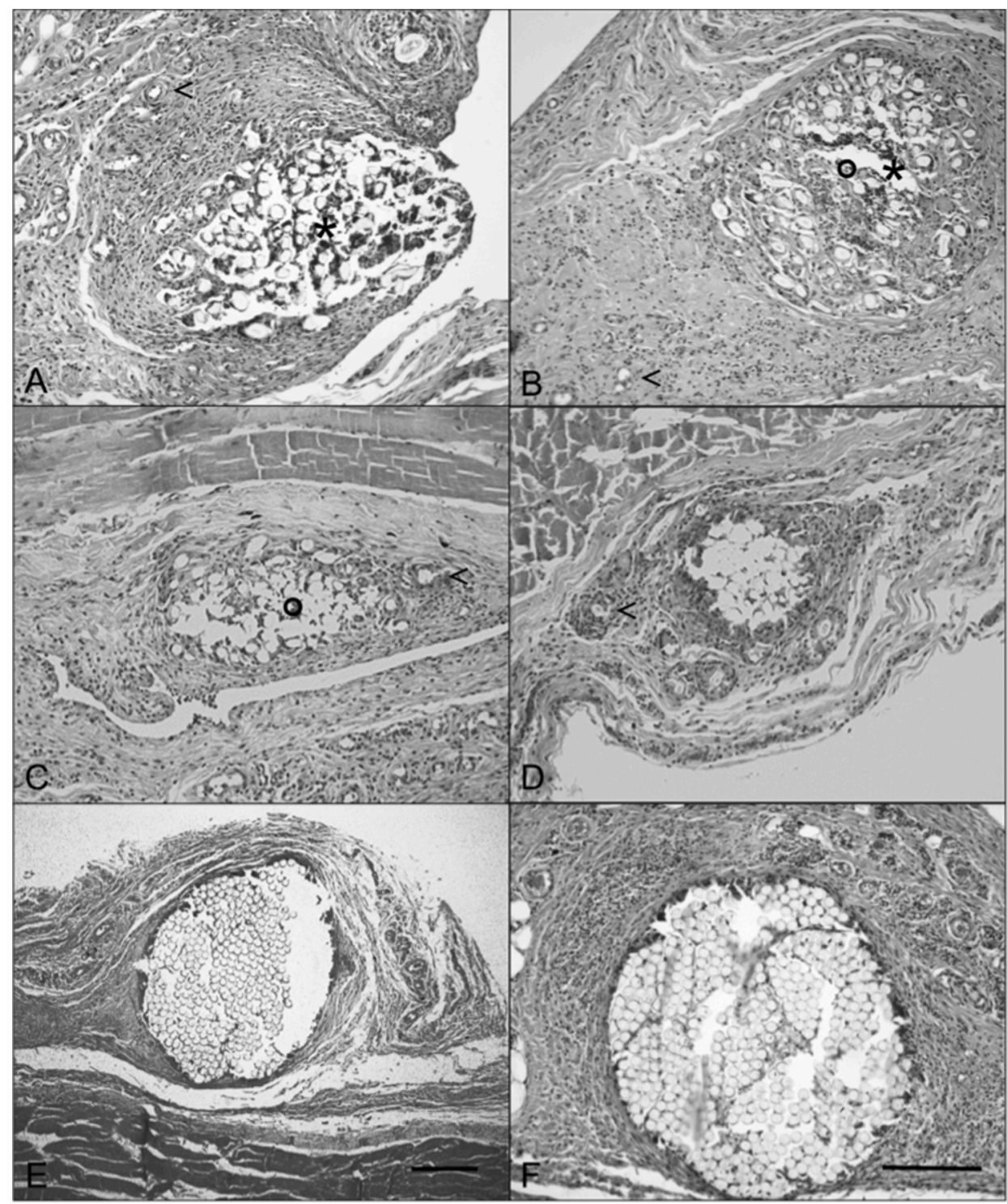

Figure 9. Representative histological images of $\mathrm{H} \& \mathrm{E}$ stained skin-thread sections from in vivo experiments after 7 days follow-up. (A-D) Uncoated flax yarns with smaller diameter from A to D. (A) Massive necrosis (asterisk) can be seen inside the biggest flax bundle (Nm 39). (B,C) Reducing the diameter (B: Nm 45; C: Nm 52) diminish the amount of necrosis. However, in both cases, inflammatory cells seem to pull the individual fibers apart, resulting in the destruction of the integrity of the tread (circle). (D) With the smallest yarn diameter (Nm 58), integrity is better conserved and seldom necrosis is encountered. In all cases, individual fibers which have been pulled away from the thread over a long distance could be seen (arrowhead). (E,F) Mersilene ${ }^{\circledR}$ thread with no necrosis and conserved integrity. Scale bar F applies for (A), (B), (C), (D) and (F); and E for (E). All scale bars represent $200 \mu \mathrm{m}$. 


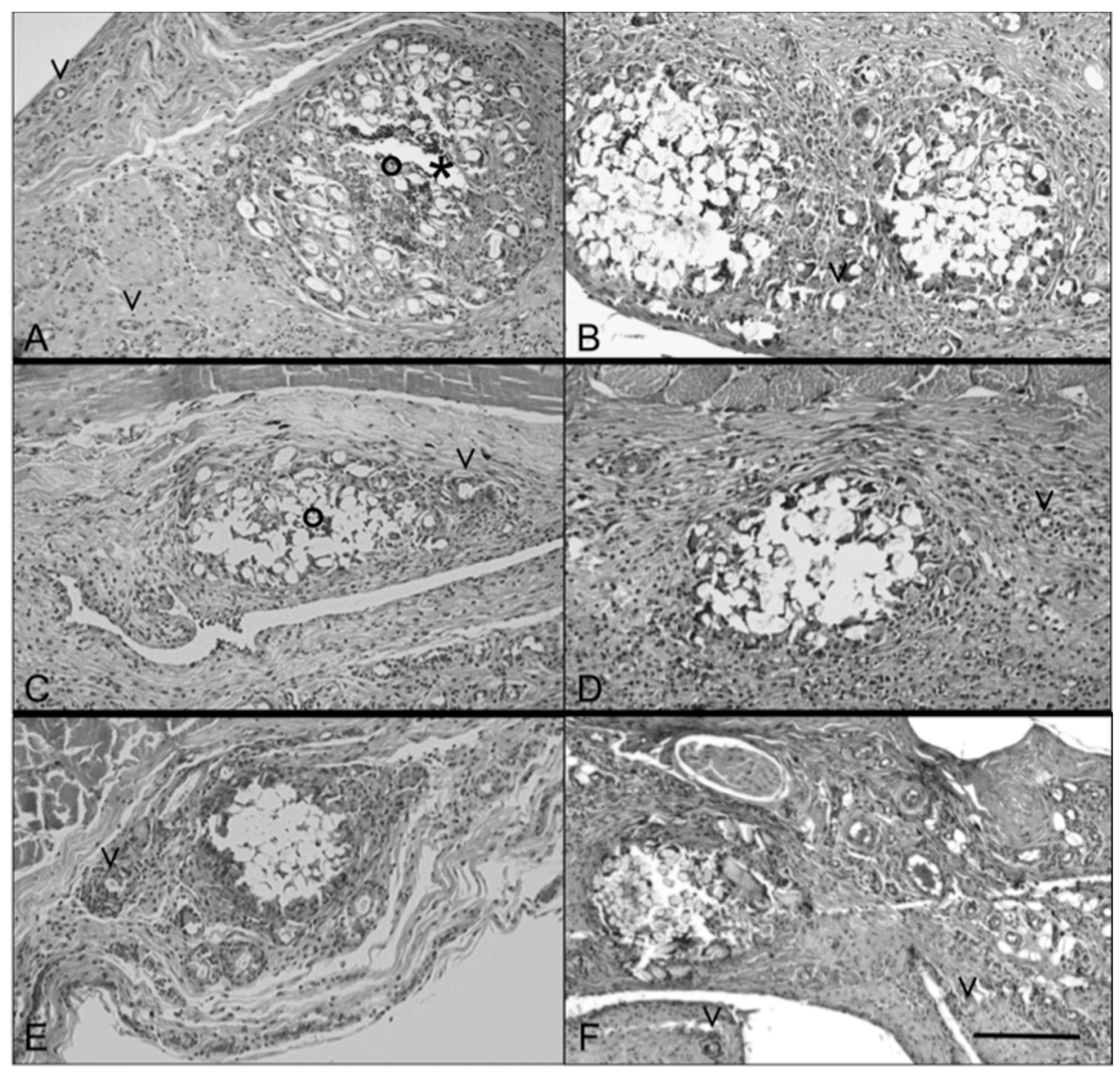

Figure 10. Representative histological images of H\&E stained skin-thread sections from in vivo experiments after 7 days follow-up. (A,B) Nm 45 threads; (C-D) Nm 52 threads; (E-F) Nm 58 threads. (A,C) Uncoated flax yarns with necrosis in A (asterisk), and loss of integrity in both cases (round). After albumin coating (B,D), necrosis is seldom encountered and physical integrity is better conserved. With the Nm 58 thread (E,F), no real effect of the albumin coating can be seen. In all cases, individual fibers which have been pulled away from the thread over a long distance could be seen (arrowhead). Scale bar F applies for (A), (B), (C), (D) and (F); and E for (E). All scale bars represent $200 \mu \mathrm{m}$. 
extended fibrotic capsule, and the presence of some individual fibers which have been pulled away by the inflammatory cells are still of a concern. It suggests that, likely, the yarn will also loose its integrity after a longer implantation time.

To check if the presence of an albumin coating could help in improving the in vivo inflammatory response, we implanted the albumin coated $\mathrm{Nm} 45, \mathrm{Nm}$ 52, and Nm 58 threads (fig. 10). Indeed, with the Nm 45 and 52 yarns, tissue reaction is improved after albumin coating. Whereas bundles had lost their integrity after 7 days implantation without albumin coating, threads were more intact when albumin coating was performed. No real difference between the two conditions could be seen using the Nm 58 thread, probably because the thread was already left intact before albumin coating.

Despite these improvements with albumin coating, a thick fibrotic capsule could still be seen. Moreover, some individual fibers seemed to be pulled away by the inflammatory cells. It confirms that the albumin coating covers only a part of the endotoxins. As a consequence, inflammatory cells still strongly react to the remaining endotoxins, leading to the problems described above. It is unsure that this albumin coating will remain on site once implanted. In particular, threads will be exposed to many different plasma proteins in vivo, and albumin may gradually degrade and be displaced by other plasma proteins (Vroman effect). Previous in vivo study dealing with albumin-coated Dacron ${ }^{\mathbb{B}}$ showed a total removal of the albumin coating in the first four weeks [39]. If this happens here, it is likely that the inflammatory response will only worsen over time, leading in particular to the physical destruction of the implant. This precludes the potential of albumin-coated flax as a vascular graft.

\section{Conclusion}

At the onset of this study, it was uncertain if flax, a hydrophilic material, can be coated with albumin. This work reveals that a single-step incubation of our knitted flax textile specimens with a diluted aqueous solution of albumin already leads to an adherent surface layer of albumin. The presence of this albumin coating effectively enhanced adhesion of endothelial cells on the mesh surface, provided that dynamic conditions were chosen. Moreover, the albumin coating successively increased thrombin generation times on all conditions tested (with or without platelets and with or without pre-incubation with leukocyte cells) and reduced platelet spreading. Nevertheless, our aim to abolish the effect of immobilized endotoxins with the albumin coating was only achieved in part, since albumin reduced endotoxin activity on the mesh by only approximately 27 
\%. In vivo analysis confirmed that the albumin coating did not cover all the endotoxins: some improvement of the tissue reaction was achieved, but results are still not satisfactory enough to permit standard use in surgery and commercialisation.

\section{Acknowledgements}

This study is a part of the Interreg IV-A project "BioMiMedics" (www.biomimedics.org). The Universities of Maastricht (The Netherlands), Liege (Belgium), Hasselt (Belgium) and Aachen (Germany; RWTH and Fachhochschule), as well as several regional biotechnological enterprises cooperate in "BioMiMedics". This particular study was financed through generous contributions of the EU (through Interreg IV-A), the government of the Province Dutch Limburg, the Dutch National Ministery of Economic Affairs, Agriculture \& Innovation, Maastricht University, the Limburg Bank for Industry Innovation (LIOF), and the company INterface BIOmaterials BV in Geleen, Netherlands. We are grateful to the company Van der Bilt Seeds \& Flax BV (Sluiskil, The Netherlands) for expert advice and generous gift of flax yarns.

\section{References}

1. Kvavadze E, Bar-Yosef O, Belfer-Cohen A, Boaretto E, Jakeli N, Matskevich Z, Meshveliani T. 30,000-year-old wild flax fibers. Science 2009;325:5946.

2. Goutianos S, Peijs T, Nystrom B, Skrifvars M. Development of flax fibre based textile reinforcements for composite applications. Appl Compos Mater 2006;13:199-215.

3. Kromer K-H. Physical properties of flax fibre for non-textile-use. Res Agr Eng 2009;55:52-61.

4. Helenius G, Backdahl H, Bodin A, Nannmark U, Gatenholm P, Risberg B. In vivo biocompatibility of bacterial cellulose. J Biomed Mater Res Part A 2006;76:431-8.

5. Petersen N, Gatenholm P. Bacterial cellulose-based materials and medical devices: current state and perspectives. Appl Microrbiol Biotechnol 2011;91:1277-86.

6. Michel S A A X, Vogels R R, Bouvy N D, Knetsch M L, van den Akker N M, Gijbels M J, van der Marel C, Vermeersch J, Molin D G, Koole L H. Utilisation of flax fibers for biomedical applications. J Biomed Mater Res Part B 2013;doi: 10.1002/jbm.b.33025.

7. Lieder R, Petersen P H, Sigurjonsson OE. Endotoxins the invisible companion in biomaterials research. Tissue Eng Part B 2013;19:391-402.

8. Beenken-Rothkopf L N, Karfeld-Sulzer L S, Zhang X, Kissler H, Mitchie S A, Kaufman D B, Fontaine M J, Barron A E. Protein polymer hydrogels: effects of endotoxin on biocompatibility. J Biomater Appl 2013;28:395-406.

9. Mooney C, Stolle-Smits T, Schols H, de Jong E. Analysis of retted and non retted flax fibres by chemical and enzymatic means. J Biotechnol 2001;89(2-3):205-16. 
10. Meijer W, Vertregt N, Rutgers B, van de Waart M. The pectin content as a measure of the retting and rettability of flax. Ind Crops Prod 1995;4(4):273-84.

11. Magalhães P O, Lopes A M, Mazzola P G, Rangel-Yagui C, Penna T C V, Pessoa A Jr. Methods of endotoxin removal from biological preparations: A review. J Pharm Pharmaceut Sci 2007;10(3):388-404.

12. Gorbet M B, Sefton M V. Endotoxin: The uninvited guest. Biomaterials 2005;26:68117.

13. Strang A C, Knetsch M L, Idu M M, Bisoendial R J, Kramer G, Speijer D, Koole L H, Stroes E S, Rotmans J L. Superior in vivo compatibility of hydrophilic polymer coated prosthetic vascular grafts. J Vasc Access 2013:doi 10.5301/jva.5000166.

14. Zinzendorf C. The Big Book of Flax; a compendium of facts, art, lore, projects, and songs. Atglen (PA): Schiffer Publishing; 2011.

15. Yamazoe H, Tanabe T. Drug-carrying albumin film for blood-contacting biomaterials. $J$ Biomater Sci, Polym Ed 2010;21:647-57.

16. Peng Q, Zhang S, Yang Q, Zhang T, Wei X Q, Jiang L, Zhang C L, Chen Q M, Zhang $\mathrm{Z}$ R, Lin Y F. Preformed albumin corona, a protective coating for nanoparticles based drug delivery system. Biomaterials 2013;34:8521-30.

17. Cedervall T, Lynch I, Foy M, Berggard T, Donnelly SC, Cagney G. Detailed identification of plasma proteins adsorbed on copolymer nanoparticles. Angew Chem Int Ed 2007;46:5754-6.

18. Bryans T D, Braithwaite C, Broad J, Cooper J F, Darnell K R, Hitchins V M, Karren A J, Lee P S. Bacterial endotoxin testing: a report on the methods, background, data, and regulatory history of extraction recovery efficiency. Biomed Instrum Technol 2004;38:73-8.

19. McCullough K Z, Weidner-Loeven C. Variability in the LAL test: comparison of three kinetic methods for the testing of pharmaceutical products. J Parenter Sci Technol 1992;46:69-72.

20. Dawson M E. Interferences with the LAL test and how to address it. LAL Update 2005;22:1.

21. Robinson K A, Candal F J, Scott N A, Ades E W. Seeding of vascular grafts with an immortalized human dermal microvascular endothelial cell line. Angiology 1995;46:107-13.

22. Wisse E, Braet F, Duimel H, Vreuls C, Koek G, Olde Damink S W M, van den Broek M A J, De Guest B, Dejong C H C, Tateno C, Frederik P. Fixation methods for electron microscopy of human and other liver. World J Gastroenterol 2010;16:2851-66.

23. Watts J F, Wolstenholme J. An introduction to surface analysis by XPS and AES. Chichester (UK): John Wiley \& Sons; 2003.

24. Zhu L P, Jiang J H, Zhu B K, Xu Y Y. Immobilisation of bovine serum albumin onto porous polyethylene membranes using strongly attached polydopamine as a spacer. Colloids Surf B Biointerfaces 2011;86:111-8.

25. Guideline on validation of Limulus Amebocyte Lysate test as end-product endotoxin test for human and animal parental drugs, biological products, and medical devices. Food and Drug Administration, Rockville, MD. 1987.

26. Bryans T D, Braithwaite C, Broad J, Cooper J F, Darnell K R, Hitchins V M, Karren A J, Lee P S. Bacterial endotoxin testing: a report in the methods, background, data, and regulatory history of extraction recovery efficiency. Biomed Instrum Technol 2004;38:73-8. 
27. Hansen M B, Nielsen S E, Berg K. Re-examination and further development of a precise and rapid dye method for measuring cell growth/cell kill. J Immunol Methods 1989;119:203-10.

28. Yamazoe H, Tanabe T. Preparation of water-insoluble albumin film possessing nonadherent surface for cells and ligand binding. J Biomed Mater Res Part A 2008;86:22834.

29. Yamazoe H, Uemura T, Tanabe T. Facile cell patterning on an albumin-coated surface. Langmuir 2008;24:8402-4.

30. Revzin A, Rajagopalan P, Tilles A W, Berthiaume F, Yarmush M L, Toner M. Designing a hepatocellular microenvironment with protein microarraying and poly(ethylene glycol). Langmuir 2004;20:2999-3005.

31. Bernards M T, Qin C, Jiang S. MC3T3-E1 cell adhesion to hydroxyapatite with adsorbed bone sialoprotein, bone osteopontin, and bovine serum albumin. Colloids Surf B Biointerfaces 2008;64:236-47.

32. Werthén M, Sellborn A, Källtorp M, Elwing H, Thomsen P. In vitro study of monocyte viability during the initial adhesion to albumin- and fibrinogen-coated surfaces. Biomaterials 2000;22:827-32.

33. Sivaraman B, Latour R A. The adherence of platelets to adsorbed albumin by receptormediated recognition of binding sites exposed by adsorption-inducing unfolding. Biomaterials 2010;31:1036-44.

34. Tijink M, Janssen J, Timmer M, Austen J, Aldenhoff Y, Kooman J, Koole L H, Damoiseaux J, van Oerle R, Henskens Y, Stamatialis D. Development of novel membranes for blood purification therapies based on copolymers of $\mathrm{N}$-vinylpyrrolidone and n-butylmethacrylate. J Mater Chem B 2013;1:6066-77.

35. Aldenhoff Y, Knetsch M L, Hanssen J H, Lindhout T, Wielders S J, Koole L H. Coils and tubes releasing heparin. Studies on a new vascular graft prototype. Biomaterials 2004;16:3125-33.

36. Wei Q, Li B, Yi N, Su B, Yin Z, Zhang F, Li J, Zhao C. Improving the bloodcompatibility of material surfaces via biomolecule-immobilized mussel-inspired coatings. J Biomed Mater Res Part A 2011;96:38-45.

37. van Rijssel E J, Brand R, Admiraal C, Smit I, Trimbos J B. Tissue reaction and surgical knots: the effect of suture size, knot configuration, and knot volume. Obstet Gynecol 1989;74(1):64-8.

38. von Fraunhofer J A, Chu C C. Mechanical properties. In: Chu C C, von Fraunhofer J A, Greisler H P, editors. Wound closure biomaterials and devices. CRC Press. 1997:107-131.

39. Rumisek J D, Wade C E, Brooks D E, Okerberg C V, Barry M J, Clarke J S. Heatdenatured albumin-coated Dacron vascular grafts: Physical characteristics and in vivo performance. J Vasc Surg 1986;4(2):136-43. 



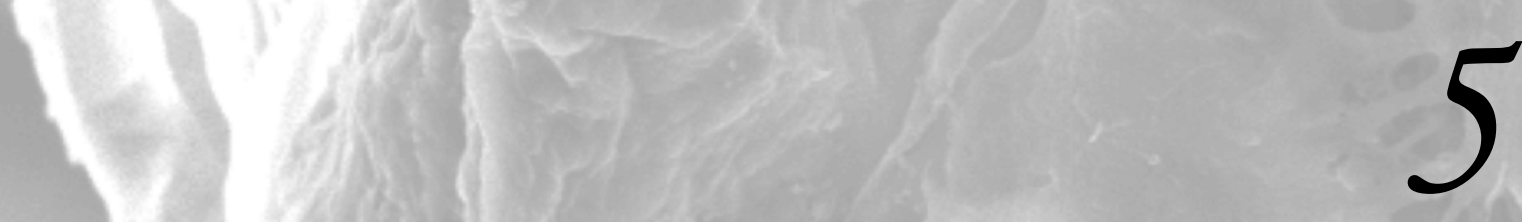

Studies on the potential use of flax (linen) as a biomedical material. Application of a synthetic antimicrobial surface coating

Sophie A A X Michel, Maxime G J Basset, Frankvan Tiel, Jacqueline Maes and Leo $\mathcal{H}$ Koole.

Submitted for publication 


\section{Abstract}

Flax has unique physical-mechanical properties, which make this material, in theory at least, interesting for various applications in the biomedical field. One particularly interesting aspect is that flax and linen can imbibe large amounts of water, leaving the material's strength unaffected. This is quite unique; most of the hydrophilic biomaterials that we know are chemically or physically crosslinked hydrogels, which have little tensile strength. However, the use of flax in biomedical applications is hampered by the fact that the material contains endotoxins. These are physically bound to the flax and very difficult to remove quantitatively. In the present study, we used a new technique to apply a synthetic biocompatible hydrophilic coating onto the surface of flax threads to cover the endotoxins. The method is a continuous reel-to-reel technique; several hundreds of meter of coated flax thread can be produced readily. Threads were studied by electron microscopy and cytotoxicity was evaluated with the MTT assay. Silver particles could also be dispersed into the coating solution, and it resulted in a marked inhibitory effect on the adhesion of S. aureus bacteria. Although the results are still preliminary (especially since many parameters of the coating procedure still need further optimization), it is clear that the resulting hydrophilic and antimicrobial coated flax threads hold promise for applications in wound care, especially since there is a need for improved moist-controlling antiinfectious materials and devices in this field.

\section{Introduction}

Hydrophilic synthetic biomaterials find many applications in the medical device industry [1]. For example, hydrogels are used extensively as soft contact lenses $[2,3]$, as prostheses for the nucleus pulposus in the spine [4], as depots for controlled delivery of drugs [5], as substitutes for cartilage [6], as swelling microspheres for use in transarterial chemo-embolization [7], in advanced biosensor technologies [8], and in regenerative medicine, e.g. intervertebral disc regeneration [9]. Most interestingly, hydrogels can also be used to modulate material-tissue interactions of permanent implants. For example, patency rates of vascular prostheses can be improved through the use of hydrophilic coating on the graft's luminal surface [10].

Most of the known synthetic biomedical hydrogels are three-dimensional cross-linked networks. This implies that, after uptake of water and swelling, these materials can withstand compressive forces much better than tear forces. 
This poses serious limitations with respect to the potential applications. In cases where a medical device is subject to tensile forces, this usually implies that a bilayer structure must be used: a hydrophilic surface coating is applied on top of a strong matrix material that can withstand the tear forces [11].

Recently, we have put forward that flax offers a unique combination of hydrophilicity and tensile strength [12]. Flax is the basis material of linen textiles. Flax threads are multifilament structures; the tensile strength of elementary flax fibers is in the range 1500-1800 MPa [13]. The material is well known for its capacity to imbibe water, and it is known that the tensile strength even increases (by approximately $10 \%$ ) upon uptake of water [14]. We proposed that this property is of interest with respect to implants that are based on textile technologies, such as implantable meshes for the repair of incisional hernias, or woven or knitted three-dimensional constructs for use as vascular prostheses. There is another very interesting aspect of flax: the individual filaments are hollow tubes [15]. The lumens could -in theory- be used as temporary depots for one or more pharmacologically active agents. These can then be released from the implant in situ, i.e. after implantation.

However, we found that flax really falls short in terms of biocompatibility $[12,16]$. The material per se is highly cytotoxic. Extensive washing did not produce any significant improvements. Furthermore, we found that flax contains high amounts of surface-bound endotoxins, causing an excessive inflammatory response after implantation. We discovered that an intensive continuous extraction (acetic acid ( $24 \mathrm{~h}$ ) followed by ethanol $(24 \mathrm{~h})$ ) improved its cytocompatibility and removed most of the endotoxins.

These experiences led us to look back at the detailed structure of flax threads. Figure 1 is a scanning electron micrograph of a bleached flax thread (as received), clearly showing the multifilament nature. What stroke us most is the fact that the individual filaments contain many irregularities and flakes. Although most of the debris can be removed through washing, and certainly by the continuous extraction method (vide supra), we experienced that it is not possible to obtain the material in a really pure form, as would be required for use in any medical device. 


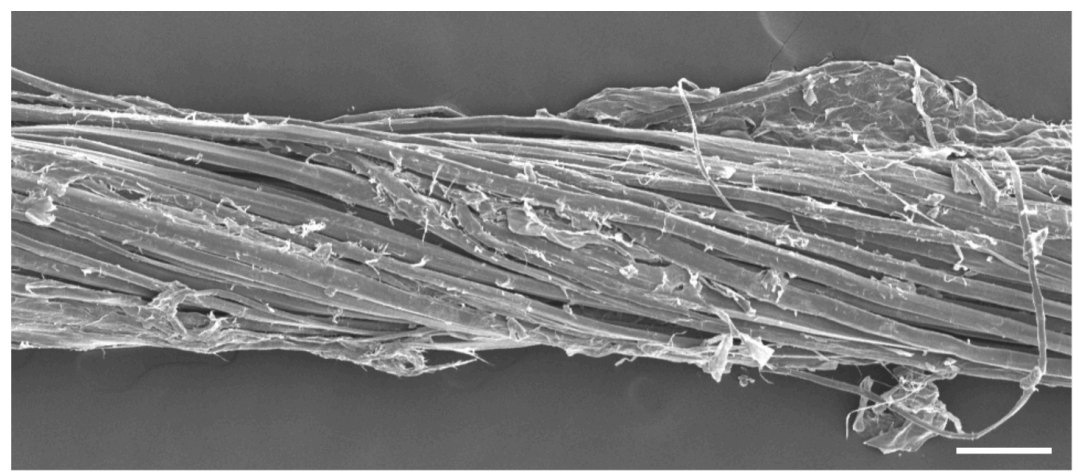

Figure 1. Scanning electron micrograph of the hydrogenperoxide-bleached flax thread as used in this study. Numerous flakes and irregularities are seen. Scale bar represents $100 \mu \mathrm{m}$.

We hypothesized that a solution of this problem can be found through the application of a hydrophilic surface coating, for which non-cytotoxicity has been established. We anticipated that such a coating could combine several functions:

1. the coating allows for passage of water from surrounding tissues into the flax threads and vice versa

2. the coating would cover the surface and -therefore- mask the presence of adherent debris, irregularities, flakes, etc.

3. the coating would resolve the cytotoxic nature of the material.

We realized, of course, that the use of such a coating will not qualify the material for use as a permanent implant. There would always remain a risk for delamination of the coating (as a long-term effect), thus igniting a late inflammatory reaction. On the other hand, hydrophilic-coated linens could be interesting for short-term extracorporeal applications, such as moist wounddressing materials or gauzes for treatment of decubitus wounds. Another interesting aspect would be to incorporate antimicrobial agents in the surface coating, attempting to decrease the risk for bacterial infection.

Here, we report a preliminary study in which we demonstrate for the first time that it is possible to apply a hydrophilic surface coating onto flax threads. An apparatus for continuous reel-to-reel coating of a flax thread was developed and built. The machine first applies a solution of a hydrophilic surface coating (in ethanol) onto the thread. Then, forced evaporation of the solvent deposits the polymer onto the flax filaments. The polymer also connects the filaments, i.e. the thread changes (more or less) from a multifilament into a monofilament structure. We show that the hydrophilic coating preserves cytocompatibility in vitro. The coating procedure was also done with a 
suspension of silver particles in the ethanol solution of the hydrophilic polymer. Technically, the coating process proceeded in the same way, but silver particles were now incorporated in the surface coating. It could be shown that adhesion of bacteria decreased substantially due to the combined action of (i) the hydrophilic coating, and (ii) the presence of silver. It is anticipated that coated linen textiles, having an antimicrobial agent embedded in the hydrophilic coating, can provide new materials for moist-controlling antibacterial gauzes to be used in wound care, etc.

\section{Materials and Methods}

\section{Materials}

A bleached flax thread was generously provided by the company van der Bilt Seeds \& Flax BV (Sluiskil, the Netherlands). The thread was wound on a spool; the thickness was in the range $190-210$ micrometer; the approximate weight of the thread was $2 \mathrm{~kg}$, and the length of the thread was several $\mathrm{km}$.

The hydrophilic surface coating was provided as a $10 \%$ (by mass) solution of the hydrophilic copolymer SlipSkin ${ }^{\mathrm{TM}}$ (50:50) in ethanol, by the company INterface BIOmaterials BV (Geleen, The Netherlands). The company manufactures the copolymer from two vinylic monomers: $\mathrm{N}$-vinylpyrrollidone (NVP, hydrophilic), and n-butylmethacrylate (BMA, hydrophobic) [10,17]. NVP building blocks render the copolymer hydrophilic, whereas the n-BMA building blocks provide adherence of the copolymer to underlying substrates. The cyto- and hemocompatibility of the SlipSkin ${ }^{\text {TM }}$ (50:50) copolymer, and other (more or less hydrophilic) similar copolymers, have been described previously.

Silver particles were purchased from the company Metalor AS (Neufchatel, Switzerland).

\section{Methods}

\section{Soxhlet extraction}

A handmade ball of flax yarn was put in a Soxhlet device without a filter for $48 \mathrm{~h}$. During the first $24 \mathrm{~h}, 10 \mathrm{wt} \% \mathrm{NaCl}$ and $5 \%(\mathrm{v} / \mathrm{v})$ acetic acid in doubly distilled water was used as the extracting liquid. During the last 24 h, $75 \%$ ethanol was used as extracting liquid. The yarn was then rinsed with ethanol and excess water, and let to dry for few hours. 


\section{Coating}

An apparatus to apply the SlipSkin ${ }^{\mathrm{TM}}$ (50:50) coating onto the flax thread in a continuous reel-to-reel procedure was designed and constructed (fig. 2). We used small reels in the coating process; these were aluminium tubes (length: 30 $\mathrm{cm}$, outer diameter $8 \mathrm{~mm}$ ). Such reels could easily hold $100-200 \mathrm{~m}$ of the flax thread.

The apparatus consisted of a vertical rectangular frame with the dimensions: width: $80 \mathrm{~cm}$; height: $120 \mathrm{~cm}$. The apparatus fitted into a normal laboratory fumehood. The following parts were mounted onto the inside of the rectangle:

1. on the bottom, to the left: a holder for the unrolling reel (containing appr. $200 \mathrm{~m}$ of the uncoated flax thread)

2. in the lower left corner: a guiding wheel

3. on the left side at $20 \mathrm{~cm}$ height: a plastic container for the coating solution. The approximate dimensions of the container were: height: 6 $\mathrm{cm}$, length and breadth: $4 \mathrm{~cm}$. A small hole (diameter $1 \mathrm{~mm}$ ) was drilled in the center of the container's bottom. A syringe needle was put through the hole (point inside), and fixed with glue.

4. on the left side, approximately $5 \mathrm{~cm}$ above the plastic container: a glass funnel, mounted upside down and filled with wrapped aluminum foil. This served to remove superfluous coating solution from the thread.

5. on the left side, approximately $20 \mathrm{~cm}$ above the plastic container: a circular infrared lamp (inner diameter $45 \mathrm{~mm}$, Heraeus). The flax thread is guided through the center of the lamp. The lamp generates heat, leading to rapid evaporation of ethanol during passage of the thread.

6. in the upper left corner: a guiding wheel

7. in the upper right corner: a guiding wheel

8. on the bottom, to the right: a motor with speed control that rotates the collecting wheel, onto which the coated and dried flax thread is wound.

During the coating procedure, the flax thread (+/- Soxhlet) is pulled clockwise along the inner side of the rectangle at a speed of approximately $5 \mathrm{~cm}$ per second. Immediately after the start of the motor, the plastic container was filled with the coating solution. Due to the viscosity of the coating solution and the upward movement of the thread through the needle, there is no leakage of the coating solution from the container. It could be noticed that the flax thread readily absorbed the coating solution. Passage of the thread along the aluminum foil in the funnel removes adherent non-absorbed coating solution; this was necessary to obtain an uniform coating. Passage of the thread through the circular 


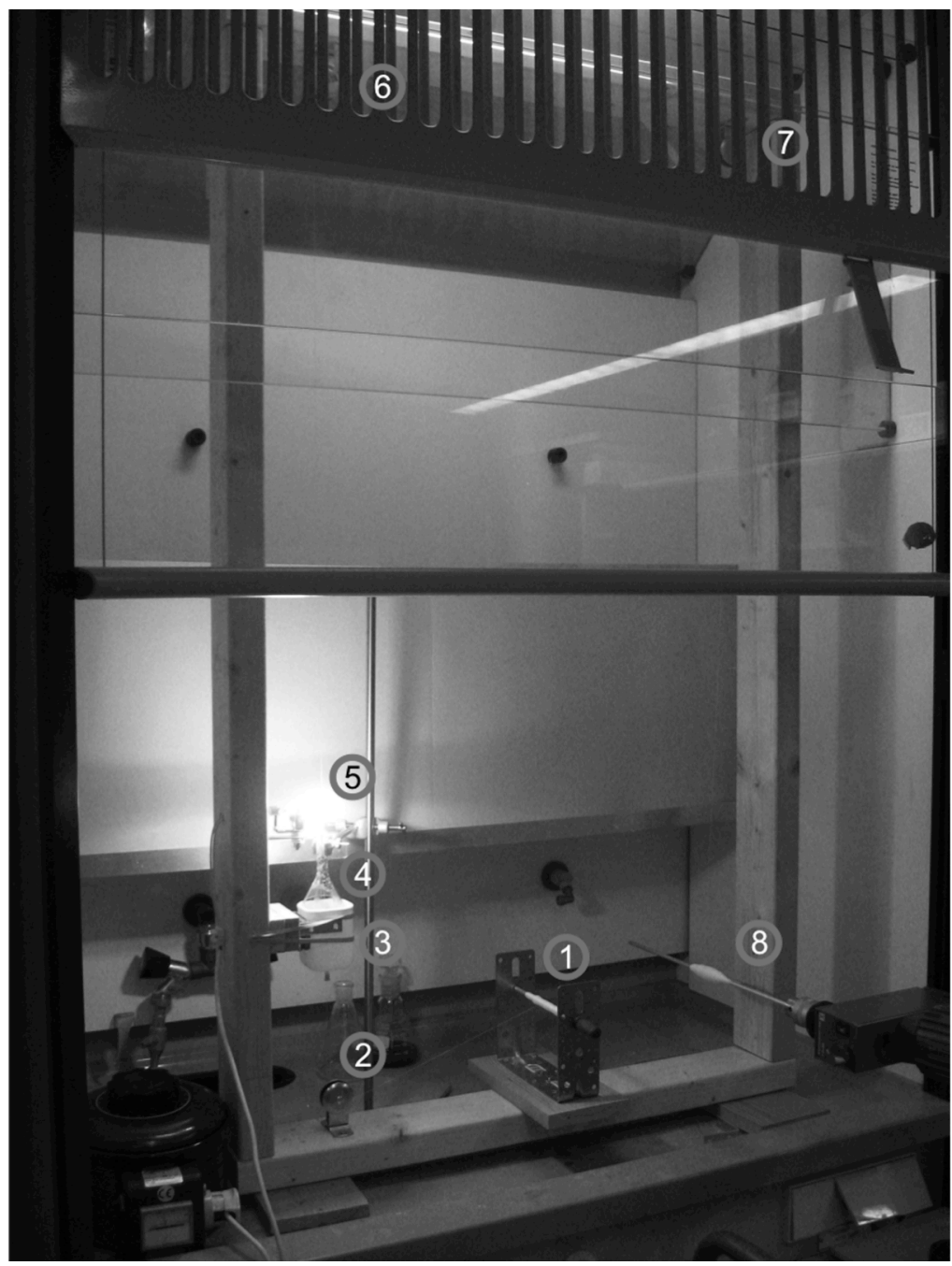

Figure 2. Picture of the coating machine under progress. It fitted perfectly under the fumehood. Labels correspond to the coating steps described in the Materials and Method part.

lamp led to quick evaporation of ethanol and adherence of the copolymer onto the flax' surface. Finally, the coated flax thread was wound onto the collecting reel. Typically, the coating process was run during approximately $1 \mathrm{~h}$, producing several hundreds of meters of coated flax thread. It was found that the coating process could also be run with SlipSkin ${ }^{\mathrm{TM}}(50: 50)+$ silver dispersions. Typically, a dispersion of $1.0 \mathrm{~g}$ silver particles in a solution of $5.0 \mathrm{~g} \mathrm{SlipSkin}^{\mathrm{TM}}$ (50:50) in $45.0 \mathrm{~g}$ of ethanol was used. The silver particles formed a homogeneous suspension that was stable for $1 \mathrm{~h}$ at least. 


\section{Coding of the material samples}

The experimental materials were:

1. the flax thread, not purified by the Soxhlet method (continuous extraction as described in our previous work). This material is abbreviated as: Flax-Sox.

2. the flax thread, not purified by the Soxhlet method and coated with SlipSkin $^{\mathrm{TM}}$ (50:50). This material is abbreviated as: Flax-Sox+SS.

3. the flax thread, purified by the Soxhlet method. This material is abbreviated as: Flax + Sox .

4. the flax thread, purified by the Soxhlet method and coated with SlipSkin $^{\mathrm{TM}}$ (50:50). This material is abbreviated as: Flax+Sox+SS.

5. the flax thread, purified by the Soxhlet method and coated with the SlipSkin $^{\mathrm{TM}}$ (50:50) coating with silver particles embedded therein. This material is abbreviated as: Flax $+\mathbf{S o x}+\mathbf{S S} / \mathbf{A g}$. The mass:mass ratio of polymer coating:embedded silver was 5:1.

Scanning electron microscopy

Samples of flax fibers were dried, put on carbon tape, and sputter-coated with gold. Images were recorded with a scanning electron microscope (Philips XL 30; FEI, Eindhoven, the Netherlands) at an operating voltage of $10 \mathrm{kV}$. For the backscattered microscopy, samples of flax fibers were sputter-coated with carbon and the operating voltage was $15 \mathrm{kV}$.

\section{Experiments with cells}

Cells

Mouse fibroblasts (clone L929 cells) were grown in DMEM/F12-1 medium containing Glutamax and supplemented with $10 \%$ FBS and antibiotics $(10 \mathrm{U} / \mathrm{mL}$ penicillin, $10 \mu \mathrm{g} / \mathrm{mL}$ streptomycin, and $0.25 \mu \mathrm{g} / \mathrm{mL}$ amphotericin B) and incubated at $37{ }^{\circ} \mathrm{C}$ and $5 \% \mathrm{CO}$. Cells were harvested with $0.05 \%$ trypsin/ $0.53 \mathrm{mM}$ EDTA. When used in contact with cells, all flax materials were steam sterilized at $121^{\circ} \mathrm{C}$ for $15 \mathrm{~min}$ or UV irradiated.

Cytotoxicity (MTT assay)

Samples were sterilised by steam $\left(121{ }^{\circ} \mathrm{C}\right.$ for $\left.15 \mathrm{~min}\right)$ and incubated in cell medium $(0.05 \mathrm{~g} / \mathrm{mL})$ for 3 days extraction at $37^{\circ} \mathrm{C}$ under agitation. Fibroblast 
cells (L929) were harvested, seeded in a 96-well plate at a density of 10.000 cells per well and incubated overnight. After removal of the medium, extracts of samples were added to the cells and incubated for $48 \mathrm{~h}$. Then, concentrated MTT solution in medium was added to a final concentration of $0.25 \mathrm{mg} / \mathrm{mL}$. The MTT was left for $2 \mathrm{~h}$ and the formed blue formazan crystals were dissolved in isopropanol. The absorbance at $570 \mathrm{~nm}$ was measured and cell viability was determined as percentage of the viable control (pure medium). Medium containing $5 \%$ DMSO was used as toxic control.

\section{Bacterial adhesion}

The semi-quantitative culture agar roll method according to [18] was used to study bacterial adhesion to the materials Flax+Sox, Flax+Sox + SS, and Flax + Sox + SS $/$ Ag. Since the agar-roll assay requires the use of cylindrical samples, we decided to make coiled samples of the flax threads using stainlesssteel sewing needles. The needles had a sharp point on one end, and an eye on the other end; their length was $50 \mathrm{~mm}$. Needles were attached at the sharp-point end to the axis of a rotating motor. Flax threads (control or coated) were guided through the eye of the needle and fixed with a small knot. Then, the needle was slowly rotated, and the thread was carefully wound on the needle, such that the windings were placed side by side. Rotation was stopped when most of the needle was covered. The thread was then fixed with a small droplet of a poly(cyanoacrylate) glue. Examples of these needle-wound samples are shown in Figure 3.

An overnight culture Staphylococcus aureus ATCC 29213 was prepared by inoculation of one bacterial colony into $10 \mathrm{~mL}$ growth medium $(37 \mathrm{~g} / \mathrm{L}$ Brain Heart Infusion Browth). From this culture, a bacterial suspension of $10^{7}$ $\mathrm{CFU} / \mathrm{mL}$ was prepared in $0.9 \% \mathrm{NaCl}[19,20]$. The suspension was 1000 times diluted in $0.9 \% \mathrm{NaCl}$ in order to have a final concentration of $10^{5} \mathrm{CFU} / \mathrm{mL}$.

Samples were UV sterilised for 15 minutes, and immerged in the bacteria suspension in $0.9 \% \mathrm{NaCl}$ for 30 minutes at $37{ }^{\circ} \mathrm{C}$ under agitation. Then, the needle samples were transferred into a tube with $5 \mathrm{~mL}$ sterile $0.9 \% \mathrm{NaCl}$ and vortexed for 5 second; this removes non-adherent bacteria. In order to remove excess fluid, samples were put into sterile tubes and centrifugated 30 seconds at 1200 RPM. Subsequently, samples were consecutively rolled over 3 different Mueller-Hinton blood agar plates (38 g/L Mueller-Hinton agar, $5 \%$ defibrinated sheep blood). Plates were incubated overnight at $37^{\circ} \mathrm{C}$, to allow each bacterium to form a visible colony. Finally, the agar plates and the colonies formed thereon were photographed and evaluated on the next day. 


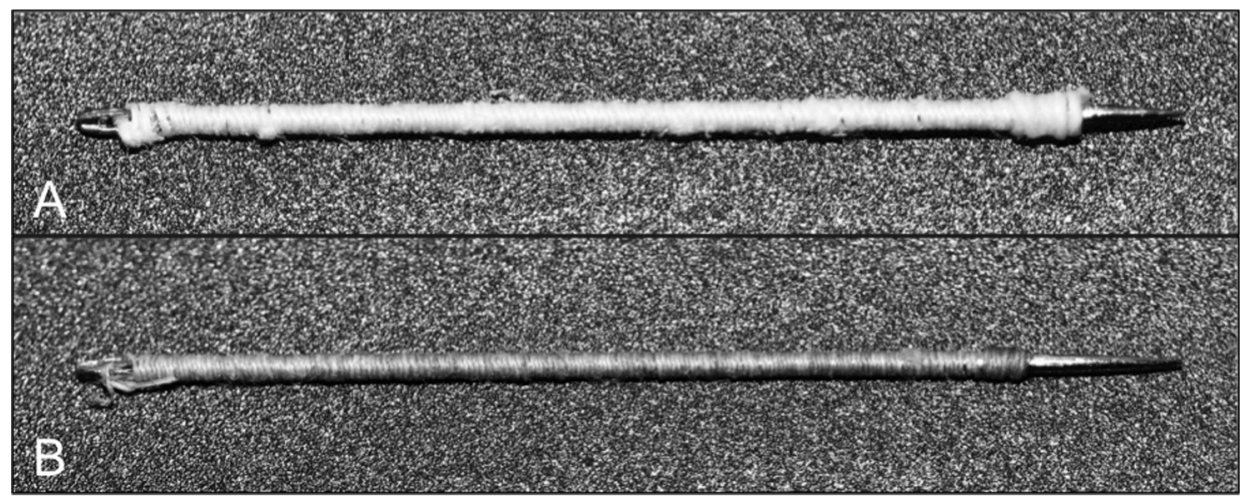

Figure 3. Photographs of the cylindrical samples. Flax threads were coiled around a stainless steel sewing needle. (A) Soxhlet flax thread after SlipSkin ${ }^{\mathrm{TM}}$ coating (Flax+Sox+SS); (B) one of the experimental materials $(\mathrm{Flax}+\mathrm{Sox}+\mathrm{SS} / \mathrm{Ag})$. Note the greyish color of this silver-containing material.

\section{Results and Discussion}

Application of the SlipSkin ${ }^{\mathrm{TM}}$ coating on the flax thread proceeded without difficulties. The coating connected adjacent filaments, which contracted the yarn. The diameter of the thread decreased from $190-210 \mu \mathrm{m}$ to $140-150 \mu \mathrm{m}$ during the coating process (fig. 4). The coating also affected the flexibility and

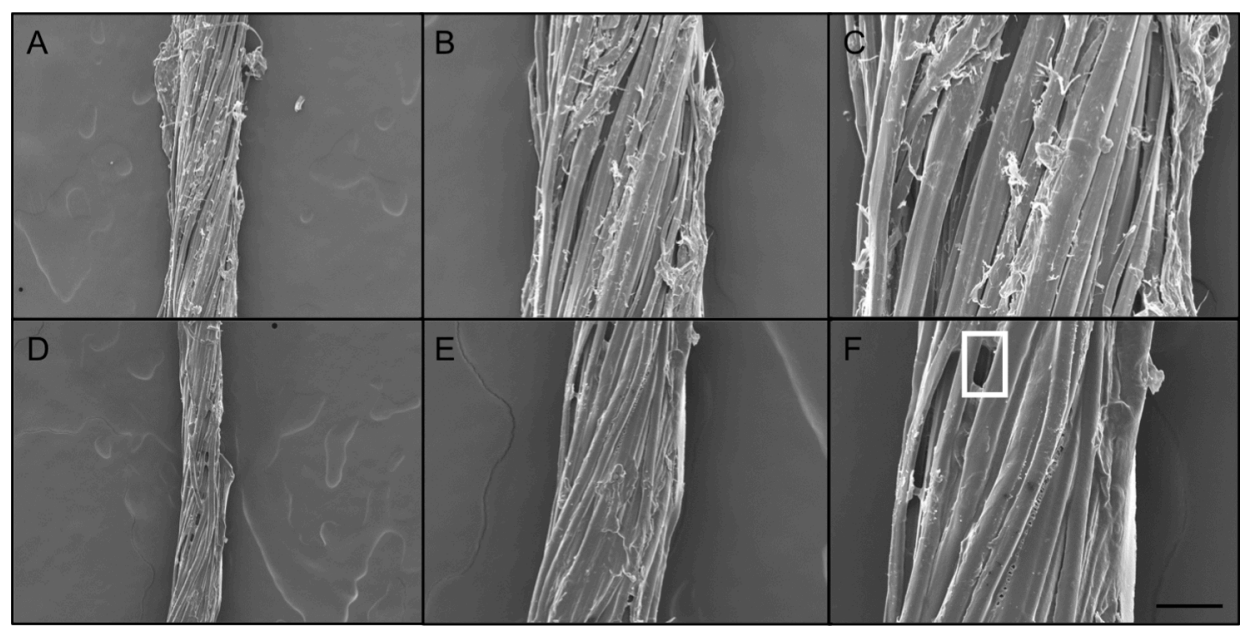

Figure 4. Scanning electron micrographs of the Flax-Sox thread (A-C), and the Flax-Sox+SS thread after application of the hydrophilic (50:50) coating (D-E). Scale bars are $200 \mu \mathrm{m}$ (A,D), $100 \mu \mathrm{m}(\mathrm{B}, \mathrm{E})$, and $50 \mu \mathrm{m}(\mathrm{C}, \mathrm{F})$. The coating covered most of the flakes at the surface of the flax filaments. The coating joins adjacent filaments, leading to apparent stiffening of the thread. Some holes in the coating could also be detected (white rectangle). 
soft-feel of the thread, which is presumably due to the gluing effect of the coating: adjacent filaments are less free to move independently.

We checked the cytocompatibility level of the steam sterilized Flax-Sox and Flax-Sox+SS samples using the MTT test. Before coating, cell survival was of $29.4 \pm 8.4 \%$. The presence of the SlipSkin ${ }^{\mathrm{TM}}$ coating increased cell survival, but only slightly $(38.3 \pm 9.3 \%)$. This is still far from the acceptable biocompatibility level (which is generally set to $80 \%$ survival) [21]. Most likely, the coating does not completely cover all individual filaments. Movements of the thread after coating will shift the filaments, thus exposing uncoated parts. Actually, such uncoated parts can be seen by electron microscopy at high magnification (Figure $4(\mathrm{~F})$ - white rectangle). For our experiments, this implies that the cells are still exposed, to some extend, to the toxic contents of the flax. A possible remedy for this problem could be to coat the thread slower and/or repeatedly. The coating parameters that would be required to ensure complete coating of all filaments must still be established.

To cross-check our reasoning, the coating was also applied onto the Soxhlet-treated flax thread. We know that Soxhlet treatment improves cytocompatibility in vitro, although some unextractable endotoxins remain present. MTT analysis now showed that cell survival was $86.9 \pm 7.8 \%$ before coating and $91.3 \pm 8.7 \%$ afterwards. This indicates that Flax-Sox+SS indeed releases toxic substances, and it proves that the coating per se is not toxic to cells. This is not surprising, in view of previous bio- and hemocompatibility data on SlipSkin ${ }^{\mathrm{TM}}$ coatings [17].

We further checked if the SlipSkin ${ }^{\text {TM }}$ coating could be used as a matrix for the embedding of silver microparticles. The embedding of silver in our material could be interesting for wound dressings, especially in the case of infections. Infections are, for example, quite common in burns, and such a problem should be solved immediately [22,23]. Silver is a popular antimicrobial agent, since it presents a broad-spectrum of antimicrobial activity [24,25]. The exact mechanism behind the anti-microbial activity of silver is still not well understood $[19,24]$, but it is known that its activity is due to the presence of $\mathrm{Ag}^{+}$ ion $[19,25,26]$. In particular, once in contact with the cytoplasmic membrane of the bacteria, $\mathrm{Ag}^{+}$leads to mitochondria dysfunction, DNA damage and bacteria death $[25,27,28]$. Note that in this study, silver microparticles were used to bring antimicrobial properties to our coating, but there is no doubt that other micro-or nanoparticles could be used in a similar manner. 


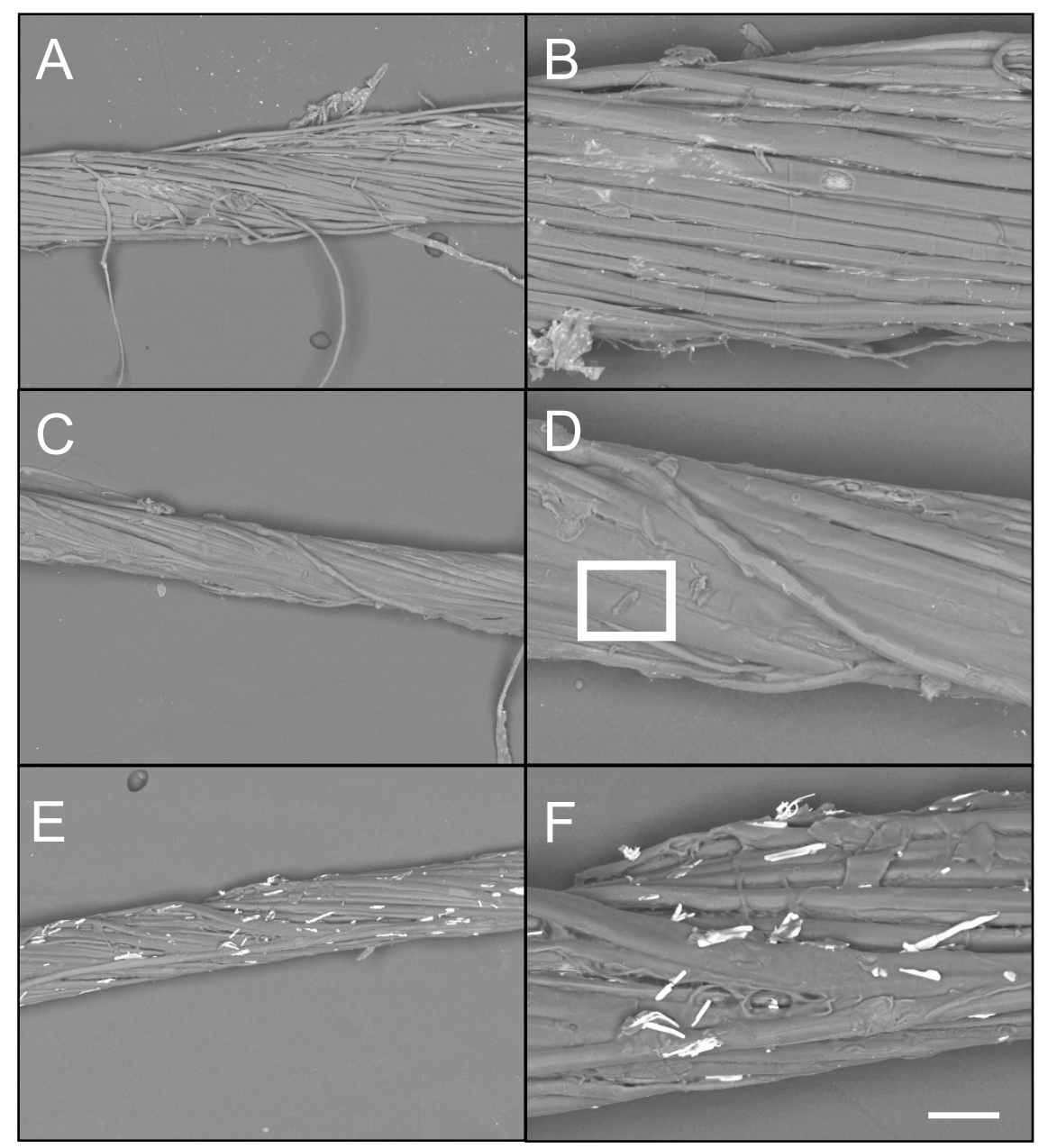

Figure 5. Scanning electron micrographs of the flax thread: (A,B) After Soxhlet treatment, (C-F) After Soxhlet treatment and SlipSkin ${ }^{\mathrm{TM}}$ coating containing silver microparticles. (A-D) Secondary electron microscopy; one silver microparticle can be seen (white rectangle). (E,F) Backscattered electron microscopy. On images (E,F), the silver particles can be discerned clearly; most of them are aligned with the flax filaments (see text). Scale bars are to (A,C,E) $200 \mu \mathrm{m},(B, D, F) 50 \mu \mathrm{m}$.

The presence of silver in the coating resulted in a grey fiber (fig. 3(B)) that was studied further with SEM (fig. 5). In our previous paper, we demonstrated that fibers were uniformly loose and clean after the Soxhlet treatment. Same result was obtained here (compare figure $4(A, C)$ with figure $5(A, B))$. Soxhlet treatment partly removed the flakes present on the fiber, and led to a substantial increase of the diameter of the fiber: from $190-210 \mu \mathrm{m}$ to $220-260 \mu \mathrm{m}$ after Soxhlet treatment. Here again, it is clear that the coating made the flax thread more compact, connected the filaments and reduced the 
diameter (now $140-160 \mu \mathrm{m}$; fig. 5(C,D)). Note that after SlipSkin ${ }^{\text {TM }}$ coating, same diameter of fiber was obtained whether Soxhlet pre-treatment was performed or not. Figure 5(E,F) shows backscattered electron micrographs (two magnifications) of the surface of the flax thread that was coated with the suspension of silver particles in a solution of SlipSkin ${ }^{\mathrm{TM}}$ (50:50) in ethanol. This technique highlights the silver particles [29]. These are mostly aligned in the direction of the flax filaments. This is caused by the coating process, since the thread is drawn through the dispersion [30]. The wet coating is, actually, pulled out of the dispersion due to its apparent adhesion to flax.

Finally, we investigated the effect of the silver particles, embedded in the SlipSkin ${ }^{\mathrm{TM}}$ coating, on adhesion of bacteria. The following UV sterilised needlewound samples were examined:

1. Flax thread after Soxhlet treatment (Flax+Sox)

2. Flax + Sox with a SlipSkin ${ }^{\mathrm{TM}}$ coating on top $(\mathrm{Flax}+\mathrm{Sox}+\mathrm{SS})$

3. Flax + Sox with 20 mass $\%$ of silver particles impregnated in the SS coating $($ Flax + Sox + SS $/ \mathrm{Ag})$

Figure 6 shows the Mueller-Hinton blood agar plates that were used in the roll test. The three rows correspond to Flax+Sox (top row), Flax+Sox+SS (middle row) and Flax+Sox $+\mathrm{SS} / \mathrm{Ag}$ (bottom row). The samples (after incubation in the bacterial suspension ( $30 \mathrm{~min})$, vortexing $(5 \mathrm{sec}$ ) and centrifugation) were placed at the top of the left agar plate and then rolled carefully over the agar surface across the plate. The sample was then lifted with a forceps and transferred to the middle agar plate. The sample was then again rolled across the surface of the plate. Finally, the sample was transferred (forceps) to the right agar plate and rolled across the surface again. During rolling, bacteria are transferred from the sample's surface to the agar. Progressively, less bacteria are transferred to the agar upon going from left to right; this is clearly visible in all three rows. The plates were left for $24 \mathrm{~h}$, during which bacterial colonies developed. These are seen as white dots in Figure 6.

The plates in the top row show a lane that is crowded with bacterial colonies, revealing that many bacteria adhered to the surface of the Soxhlettreated flax. Far less colonies are found in the middle row, which implies that the SlipSkin ${ }^{\mathrm{TM}}$ coating is a much less favoured surface for adhesion of the bacteria. Note that the number of transferred bacteria decreases, in every row, after the first, second and third rolling steps (i.e., from left to right). The bottom row shows only very few bacterial colonies, i.e. almost no bacteria adhered to the Flax + Sox + SS $/$ Ag sample. The differences between the plates in the middle row and those in the low row can be attributed to the presence of the silver in the 
coating. Hence, a clear antimicrobial effect of the silver particles is noted, which is in good agreement with the previous work of Stevens et al. [26,30].

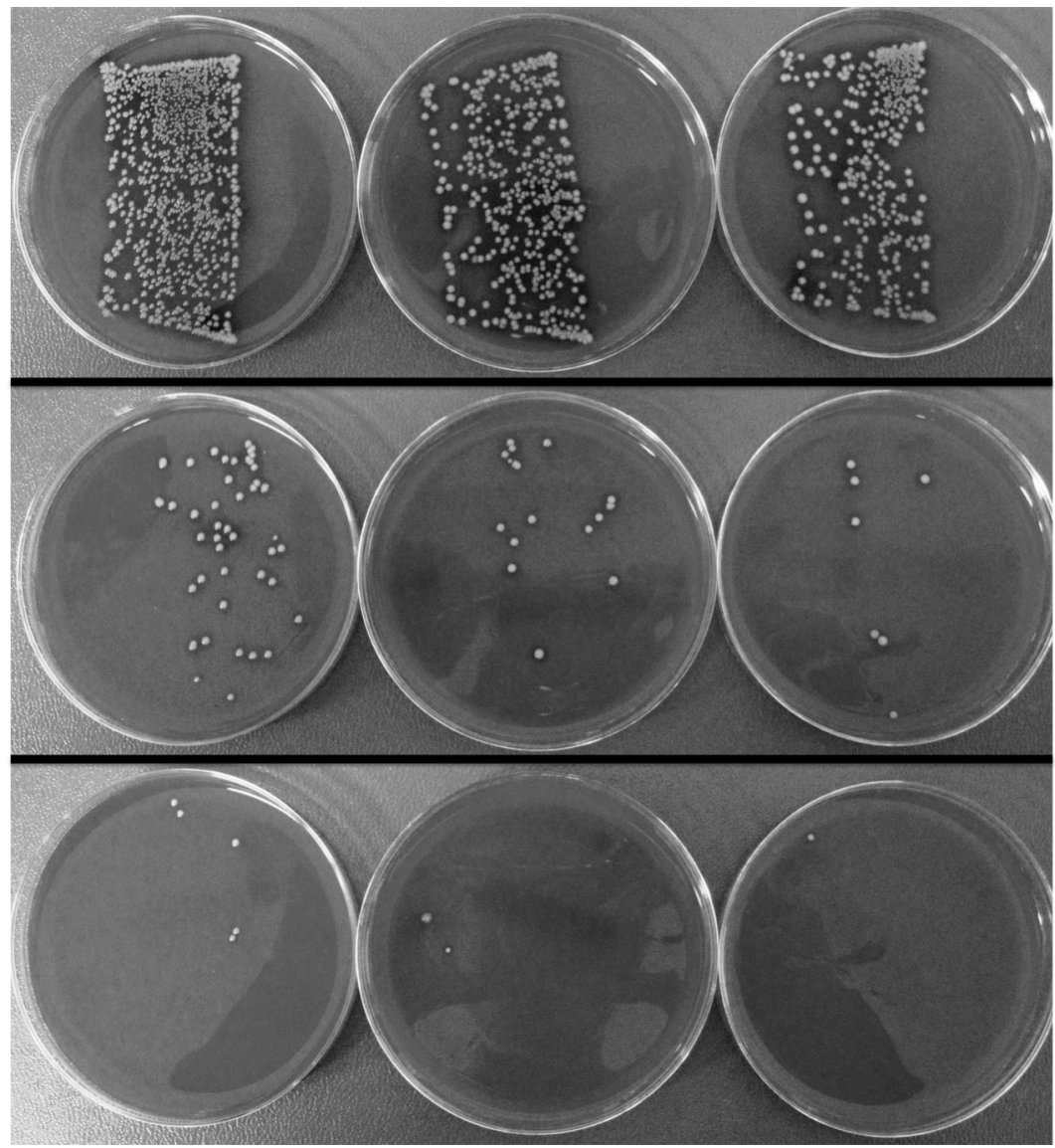

Figure 6. Agar plates used in the roll assay according to [18]. The upper row shows the bacterial colonies that formed bacteria that were transferred from the needle sample with the material Flax + Sox, to the agar. The sample was first rolled across the agar surface of the upper left plate. Then, the sample was transferred (forceps) to the middle plate, and carefully rolled across that plate. Finally, the sample was transferred to the right plate (forceps), and again rolled across the agar. Note that progressively less bacteria were transferred to the agar. Analogously, the middle row shows the three agar plates to which bacteria from the sample Flax+Sox+SS were transferred. Again, the number of transferred bacteria decreases from left to middle to right. The bottom row shows the agar plates to which bacteria from the sample Flax+Sox+SS/Ag were transferred. Almost no colonies are seen, showing that bacterial adhesion to this material is very low. For each material, five independent needles were used. 


\section{Conclusion}

Using flax in biomedical applications is both attractive and problematic. The attractive side is that flax imbibes water while its strength is maintained. This, however, is counterbalanced by the fact that flax invokes inflammatory reactions. The material is contaminated with endotoxins, which are very difficult to remove quantitatively. Now, we have shown that it is possible to apply a synthetic hydrophilic coating onto flax yarns, using a continuous reel-to-reel technique. The hydrophilic coating covers the mutilfilament fibers, leading to contraction and stiffening of the yarn, and preserves its cytocompatibility, provided that extensively Soxhlet washed fibers were used. Silver microparticles could also be embedded into the hydrophilic coating, resulting in interesting anti-microbial properties. Silver microparticles were used, but there is no doubt that other micro-or nanoparticles could be used in a similar manner.

This approach may lead to new biocompatible textiles that could be functionalised with various micro-particles depending on the properties demanded. In this aspect, we manufactured antimicrobial linen-like textiles. We anticipate that such products will be suitable for temporary use at the body's surface, such as for wound dressings. In this field, there is a clear need for materials that combine hydrophilicity (to generate a controlled moist milieu in the wound bed) and antimicrobial features (that can lower risk for infection).

\section{References}

1. Chawla P, Srivastava A R, Pandey P, Chawla V. Hydrogels: a journey from diapers to gene delivery. Mini Rev Med Chem 2014;14:154-67.

2. Tighe B J. A decade of silicone hydrogel development: surface properties, mechanical properties, and ocular compatibility. Eye Contact Lens 2013;39:4-12.

3. Guillon M. Are silicone hydrogel contact lenses more comfortable than hydrogel contact lenses? Eye Contact Lens 2013;39:86-95.

4. Kranenburg H J, Meij B P, Onis D, van der Veen A J, Saralidze K, Smolders L A, Huizinga J G, Knetsch M L, Luijten P R, Visser F, Voorhout G, Dhert W J, Hazewinkel H A, Koole L H. Design, synthesis, imaging, and biomechanics of a softness-gradient hydrogel nucleus pulposus prosthesis in a canine lumbar spine model. J Biomed Mater Res B 2012;100:2148-55.

5. Gong C, Qi T, Wei X, Qu Y, Wu Q, Luo F, Qian Z. Thermosensitive polymeric hydrogels as drug delivery systems. Curr Med Chem 2013;20:79-94.

6. Bodugoz-Senturk H, Macias C E, Kung J H, Muratoglu O K. Poly(vinyl alcohol)acrylamide hydrogels as load-bearing cartilage substitute. Biomaterials 2009;30:589-96.

7. Verret V, Ghegediban S H, Wassef M, Pelage J P, Golzarian J, Laurent A. The arterial distribution of Embozene and Embosphere microspheres in sheep kidney and uterus embolization models. J Vasc Interv Radiol 2011;22:220-8. 
8. Yang W, Bai T, Carr L R, Keefe A J, Xu J, Xue H, Irvin C A, Chen S, Wang J, Jiang S. The effect of lightly crosslinked poly(carboxybetaine) hydrogel coating on the performance of sensors in whole blood. Biomaterials 2012;33:7945-51.

9. Frith J E, Menzies D J, Cameron A R, Ghosh P, Whitehead D L, Gronthos S, Zannettino A C, Cooper-White J J. Effects of bound versus soluble pentosan polysulphate in PEG/HA-based hydrogels tailored for intervertebral disc regeneration. Biomaterials 2014;35:1150-62.

10. Strang A C, Knetsch M L, Idu M M, Bisoendial R J, Kramer G, Speijer D, Koole L H, Stroes E S, Rotmans J I. Superior in vivo compatibility of hydrophilic polymer coated prosthetic vascular grafts. J Vasc Access 2013; doi: 10.5301/jva.5000166.

11. Stammen J A, Williams S, Ku D N, Guldberg R E. Mechanical properties of a novel PVA hydrogel in shear and unconfined compression. Biomaterials 2001; 22: 799-806.

12. Michel S A A X, Vogels R R, Bouvy N D, Knetsch M L, van den Akker N M, Gijbels M J, van der Marel C, Vermeersch J, Molin D G, Koole L H. Utilization of flax fibers for biomedical applications. J Biomat Mater Res B 2014;102:477-87.

13. Bos H L, van den Oever M J, Peters O C. Tensile and compressive properties of flax fibres for natural fibre reinforced composites. Journal of Materials Science 2002;37:1683-92.

14. Baley C, Morvan C, Grohens Y. Influence of the Absorbed Water on the Tensile Strength of Flax Fibers. Macromolecular Symposia. Special Issue: Polymer-Solvent Complexes and Intercalates V 2005; 222:195-202.

15. Flax: the genus linum. Muir A D, Westcott N D, editors. CRC Press; 2003.

16. Michel S A A X, Knetsch M L, Koole L H. Adsorption of albumin on flax fibers increases endothelial cell adhesion and blood compatibility in vitro. J Biomater Sci Polym Ed 2014.

17. Tijink M, Janssen J, Timmer M, Austen J, Aldenhoff Y B, Kooman J, Koole L H, Damoiseaux J, van Oerle R, Henskens Y, Stamatialis D. Development of novel membranes for blood purification therapies based on copolymers of $\mathbf{N}$-vinylpyrrolidone and n-butylmethacrylate. J Mater Chem B 2013;1:6066-73

18. Maki D G, Weise C E, Sarafin H W. A semiquantitative culture method for identifying intravenous catheter related infections. N Engl J Med 1977;296:1305-9.

19. Stevens K N, Crespo-Biel O, van den Bosch E E, Dias A A, Knetsch M L, Aldenhoff Y B, van der Veen F H, Maessen J G, Stobberingh E E, Koole L H. The relationship between the antimicrobial effect of catheter coatings containing silver nanoparticles and the coagulation of contacting blood. Biomaterials 2009;30(22):3682-90.

20. Stevens K N, Croes S, Boersma R S, Stobberingh E E, van der Marel C, van der Veen F H, Knetsch M L, Koole L H. Hydrophilic surface coatings with embedded biocidal silver nanoparticles and sodium heparin for central venous catheters. Biomaterials 2011;32:1264-9.

21. Mihai R, Florescu I P, Coroju V, Oancea A, Lungu M. In vitro biocompatibility testing of some synthetic polymers used for the achievement of nervous conduits. J Med Life 2011;4(3):250-5.

22. Jones V, Grey J E, Harding K G. ABC of wound healing. Wound dressings. BMJ 2006;332:777-80. 
23. Seetharaman S, Natesan S, Stowers R S, Mullens C, Baer D G, Suggs L J, Christy R J. A PEGylated fibrin-based wound dressing with antimicrobial and angiogenic activity. Acta Biomater 2011;7(7):2787-96.

24. Peršin Z, Maver U, Pivec T, Maver T, Vesel A, Mozetič M, Stana-Kleinschek K. Novel cellulose based materials for safe and efficient wound treatment. Carbohydr Polym 2014;100:55-64.

25. Liu J, Sonshine D A, Shervani S, Hurt R H. Controlled release of biologically active silver from nanosilver surfaces. ACS Nano 2010;4(11):6903-13.

26. Lok C-N, Ho C-M, Chen R, He Q-Y, Yu W-Y, Sun H, Tam P K-H, Chiu J-F, Che CM. Silver nanoparticles: partial oxidation and antibacterial activities.J Biol Inorg Chem 2007;12:527-34.

27. Kim Y-J, Yang S I, Ryu J-C. Cytotoxicity and genotoxicity of nano-silver in mammalian cell lines. Mol Cell Toxicol 2010;6:119-25.

28. AshaRani P V, Low Kah Mun G, Hande M P, Valiyaveettil S. Cytotoxicity and genotoxicity of silver nanoparticles in human cells. ACS Nano 2009;3(2):279-90.

29. Islam M S, Larimer C, Ojha A, Nettleship I. Antimycobacterial efficacy of silver nanoparticles as deposited on porous membrane filters. Mater Sci Eng C Mater Biol Appl 2013;33(8):4575-81.

30. Croes S, Stobberingh E E, Stevens K N J, Knetsch M L W, Koole L H. Antimicrobial and Anti-Thrombogenic Features Combined in Hydrophilic Surface Coatings for SkinPenetrating Catheters. Synergy of Co-embedded Silver Particles and Heparin. ACS Appl Mater Interfaces 2011;3:2543-50. 



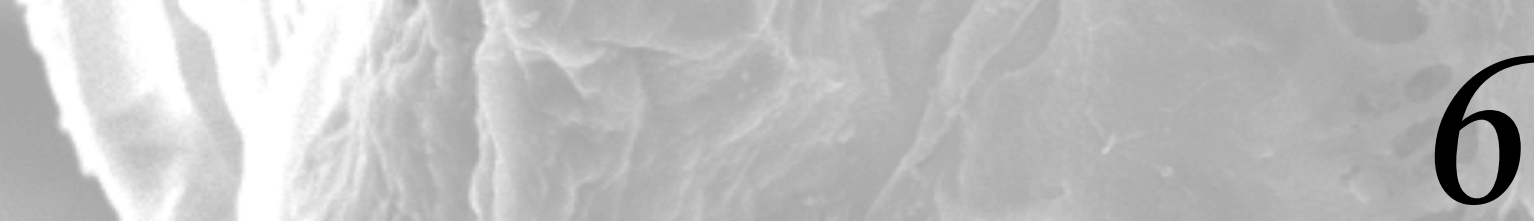

GeneralDiscussion 
The use of plastics for implantable devices was clearly a milestone in the biomedical history. It all started with the discovery from Harold Ridley that shards of poly(methylmethacrylate) coming out from fighters were highly biocompatible to the eye of second World War aviators [1]. This finding led to the commercialization of plastic lenses to replace cataracts in 1949. Since this time, the utilization of plastics to manufacture implants has incredibly increased. This is mostly due to the fact that a huge diversity of plastics can be manufactured, with different mechanical properties, biocompatibility or biodegradability levels. For example, hernia repair procedures or blood vessel replacement are mostly performed with implants made out of polypropylene (Prolene ${ }^{\circledR}$ or Parietene ${ }^{\circledR}$ mesh) or polyester (Mersilene ${ }^{\circledR}$ mesh, Dacron ${ }^{\circledR}$ tubes) $[2,3]$. These materials are hydrophobic and non-biodegradable in vivo. Moreover, they possess mechanical properties and degrees of flexibility that makes them interesting for such applications: i.e. by playing on the design, implants with characteristics closed to the abdominal wall or blood vessels can be manufactured [4-7]. On the contrary, hydrogel materials, commonly used to cure wound dressings, are hydrophilic materials which can maintain a moist atmosphere at the wound site [8]. They can be designed so to be biodegradable, especially if some drug release should take place [9]. Yet, although the utilization of plastics brought substantial improvements as compared to previously used materials, they are not free from several disadvantages. Hence, polypropylene meshes might lead to several complications, as inflammatory response or adhesion with the bowel, which might cause chronic pain [10]. Similarly, Dacron ${ }^{\circledR}$ or ePTFE $^{\circledR}$ prosthesis cannot be used to replace blood vessels of less than $6 \mathrm{~mm}$ [11].

In the recent years, there has been a great interest in bio-based materials. It was supposed that such materials would better mimic the internal tissue structure of the body, and so perform better. Indeed, biological materials are more biocompatible than their synthetic counterparts and they are biodegradable, meaning that they favor remodeling and facilitate a future surgery in case of recurrence [12-14]. Nevertheless, in case of hernia surgery, their use is limited to complex situations due to their elevated price (synthetic meshes cost between 0.2 to $1.0 \$ / \mathrm{cm}^{2}$; biological meshes cost between 8.6 to $\left.26.0 \$ / \mathrm{cm}^{2}\right)$ [13,14]. Bio-based artificial blood vessels are not available on the market up to now, but it can be expected that prices will be even more elevated, as the current tendency is to first seed autologous endothelial cells on the luminal surface of the prosthesis before implantation in vivo [15].

Considering these different aspects, it could be interesting to also include plant fibers in the search for the ideal prosthesis. In particular, we decided to focus on flax fibers. From a biomedical point of view, flax fibers are interesting 
since they are mostly composed of cellulose, whose biocompatibility is well assessed in vivo $[16,17]$. They are low dense with high mechanical properties (Young's modulus of $58 \mathrm{GPa}$ on average; no plastic behavior), meaning that implants manufactured out of them should not easily deform once inside the body [18]. Because flax fibers are already used since centuries in the textile industry, huge knowledge on the weaving/knitting of such fibers is available. In particular, it is possible to tailor-made the textile fabric so to meet the implant specifications. For example, in hernia surgery, the lack of elasticity inherently present in flax fibers could be compensated by choosing the right design to approach the natural elasticity level of the abdominal wall $(38 \%$ at $32 \mathrm{~N} / \mathrm{cm}$ ) [12]. Flax fibers being rather long $(300-600 \mathrm{~mm})$, we also expect such implants to be stable in vivo (i.e. they should not fall apart as a result of the immune response) [19]. Finally, flax fibers are hollow structure whose lumens could be used as reservoirs for drugs or active molecules to be slowly released in situ. The use of flax fibers to manufacture new kind of chirurgical implants would also be appealing from an environmental point of view. Indeed, concerns about the environment protection are becoming more and more important and western societies are now promoting the use of sustainable materials of biological origin [9,20-22]. In this aspect, flax fibers are interesting because there are nonexpensive, recyclable, renewable and biodegradable [22-25]. Moreover, their environment impact is minimal (its culture need few water) and they can be organically grown [22].

The study presented in this thesis is investigating a completely new area of research. Indeed, at the beginning of the project, only one paper investigating the biocompatibility of pure flax fibers in vitro and in vivo could be found [26]. Quickly, the main problem appeared to be the huge amount of endotoxins present on the fibers (Chapter 2). Although such a contamination can be easily explained by the retting process which widely involves bacterial fermentation [27], people were generally more surprised that endotoxins could still be found on flax fibers after all the chemical treatments they had been through. First, directly after retting, flax plant is threshed, meaning that retted stems are broken down so to separate flax fibers from them. Logically, an appreciable amount of bacteria (and so endotoxins) are still present on the surface of the fibers after this step. Then, flax fibers are hackled, combined into threads, and bleached. Back to our laboratory, flax threads are also steam sterilized. Some reviewers were especially surprised that the combination of bleaching and steam sterilization processes was not sufficient enough to remove endotoxins. Surely such treatments kill bacteria. However, and unfortunately for us, endotoxins - which are the pyrogenic part of gram-negative bacteria - are extremely stable and can 
only be destroyed by a thermal treatment at $250{ }^{\circ} \mathrm{C}$ for more than $30 \mathrm{~min}$, or $180^{\circ} \mathrm{C}$ for more than $3 \mathrm{~h}$ [28]. Flax, being mostly composed of cellulose, cannot withstand such treatments. From another angle, bleaching and steam sterilization steps are not strong enough to remove endotoxins.

Alternatives to heat-deactivation treatment can be found in literature [28]. However, it was a hard task to find a green chemical process that would maintain flax fibers mechanical properties (i.e. basic treatments could not be done as they lead to pure cellulose II with poor mechanical properties) [29,30]. In Chapter 2, we designed a tandem Soxhlet treatment build on bio-based solvents to purify the fibers. First treatment with $5 \% \mathrm{v} / \mathrm{v}$ acetic acid and $10 \%$ wt $\mathrm{NaCl}$ in water aimed at suppressing the in vitro toxicity of flax. Second treatment with $75 \%$ ethanol in water set at removing adhered endotoxins. By using these solvents, we were able to keep "green" fibers presenting a minimal environmental impact. Combination of these two Soxhlet treatments succeeded at removing most of the endotoxins. This was demonstrated by the LAL test and XPS analysis, which corroborated nicely. Interestingly, we were the first one to prove that it is feasible to use the XPS analysis to detect the presence of endotoxins on a surface. This technique was especially appropriate with flax, as endotoxin molecule contain $\mathrm{C}$-C bounds which are absent from cellulosic materials $[28,31,32]$.

In vivo analysis proved that the tandem Soxhlet treatment we designed led to a significantly better immune response as compared to untreated flax fibers. However, the level of biocompatibility achieved was not satisfactory enough, probably due to the presence of some residual and unextractable endotoxins. Giant cells could be found around the flax bundles and some necrosis was also present inside the flax threads, which should be considered as the main issue. When I was in Boston, one participant pointed out to me that meshes should provoke some inflammatory response in vivo so to accelerate their integration in the body. Although this argument is right [33], we are here clearly above the acceptable immune response, particularly due to the presence of necrosis inside the bundles which can only go worse with the time going. Two solutions could be found to reduce the inflammatory response in vivo:

1. Flax threads can be coated with "green" bio-based materials to cover the endotoxins.

2. The diameter of the yarns can also be reduced. Likely, this would decrease the amount of necrosis inside the flax bundles. Concerning hernia surgery, meshes with a more open design should also be manufactured.

We hypothesized that the answer to the endotoxin problem would be probably found by combining these two parameters. 
Parameter 1 was further investigated in Chapters 3 and 4. We first chose to coat the threads with polydopamine (pDA). Dopamine is a natural compound, and it has been shown in 2007 that it could spontaneously polymerize on various surfaces once polymerisation medium buffered at $\mathrm{pH}=8.5$ [34]. Moreover, functionnalisation with polydopamine is generally considered as a kind of green chemistry, as it can be done under mild reaction conditions and does not necessitate the use of toxic-solvents [35,36]. Unfortunately, the presence of a pDA coating on Soxhlet flax yarns led to an increased inflammatory response in vitro, which precluded its utilisation as a cover for adherent endotoxins (Chapter 3). Nevertheless, we could observe that the presence of a secondary albumin coating on top of the pDA one was really efficient at removing the in vitro immunotoxicity of pDA coated threads. Even, the immunogenicity after albumin coating was lower than the one of uncoated Soxhlet flax yarns. Such a result bewildered us, and we decided to directly coat the Soxhlet treated threads with albumin in a new study, i.e. the polydopamine layer which served as an intermediate between flax yarns and albumin in Chapter 3 was removed in Chapter 4.

First, we observed that the presence of an albumin coating decreased the amount of surface-activated endotoxins, with $27 \%$ less endotoxins being detectable in vitro. Other results showed this albumin coating also promoted cell adhesion and increased blood compatibility, encouraging its utilisation to design new kind of blood vessel replacement. The effect of the presence of an albumin coating on flax yarns immunotoxicity was further investigated in vivo, along with the influence of fiber size on the tissue reaction. Some improvements could be obtained by reducing flax threads diameter and addition of an albumin coating, but it was still not satisfactory enough to permit standard use in surgery and commercialization.

Considering that it might be extremely hard to find a green compound that can effectively coat the endotoxins present on flax fibers, we took a different approach. In the last chapter of this book (Chapter 5), we decided to cover the threads with a polymeric mixture of BMA and NVP (Slipskin coating). This can look as a conflicting approach, as it definitely generates a non-green product. However, we believe that it was probably the only way to get rid of the endotoxin problem. A hydrophilic coating (50\% BMA, $50 \%$ NVP) could be easily applied on Soxhlet flax yarns and it transformed the multifilament threads to almost monofilament ones. The coating was non-toxic to cells, and silver nanoparticles could be effectively embedded in it, resulting in high antimicrobial properties. Nevertheless, more work is necessary, especially in order to optimize the coating parameters (e.g. analysis of the ideal thickness of the coating and 
ratios of monomers, determination of the hydrophilicity, study of the permeability to air, fluids, bacteria, heat,... )

At the onset of this thesis, it was impossible to predict that flax fibers biocompatibility in vivo would be so hard to achieve. Looking backwards, the only approach that seems satisfying is to cover the flax yarn with a polymeric coating (Slipskin 50/50). Of course, the resulting material could neither be used for applications inside the body, nor for permanent implants, since any damages to the coating would lead to the exposure of surface-adherent endotoxins. However, it can certainly be of interest for the manufacturing of new kinds of wound dressings, as hydrophilic gauzes possessing antibacterial properties are scarcely available on the market.

Most of the problems encountered during my $\mathrm{PhD}$ were due to the presence of endotoxins on flax. If we were able to step over the retting stage, biocompatibility of flax fibers in vivo would be probably improved, maybe even reaching the one of bacterial cellulose. Currently, retting stage is performed either by dew-retting (flax plants are laid in fields), or by water retting (plants are immersed in water) $[37,38]$. Both techniques widely involve bacteria. Some groups investigate new retting methods. Notably, enzyme retting was developed in the nineties and led to the commercialization of many products as Flaxzyme, which was composed of pectinases, hemicellulases and cellulases [39]. Nevertheless, the elevated price and non-reusability of the enzymes precluded the utilization of this retting method at an industrial scale $[39,40]$. Very recently, a microwave-assisted retting method was developed $[38,40]$. It rests on the fact that flax plants do not absorb water in the same way: i.e. regios outside flax fibers are more hydrophilic than flax fibers themselves. When submitted to a microwave energy, water dipoles will strongly rotate, leading to local heating and degradation of the pectin matrix keeping the fibers together [40]. Although this retting technique looks promising, much more work is necessary to assess the impact of this technique on the fibers and define its adaptability at an industrial scale.

Thanks to the dynamic research of some R\&D groups and to the desire of industrial companies to develop a reproducible and cheap retting method, we are confident that new retting techniques will appear in the coming years. Most likely, this will also revitalize the research on the utility of flax fibers for biomedical applications. 


\section{References}

1. Burns J W. Biology takes centre stage. Nature Mater 2009;8:441-3.

2. Brown C N, Finch J G. Which mesh for hernia repair? Ann R Coll Surg Engl 2010;92:272-8.

3. Ku D N, Allen R C. Vascular grafts. In: Bronzimo J D. The biomedical engineering handbook: $2^{\text {nd }}$ edition. CRC Press. 2000.

4. Afonso J S, Jorge R M N, Martins P S, Soldi M Da S, Alves O L, Patricio B, Mascarenhas T, Sartori M G F, Girao M J B C. Structural and thermal properties of polypropylene mesh used in treatment of stress urinary incontinence. Acta Bioeng Biomech 2009;11(3):27-33.

5. Deeken C R, Abdo M S, Frisella M M, Matthews B D. Physicomechanical Evaluation of Polypropylene, Polyester, and Polytetrafluoroethylene Meshes for Inguinal Hernia Repair. J Am Coll Surg 2011;212(1):68-79.

6. Chlupác J, Filová E, Bacáková L. Blood Vessel Replacement: 50 years of Development and Tissue Engineering Paradigms in Vascular Surgery. Physiol Res 2009;58:S1 19-39.

7. Nerem R M, Braddon L G, Seliktar D. Tissue Engineering and the cardiovascular system. In: Patrick Jr C W, Mikos A G, McIntire L V. Frontiers in tissue engineering. Elsevier Science Ltd. 1998:561-79.

8. Jones V, Grey J E, Harding K G. ABC of wound healing. Wound dressings. BMJ 2006;332:777-80.

9. Rao M K, Rao K K S V, Ramanjaneyulu G, Rao C K, Subha M C S, Ha C-S. Biodegradable sodium alginate based semi-interpenetrating polymer network hydrogels for antibacterial application. J Biomed Mater Res Part A 2014; doi: 10.1002/jbm.a.34991

10. Burger J W A, Halm J A, Wijsmuller A R, ten Raa S, Jeekel J. Evaluation of new prosthetic meshes for ventral hernia repair. Surg Endosc 2006;20:1320-5.

11. Zhang W J, Liu W, Cui L, Cao Yilin. Tissue engineering of blood vessel. J Cell Mol Med 2007;11(5):945-57.

12. Brown CN, Finch JG. Which mesh for hernia repair? Ann R Coll Engl 2010;92:272-8.

13. Smart N J, Marshall M, Daniels I R. Biological meshes: a review of their use in abdominal wall hernia repairs. Surgeon 2012;10:159-71.

14. Shankaran V, Weber D J, Reed R L, Luchette F A. A review of available prosthetics for ventral hernia repair. Ann Surg 2011;253:16-26.

15. Heyligers J M, Arts C H, Verhagen H J, de Groot P G, Mool F L. Improving smalldiameter vascular grafts: from the application of an endothelial cell lining to the construction of a tissue-engineered blood vessel. Ann Vasc Surg 2005;19(3):448-56.

16. Wippermann J, Schumann D, Klemm D, Kosmehl H, Salehi-Gelani S, Wahlers T. Preliminary results of small arterial substitute performed with a new cylindrical biomaterial composed of bacterial cellulose. Eur J Endovasc Surg 2009;37:592-6.

17. Helenius G, Bäckdahl H, Bodin A, Nannmark U, Gatenholm P, Risberg B. In vivo biocompatibility of bacterial cellulose. J Biomed Mater Res A 2006;76(2):431-8.

18. Baley C. Fibres naturelles de renfort pour matériaux composites. Technique de l'Ingénieur. Reference number: N2220

19. Ghosh P. Natural fibres. In: Ghosh P, editor. Fibre Science and technology. Tata McGraw-Hill Education. 2003:36-102. 
20. Elsabee MZ, Abdou ES. Chitosan Based Edible Films and Coatings: A Review. Mater Sci Eng C 2013;33:1819-41.

21. Fernandes EM, Pires RA, Mano JF, Reis RL. Bionanocomposites from lignocellulosic resources: Properties, applications and future trends for their use in the biomedical field. Prog Polym Sci 2013;38:1415-41.

22. Lefeuvre A, Bourmaud A, Lebrun L, Morvan C, Baley C. A study of the yearly reproducibility of flax fiber tensile properties. Ind Crops Prod 2013;50:400-7.

23. Yan L, Chouw N, Jayaraman K. Flax fibre and its composites - a review. Composites Part B 2014;56:296-317.

24. Bismarck A, Aranberri-Askargorta I, Springer J. Surface characterization of flax, hemp and cellulose fibers; surface properties and the water uptake behavior. Polym composites 2002;23(5):872-94.

25. Baley C. Analysis of the flax fibres tensile behavior and analysis of the tensile stiffness increase. Compos Part A-Appl S 2002;33:939-48.

26. Vavřik J, Foltýnová V, Vítková I, Adámek S, Poučková P. Changes in abdominal wall after mesh implantation in rats. Med Sci Monit 2000;6(3):476-9.

27. Martin N, Mouret N, Davies P, Baley C. Influence of the degree of retting of flax fibers on the tensile properties of single fibers and short fiber/polypropylene composites. Ind crops prod 2013;49:755-67.

28. Gorbet M B, Sefton M V. Endotoxin: the uninvited guest. Biomaterials 2005;26:68117.

29. Raj G, Balnois E, Baley C, Grohens Y. Role of polysaccharides on mechanical and adhesion properties of flax fibres in flax/PLA biocomposites. Int J of Polym Sci 2011, Article ID 503940

30. Arbelaiz A, Cantero G, Fernandez B, Mondragon I. Flax fiber surface modifications: effects on fiber physic mechanical and flax/polypropylene interface properties. Polymer Compos 2005;26(3):324-32

31. Zafeiropoulos N E, Watts J F. An experimental investigation of modified and unmodified flax fibres with XPS, ToF-SIMS and ATR-FTIR. J of Mater Sci 2003;38:3903-14.

32. Johansson L S, Campbell J M. Reproducible XPS on biopolymers: cellulose studies. Surf Interface Anal 2004;36:1018-22.

33. Penttinen R, Grönroos J M. Mesh repair of common abdominal hernias: a review on experimental and clinical studies. Hernia 2008;12:337-344.

34. Lee H, Dellatore SM, Miller WM, Messersmith PB. Mussel-inspired surface chemistry for multifunctional coatings. Science 2007;318:426-30.

35. Tsai WB, Chen WT, Chien HW, Kuo WH, Wang MJ. Poly(dopamine) coating of scaffolds for articular cartilage tissue engineering. Acta Biomater 2011;7(12):4187-94.

36. Sureshkumar M, Siswanto DY, Lee C-K. Magnetic antimicrobial nanocomposite based on bacterial cellulose and silver nanoparticles. J Mater Chem 2010;20:6948-55.

37. Evans J D, Akin D E, Foulk J A. Flax-retting by polygalacturonase-containing enzyme mixtures and effects on fiber properties. J Biotechnol 2002;97:223-31. 
38. Nair G R, Kurian J, Yaylayan V, Rho D, Lyew D, Raghavan G S V. Microwave-assisted retting and optimization of the process through chemical composition analysis. Ind Crops Prod 2014;52:85-94.

39. Akin D E, Foulk J A, Dodd R B, McAlister III D D. Enzyme-retting of flax and characterization of processed fibers. J Biotechnol 2001;89:193-203.

40. Nair G R, Rho D, Yaylayan V, Raghavan V. Microwave assisted retting - A novel method of processing of flax stems. Biosyst Eng 2013;116:427-35. 

Summary

Samenvatting

Résumé 


\section{Summary}

Although plastics led to important breakthroughs in the biomedical field, their use is not free from several complications and limitations. As an example, polypropylene (PP), which is the standard material to manufacture hernia repair meshes, is used since the end of the fifties and can lead to several problems in vivo as adherence to the bowels or chronic inflammation and pain. Likewise, Dacron ${ }^{\circledR}$ artificial vascular grafts cannot be used to replace blood vessels of less than $6 \mathrm{~mm}$. To solve such problems, several groups investigated the use of biobased materials, as bovine or porcine cross-linked and decellularized skin. Results were promising and led to the commercialization of these materials for hernia surgery. However, due to their elevated price (synthetic meshes cost between 0.2 to $1.0 \$ / \mathrm{cm}^{2}$; biological meshes cost between 8.6 to $26.0 \$ / \mathrm{cm}^{2}$ ), their use is restricted to complicated situations only. Up to date, bio-based vascular grafts are still not available on the market.

In this thesis, we investigated whether plant fibers, and especially flax fibers, could represent a new class of bio-based biomaterials. Flax fibers are mostly composed of cellulose, which is well known to be biocompatible in vivo. They are low-dense (i.e. considered as light materials) and they possess good mechanical properties (i.e. a high young's modulus of $58 \mathrm{GPa}$ on average without any plastic behavior), meaning that any implant manufactured out of them should not easily deform once implanted. Finally, they are hollow structures. Their lumen could be used to stock bio-active molecules that could be later released in vivo. From an environmental point of view, flax fibers are also interesting compounds, since they are recyclable, biodegradable, renewable and cheap. In addition to this, their growing has a minimal impact on the environment and they can be organically grown.

We supposed flax fibers would be especially interesting as biomedical textiles. Flax fibers are rather long, and there is an extensive knowledge on their weaving/knitting. It means that a textile fabric can be easily adapted to implant specifications and that the resulting material should be stable in vivo. We first assessed the potential of hernia meshes manufactured out of flax fibers (Chapter 2). Bleached flax fibers as received from our supplier could be easily knitted into a mesh. However, this mesh exhibited cytotoxicity in vitro and once implanted subcutaneously in rats for 7 days, it led to a severe inflammatory reaction with huge amount of necrosis inside and in between the flax bundles. We supposed this was due to the presence of endotoxins on the flax threads. Indeed, the retting process necessary to obtain flax fibers widely involves bacteria. To solve 
this problem, we designed a purification treatment using a Soxhlet device and built on bio-based solvents only. This allowed us to keep at the end of the process fibers presenting a minimal environmental impact. Cytocompatibility was achieved in vitro; XPS and LAL analyses confirmed that this treatment removed more than $85 \%$ of the endotoxins. In vivo analysis was repeated with the Soxhlet treated mesh and indeed, it led to a much improved inflammatory response: a mild inflammation was observed around the flax bundles, similarly to what was observed with our PP control mesh. Nevertheless, some necrosis could still be observed inside the flax bundles. We assumed that this necrosis issue could be solved by combining two different techniques. First, flax fibers could be covered by a bio-based coating to hide the endotoxins; secondly, the diameter of the thread could be reduced until no necrosis can be seen inside the flax bundles. In particular, it is well known that the inflammatory reaction can be reduced by decreasing the yarn size. This hypothesis was further checked in Chapter $3 \& 4$.

In Chapter 3, flax fibers were coated with polydopamine (pDA). Polymerisation of dopamine on a material occurs spontaneously when $\mathrm{pH}$ is buffered at 8.5, and it is generally considered as a kind of green chemistry. Moreover, in previous reports, once coated on hydrophobic substrates, pDA led to a marked increased cell adhesion. Our experiments showed results in high contradictions with previous articles, probably due to the hydrophilic nature of flax fibers. After pDA coating, Soxhlet treated flax threads needed to be extensively washed to be cytocompatible in vitro again, and cell adhesion using fibroblast and endothelial cells showed no improvement. Finally, pDA coated flax fibers exhibited a high immunogenicity in vitro. This is most probably due to the presence of some non-polymerised dopamine molecules into the flax fibers. Immediately after the beginning of the coating process, hydrophilic flax fibers might absorb dopamine molecules which get entrapped inside them and cannot easily nor polymerize, nor be removed by washing. This hypothesis is further supported by the fact that dopamine is widely recognized as a pro-inflammatory compound in vitro and in vivo. All in all, such results disqualify using pDA as a coating for flax fibers.

An alternative could be to use albumin as a coating (Chapter 4). In Chapter 3, we observed that when albumin was coated on top of pDA coated flax fibers, a markedly reduced immunogenicity was obtained as compared to pDA coated fibers only. This urged us to examine the potential of albumin as a direct coating for flax fibers (i.e. no pDA coating was present as an intermediate anymore in Chapter 4). Results showed that the presence of albumin covered approximately $27 \%$ of the endotoxins and increased endothelial cell adhesion in 
vitro. Moreover, the presence of albumin also improved blood compatibility with delayed thrombogenicity and less platelets activation. This could be interesting for blood contacting devices as artificial vascular tubes. Nevertheless, in vivo results were mixed. They proved that the inflammatory reaction could be indeed reduced by decreasing thread diameter or adding albumin, i.e. necrosis could be suppressed by choosing the right conditions. However, in all conditions tested, inflammatory cells seemed to pull away the individual flax fibers, suggesting that the implant will loose its physical integrity over a longer time scale. Such a result might be caused by the remaining endotoxins which could not be covered by the albumin coating.

Considering that it may be extremely hard to efficiently cover all the endotoxins with a green bio-based coating, we took a new approach. In Chapter 5, flax threads were covered with a hydrophilic SlipSkin ${ }^{\circledR}$ coating composed of 50 $\%$ BMA and $50 \%$ NVP. Although this can look as a conflicting approach at first (it definitely suppresses the green character of our fibers), we strongly believe it was the only path that could be taken to cover the endotoxins. The SlipSkin ${ }^{\circledR}$ coating could be easily applied on the flax thread, transforming the irregular multifilament yarn into a uniform monofilament one. Moreover, the coated thread was cytocompatible in vitro, provided that a Soxhlet treated yarn was used. Finally, silver micro-particles could be easily embedded in the coating, resulting in a grey thread displaying high anti-bacterial properties. In this chapter, silver micro-particles were selected for their bactericidal properties, but there is no doubt that other micro/nano particles could also be embedded in the coating depending on the desired material properties. Of course the resulting material would not be implanted inside the body, as any scratching of the coating might led to the exposure of surface-adherent endotoxins. SlipSkin ${ }^{\circledR}$ coated flax threads with silver embedded in them could be useful as wound dressings considering that there is a need for gauzes that possess hydrophilic and antibacterial properties. 


\section{Samenvatting}

In sommige chirurgische toepassingen gaat het gebruik van kunststoffen nog steeds gepaard met complicaties en beperkingen. Polypropyleen (PP) textielen, bijvoorbeeld, worden al sinds de jaren 1950 gebruikt voor het herstel van buikwand hernia's. Niettemin treden complicaties zoals infecties, chronische ontsteking of verkleving aan organen in de buikwand nog steeds op in de alledaagse klinische praktijk. Een ander voorbeeld vormen kunststof (Dacron ${ }^{\mathbb{B}}$ ) bloedvat prothesen. Deze kunnen niet toegepast worden voor het vervangen van bloedvaten met een diameter minder dan $6 \mathrm{~mm}$. Om de geschetste problemen met PP bij herstel operaties van buikwand hernia's op te lossen, wordt veel aandacht besteed aan alternatieve materialen met een biologische oorsprong. Hierbij is vooral gewerkt aan gedecellulariseerde varkens- of runderhuid. Hiermee werden goede resultaten verkregen, en dit heeft geleid tot nieuwe producten ten behoeve van buikwand hernia operaties. Door de hogere prijs van deze producten (synthetische gaasjes kosten tussen 0.2 tot $1.0 \$ / \mathrm{cm}^{2}$; gaasjes van biologische oorsprong kosten tussen 8.6 tot $26.0 \$ / \mathrm{cm}^{2}$ ) is het gebruik ervan beperkt tot ingewikkelde situaties. Tot op de dag van vandaag zijn vaatprothesen op basis van biologische materialen niet beschikbaar.

In dit proefschrift werd onderzocht of plantaardige vezels, vlasvezels in het bijzonder, gebuikt kunnen worden als een nieuwe klasse van biologische gebaseerde goedkope biomaterialen. Vlasvezels zijn vooral samengesteld uit cellulose, hetgeen leidde tot de verwachting a priori, dat dit materiaal een hoge mate van biocompatibiliteit zal bezitten. Vlas heeft een lage dichtheid, en tegelijkertijd goede mechanische eigenschappen (d.w.z. een hoge elasticiteitsmodulus van gemiddeld $58 \mathrm{GPa}$ zonder plastisch verloop). Dit zorgt ervoor dat een vlas-textiel niet gemakkelijk zal vervormen na het implanteren. Verder is het interessant dat de filamenten in de vlasvezel een holle structuur bezitten. Het lumen kan gebruikt kan worden voor het opslaan van bioactieve moleculen die later in vivo afgestaan kunnen worden. Hierbij kan gedacht worden aan antibiotica. Ook bezien vanuit een milieuoogpunt, is vlas erg interessant. Het materiaal is recyclebaar en bio-afbreekbaar en het heeft een negatieve " $\mathrm{CO}_{2}$ footprint".

De belangrijkste hypothese van dit proefschrift is dat vlas interessant zal zijn in de vorm van biomedisch textiel. Vlasvezels zijn lang (rond $50 \mathrm{~cm}$ ) en er is een uitgebreide kennis op het gebied van het weven/breien hiervan. Er kan een enorme variatie aan twee- en driedimensionale structuren worden gefabriceerd. We hebben als eerst het potentieel van vlasvezels als hernia reparatie gaasjes bestudeerd. (Hoofdstuk 2). Gebleekte vlas vezels, zoals verkregen van onze 
leverancier, kunnen gemakkelijk tot een een gaasje worden gewoven. Vervolgens is vastgesteld dat deze gaasjes sterk cytotoxisch zijn. Ook bij subcutane implantatie (rattenmodel) wordt na 7 dagen een ernstige ontstekingsreactie waargenomen met necrose rond en binnenin de vlasbundels. We veronderstellen dat dit komt door de anwezigheid van endotoxines op de vlas draden. De aanwezigheid van endotoxines is heel goed verklaarbaar, aangezien bacteriën een essentiële rol spelen bij het vrijmaken van de vlasvezel uit de stengel van de plant. Om dit probleem op te lossen hebben we een Soxhlet zuiveringsbehandeling toegepast waarbij alleen "groene" oplosmiddelen zijn gebruikt (ethanol, azijnzuur). Dit zorgt ervoor dat aan het eind van het proces vezels verkregen worden met een minimale belading aan endotoxines. Bevredigende cytocompatibliteit kon bereikt worden (in vitro en in vivo). Andere technieken zoals XPS en LAL analyse bevestigden dat deze behandeling meer dan $85 \%$ van de endotoxines verwijderde. Hernieuwde dierexperimenten met herhaald met de Soxhlet behandelde gaasjes lieten een sterk verminderde ontstekingsrespons zien. Milde ontsteking rond de vlas bundel werd nog wel waargenomen; het histologisch beeld was vergelijkbaar met waarnemingen die werden gedaan met PP controle gaasjes. Toch werd ook nog necrose gevonden, in het bijzonder binnen de vlas bundels. Naar alle waarschijnlijkheid zal dit probleem opgelost kunnen worden via verschillende benaderingen technieken. Vlasvezels kunnen bedekt worden met een coating om de endotoxines te bedekken. Ook kan de diameter van vlasdraden verminderd worden. Onderzoek naar deze benaderingen is beschreven in de Hoofdstukken 3 en 4 .

In Hoofdstuk 3 worden vlasvezels bedekt met polydopamine (pDA). Polymerisatie van dopamine op een materiaal vindt spontaan plaats als de $\mathrm{pH}$ is gebufferd op 8.5. Dit proces wordt in het algemeen gezien als "groene" chemie. Het is bekend dat een coating van pDA op een hydrofobe ondergrond leidt dit tot een duidelijke toename van cel adhesie. Onze experimenten lieten grote contradicties zien vergeleken met literatuur gegevens, waarschijnlijk door de hydrofiele aard van vlas. Na de pDA coating moesten de Soxhlet behandelde vlas vezels uitvoerig gewassen worden om opnieuw cytocompatibel in vitro te worden. Experimenten waarbij werd gekeken naar adhesie van fibroblasten en endotheel cellen lieten geen verbetering zien. Ook vertoonde pDA gecoate vlas vezels een hoge mate van immunogeniciteit in vitro. Dit komt waarschijnlijk door de aanwezigheid van niet-gepolymeriseerde dopamine moleculen binnenin de vlas vezels. Onmiddellijk na de start van het coating proces zal het hydrofiele vlas dopamine absorberen. De monomeren kunnen daardoor niet makkelijk deelnemen aan de polymerisatie reactie, en ze zullen ook niet gemakkelijk uitgewassen worden. Deze hypothese is verder ondersteund door het feit dat 
dopamine een pro-inflammatoire stof is. Al met al maken de resultaten duidelijk dat pDA coatings niet toegepast kunnen worden ter verbetering van de cytocompatibiliteit van vlas.

Het gebruik van albumine als coating biedt een alternatieve weg (Hoofdstuk 4). Eerdere experimenten (Hoofdstuk 3) hadden al aangetoond dat een albumine coating "bovenop" pDA leidt tot duidelijk verminderde immunogeniciteit. Dit zette ons aan tot het onderzoeken van albumine op zijn bruikbaarheid als biocompatibele coating voor vlas. Onze resultaten laten zien dat de aanwezigheid van albumine ongeveer $27 \%$ van de endotoxines bedekt. Adhesie van endotheel cellen in vitro wordt daardoor versterkt. Ook verbeterde de bloed compatibiliteit: parameters als thrombogeniciteit en de neiging van bloedplaatjes om te hechten aan het materiaal werden kleiner. Dit principe kan zeer interessant worden voor medische hulpmiddelen die met bloed in aanraking komen, zoals catheters en kunstmatige bloedvat prothesen. Er is nog veel werk te verrichten op dit gebied, zoals blijkt uit onze eerste in vivo experimenten. Deze lieten zien dat ontstekingsreacties en necrose inderdaad gereduceerd worden door het toepassen van albumine als coating.

Hoofdstuk 5 beschrijft een meer rigoreuze methode om alle endotoxines op vlasvezels te bedekken. Met een nieuwe continue reel-to-reel techniek werd vlas werd bedekt met een hydrofiele SlipSkin ${ }^{\circledR}$ coating, samengesteld uit $50 \%$ BMA en $50 \%$ NVP. Hoewel deze aanpak in eerste instantie tegenstrijdig lijkt (SlipSkin $^{\circledR}$ is immers een synthetisch hydrogel materiaal), geloven we er ten zeerste in dat dit de enige weg is om de endotoxines te bedekken. SlipSkin ${ }^{\circledR}$ kon gemakkelijk en goed gecontroleerd worden aangebracht op de vlas vezel. Hierdoor wordt de multi-filament vezel getransformeerd in een min of meer uniform monofilament draad. De gecoate draad was cytocompatibel in vitro, wanneer werd uitgegaan van Soxhlet behandelde draad was gebruikt. Ten slotte is gevonden dat zilver microdeeltjes makkelijk ingebed worden in de SlipSkin ${ }^{\circledR}$ coating. Dit resulteert in een grijze draad. Deze SlipSkin ${ }^{\circledR} /$ zilver coating heeft interessante antimicrobiële eigenschappen. Ongetwijfeld zouden ook andere micro- en nanodeeltjes in de coating opgenomen kunnen worden. Het resulterende materiaal is niet geschikt voor permanente implantatie. Een eventuele beschadiging van de coating zou dan kunnen leiden tot inflammatie, vanwege de blootstelling van endotoxines. Deze techniek kan de basis leggen voor nieuwe gaasjes die kunnen dienen als wondbedekkings materiaal. Met dit oppervlakte-gemodificeerde vlas wordt een unieke combinatie bereikt van sterkte, flexibiliteit, hydrofiliciteit, biocompatibiliteit en antimicrobiële activiteit. 



\section{Résumé}

Bien que l'apparition des matières plastiques ait révolutionné le domaine du biomédical, leur utilisation a engendré son lot de complications ou de limitations. Par exemple, le polypropylène (PP) -fréquemment utilisé pour confectionner des filets prothétiques et corriger des hernies - est employé depuis la fin des années cinquante et peut ainsi entrâner, une fois implanté, des problèmes d'adhésion avec les intestins ou d'inflammation chronique accompagnée de douleurs. De même, les vaisseaux sanguins artificiels, tel que ceux faits à base de Dacron $^{\circledR}$, ne peuvent pas être utilisés pour remplacer des vaisseaux de moins de 6 $\mathrm{mm}$ de diamètre. Pour résoudre ces problèmes, plusieurs équipes de chercheurs se sont penchés sur l'utilisation de matériaux biosourcés, tels que la peau de bœuf ou de porc réticulée et décellularisée. Au vu des résultats encourageants, ces matériaux ont rapidement été commercialisés pour corriger les hernies. Néanmoins, à cause de leur prix substantiel (les filets synthétiques coûtent entre 0,2 et $1,0 \$ / \mathrm{cm}^{2}$; les filets biologiques coûtent entre 8,6 et $26,0 \$ / \mathrm{cm}^{2}$ ), leur utilisation est réservée aux situations complexes. Parallèlement, des vaisseaux sanguins artificiels à base de matériaux biologiques ne sont toujours pas disponibles sur le marché.

$\mathrm{Au}$ cours de cette thèse, nous nous sommes demandés si les fibres de plantes, et plus particulièrement les fibres de lin, pourraient représenter une nouvelle classe de matériaux biosourcés implantables. Les fibres de lin sont majoritairement composées de cellulose, la cellulose étant largement reconnue comme biocompatible in vivo. Elles sont peu denses (considérées comme un matériau léger) et présentent d'excellentes propriétés mécaniques (un module d'Young élevé de $58 \mathrm{GPa}$ en moyenne et une absence de comportement plastique). Ainsi, les implants fabriqués à partir des fibres de lin ne devraient pas facilement se déformer une fois implantés. Enfin, ce sont des structures creuses dont le lumen pourrait être utilisé comme zone de stockage de molécules bioactives, qui pourraient être libérées progressivement une fois les fibres implantées. D'un point de vue environnemental, les fibres de lin sont aussi un matériau intéressant, puisqu'elles sont recyclables, biodégradables, renouvelables et bon marché. En plus de tout cela, leur culture a un impact minimal sur l'environnement et elles peuvent être issues de l'agriculture biologique.

Nous avons supposé que les fibres de lin seraient surtout intéressantes dans la confection de textiles biomédicaux. Elles sont plutôt longues, et un savoir-faire considérable concernant leur tissage/tricotage est disponible. Ainsi, le design du tissu pourrait être facilement adapté au cahier des charges de l'implant et le matériau en résultant devrait être stable in vivo. Dans un premier 
temps, nous avons évalué le potentiel de filets chirurgicaux fabriqués à partir de fibres de lin (Chapitre 2). Ces filets chirurgicaux seraient principalement utilisés dans les cas d'hernie. Les fibres de lin javellisées mises à notre disposition ont pu être facilement tricotées en un filet chirurgical. Néanmoins, nos expériences ont montré que le filet était cytotoxique in vitro et que son implantation sous la peau de rats pendant 7 jours entraînait une importante réaction inflammatoire, avec notamment la présence d'une grande quantité de nécrose à l'extérieur comme à l'intérieur des faisceaux de fibres de lin. Nous avons émis l'hypothèse que ce problème était dû à la présence d'endotoxines à la surface des fibres de lin. En effet, l'étape de rouissage, nécessaire à l'obtention des fibres de lin, repose largement sur la présence de bactéries. Afin de résoudre ce problème, nous avons conçu un traitement de purification basé sur l'emploi de solvants biosourcés et d'un appareil de Soxhlet. Grâce à cette technique, nous avons pu conserver en fin de traitement des fibres présentant un impact environnemental minimal. De nouvelles expériences ont démontré la cytocompatibilité du filet après purification. Les analyses LAL et XPS ont confirmé que ce traitement retirait plus de $85 \%$ des endotoxines. L'implantation in vivo a été réitérée et en effet, le filet une fois purifié entraîne une bien meilleure réponse inflammatoire: une inflammation bénigne est présente autour des faisceaux de fibres de lin, d'un degré équivalent à ce qui est observé autour d'un filet en polypropylène. Cependant, des cas de nécrose sont toujours visibles à l'intérieur des faisceaux. Il est probable que ce problème puisse être résolu en combinant deux techniques. D'abord, les fibres de lin pourraient être recouvertes d'un revêtement biosourcé afin de cacher la présence des endotoxines. Ensuite, le diamètre du fil de lin pourrait être réduit jusqu'à ce qu'aucune nécrose ne soit visible à l'intérieur des faisceaux. En effet, il est bien connu que la réponse inflammatoire peut être diminuée en réduisant la taille d'un fil chirurgical. Ces deux hypothèses ont été l'objet d'études approfondies dans les Chapitres $3 \& 4$.

Dans le Chapitre 3, les fibres de lin ont été recouvertes de polydopamine ( $\mathrm{pDA}$ ). La dopamine polymérise spontanément sur un matériau si le $\mathrm{pH}$ de la solution est de 8,5 , et sa polymérisation est généralement considérée comme relevant de la chimie verte. De plus, de précédentes études ont montré qu'une fois déposée sur des substrats hydrophobiques, la présence d'une couche de pDA améliorait grandement l'adhésion cellulaire. Nos expériences ont révélé des résultats en forte contradiction avec ceux décrits précédemment, ce qui est probablement dû à la nature hydrophilique des fibres de lin. Une fois recouvertes de pDA, les fibres de lin purifiées au Soxhlet ont dû être considérablement lavées pour rester cytocompatibles in vitro. De plus, nos expériences n'ont pas montré d'amélioration concernant l'adhésion des fibroblastes ou des cellules 
endothéliales sur notre matériau. Finalement, les fibres de lin recouvertes de pDA causent une forte imménogenicité in vitro. Cela est très probablement dû à la présence de molécules de dopamine non polymérisées à la surface des fibres de lin. Dès que le processus de polymérisation a débuté, les fibres de lin, étant hydrophiles, absorbent une partie des molécules de dopamine qui se retrouvent coincées a l'intérieur de celles-ci et ne peuvent donc plus ni polymériser facilement, ni être retirées aisément lors du lavage au Soxhlet. Cette hypothèse est soutenue par le fait que la dopamine est largement reconnue comme une molécule pro-inflammatoire in vitro et in vivo. Dans l'ensemble, ces résultats disqualifient l'utilisation de la pDA comme revêtement pour les fibres de lin.

L'albumine pourrait être utilisée comme revêtement alternatif (Chapitre 4). Dans le Chapitre 3, nous avons pu observer que la présence d'une couche supplémentaire d'albumine au-dessus de celle de pDA réduisait largement l'immunogenicité des fibres de lin recouvertes de pDA. Cela nous a poussé à examiner l'effet d'une couche d'albumine directement déposée comme revêtement sur les fibres de lin (la couche intermédiaire de pDA a été éliminée dans le Chapitre 4). Les résultats prouvent que la couche d'albumine couvre approximativement $27 \%$ des endotoxines et qu'elle entraine une amélioration de l'adhésion cellulaire in vitro. De plus, elle a un effet bénéfique sur les interactions entre le matériau et le sang: elle réduit la thrombogénicité des fibres de lin et l'activation des plaquettes par celles-ci. Ces propriétés en font un matériau intéressant pour la confection de dispositifs médicaux à mettre en contact avec le sang, par exemple les vaisseaux sanguins artificiels. Néanmoins, l'implantation du matériau in vivo a mené à des résultats contrastés. Ils ont montré que la réponse inflammatoire pouvait en effet être réduite en diminuant la taille du fil de lin ou en ajoutant une couche d'albumine. La nécrose présente au sein des faisceaux de fibres de lin a donc pu être supprimée en choisissant de bonnes conditions expérimentales. Cependant, et dans toutes les conditions testées, les cellules inflammatoires semblaient vouloir séparer les fibres de lin les unes des autres, suggérant que le matériau, une fois implanté, pourrait perdre sa forme initiale à long terme. Ce résultat pourrait être causé par la présence d'endotoxines résiduelles qui n'ont pas pu être recouvertes par la couche d'albumine.

Considérant qu'il sera sans doute très difficile de recouvrir efficacement les endotoxines à l'aide d'un revêtement biosourcé, nous avons adopté une nouvelle approche. Dans le chapitre 5, les fibres de lin ont été recouvertes d'une couche de SlipSkin ${ }^{\circledR}$, un revêtement hydrophile composé de $50 \%$ de BMA et de $50 \%$ de NVP. Bien que cette approche puisse paraitre contradictoire de prime abord (les fils une fois recouverts de SlipSkin ${ }^{\mathbb{Q}}$ ne peuvent plus en effet 
être considérés comme des matériaux entièrement biosourcés et écologiques), nous sommes convaincu que c'est le seul moyen de cacher la présence d'endotoxines. Les fils de lin ont pu facilement être recouverts de SlipSkin ${ }^{\circledR}$, transformant les multifilaments irréguliers en des monofilaments uniformes. La présence de SlipSkin ${ }^{\circledR}$ n'a pas corrompu la cytocompatibilité des fibres in vitro, à partir du moment où des fils de lin purifiés ont été utilisés comme substrat. Finalement, des microparticules d'argent ont pu facilement être incorporé dans le SlipSkin ${ }^{\circledR}$, donnant naissance à un fil grisâtre exhibant de fortes propriétés antibactériennes. Dans ce chapitre, les microparticules d'argent ont été sélectionnées à cause de leurs fortes propriétés antimicrobiennes, mais il ne fait aucun doute que d'autres micro/nanoparticules pourraient être aussi incorporées dans le revêtement selon les propriétés finales souhaitées. Bien entendu, le matériau final ne pourrait jamais être implanté dans le corps humain: la moindre éraflure du revêtement pourrait exposer les endotoxines sous-jacentes et entraîner une forte réponse immunitaire. Les fils de lin recouverts de SlipSkin ${ }^{\circledR}$ et de microparticules d'argent pourraient être utiles à la confection de pansements, étant donné qu'il existe un réel manque de matériaux présentant à la fois des propriétés hydrophiles et antibactériennes. 
Acknowledgments

Curriculum Vitae

List of publications 


\section{Acknowledgements}

Now that I am reaching the end of my PhD, I would like to thank all the people I met and worked with.

Of course, my first thanks go to my promoter professor Leo Koole, who gave me the opportunity to work in his department. Leo, you took time to help and advice me in my research. Without your guidance, I would certainly not have been able to produce this thesis. Thanks to you, I acquired the research mind I will need for my future carrier. Working with you also gave me the opportunity to attend international conferences and present my work in front of a scientific audience. More prosaically, it was also the occasion for me to visit for the first time the United States of America, and I shall certainly not forget our group activities in Disneyworld Orlando, or our whale watching in Boston.

My greatest gratitude also goes to Menno. At the beginning of my thesis, I had not had any class about biology for six years, all my memories of it dating back to when I was in high school. I had certainly lots of things to learn! Nevertheless, you have always been kind and patient with me, taking enough time when necessary to explain in easy words the complex biological processes. I certainly owe you all the in vitro skills and biological knowledge I now have.

Dear Daniel and Nynke, I would also like to thank you for your helpfulness in the project. You were always very supportive and encouraging, and your inputs were highly appreciated. In particular, you designed and realized the immunological experiments that appeared to be crucial to my thesis. Also many thanks to Mike, who helped for the experiments and analyses.

I would like also like to express my sincere gratitude to Ruben Vogels and Nicole Bouvy, who took care of all the in vivo experiments. This thesis would not have been doable without you. Whatever our new idea was, you were constantly motivated by it and ready to test it in vivo. Working with you was also the occasion to learn about histology, and I am grateful for your patience when explaining in details the in vivo images to me.

Dear Jorrit, you became a true friend over this $\mathrm{PhD}$ thesis. It was a real delight to talk with you each time you came here. You made me discover Maastricht by night, and we had great fun together. It was also a pleasure to receive you in Paris, and I hope you have kept a happy memory of your stay. I am certain we will keep seeing each other after my thesis, and you are wholeheartedly welcome again in Paris. 
My dear Yujing, it will be awkward to not see you everyday anymore. I hope you survived to my flow of words! I will personally keep great memories of our discussions about infinite subjects. In particular, I always found strange that you could work without any music, whereas all my life is depending on it! I tried to introduce you to it, but it seemed like you definitely preferred quiet music to my hard rock \& roll waking up one. Even, I would say, you probably preferred none. It was probably sufficient for you to see me constantly swinging on my chair or humming when the song was too captivating. But I have not lost hope to bring you in a festival of music... why not in Paris?

Next, I would like to thank all the other persons I have met during this thesis. Maxime, you were a great student and I had lots of pleasure to work with you. It was the first time I had to manage someone but it proceeded smoothly and easily thanks to your nice personality. Ketie and Abdel, your presence was much appreciated throughout my $\mathrm{PhD}$. Your continuous support especially cheered me up when I felt a little down. I am also thankful to Jeroen and Claire for their help and time with the microscopic experiments or administrative affairs. Finally, I express all my gratitude to Dr. Cees van der Marel, who realized and analyzed the XPS experiments for me, and to the company Van der Bilt Seeds \& Flax BV that kindly provided us with the flax threads.

Bien sur, je profite aussi de l'occasion pour remercier mes parents. Papa, maman, si je suis aujourd'hui en train de soutenir ma thèse c'est entièrement grâce à vous. Vous nous avez toujours poussé à nous ouvrir sur le monde, à acquérir de nouvelles connaissances et à aller de l'avant malgré nos échecs. Aujourd'hui, je réalise la chance incroyable que cela a été pour nous de pouvoir baigner dans un tel environnement culturel. Même si cela n'a pas toujours été facile, vous avez constamment fait de l'éducation de vos enfants une priorité. Cette thèse, comme toute la formation d'avant, n'aurait jamais pu être possible sans votre aide.

Papa, maman, mamie, tatiana, Christine, Stéphane, je vous remercie tous de votre soutien permanent et de vos encouragements. Aucun d'entre vous ne comprenait vraiment ce que je faisais, mais vous m'avez toujours demandé des nouvelles du projet et de ses aboutissements. Je me souviens notamment du week-end de Pâques juste avant ma conférence à Orlando, où pour m'entrainer, j'ai récité ma présentation orale devant vous. C'était en anglais, personne n'a rien compris, mais vous m'aviez quand même posé plein de questions!

Enfin, je voudrais remercier mon inébranlable soutien, Mathieu. Durant cette longue période de thèse, c'est toi qui as eu le plus à recoller les pots cassés. 
Tu as été une source de réconfort incroyable dans les moments difficiles et tu m'as toujours soutenu avec une patience indéfectible. Je crois même t'avoir tellement parlé de ma thèse que tu pourrais presque la soutenir à ma place! Très certainement, finir ce doctorat sans toi à mes côtés n'aurait pas été possible, et je ne pourrai jamais assez te remercier de l'appui que tu m'as apporté.

Lastly, all my thanks go to the BioMedical Engineering department. Tammo, I wish you to have a new student who attends opera too. It was always very interesting to discuss about the performances with you. Also many thanks to the Orthopaedic department. Dear Mandy, I had great fun with you in the cell lab. I wish you all the best for the continuation of your $\mathrm{PhD}$.

Sophie Michel 


\section{Curriculum Vitae}

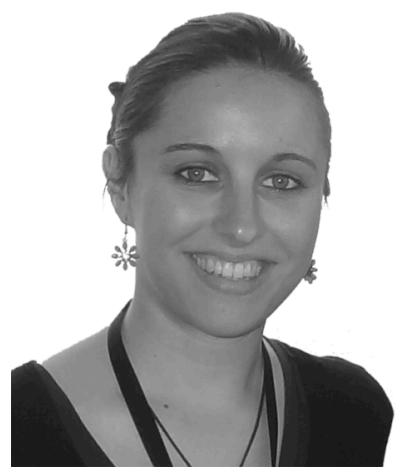

Sophie Michel was born on the $19^{\text {th }}$ of November, 1987 in Montauban, France. In 2005, at the end of her secondary education in Paris, she obtained a scientific baccalaureate with upper second class Honours. Consequently, she started a preparatory school for the "grandes écoles" with major in Physics and Chemistry, and integrated in 2007 the European Engineering School of Chemistry, Polymers and Materials from Strasbourg (ECPM). In 2008, she specialized into Material Science and she obtained her Engineering diploma in 2010. In parallel, she obtained in 2010 a Research master in Material Engineering from the University of Strasbourg with first class Honours. At the end of her studies, she also made an internship of six months in Philips Research, Cambridge, United Kingdom. This internship was extended with a short-term contract of four months. During this project, she worked on ion-selective electrodes for ion detection inside the human blood and developed a strong interest for biomedical engineering and, in particular, biomaterial medical devices. In 2011, she started a PhD training at the BioMedical Engineering department of Maastricht University under the supervision of Prof. Leo H. Koole. The focus of her work laid on the utilization of flax fibers for biomedical applications, and in particular, for the manufacturing of new kinds of hernia meshes. 


\section{List of publications}

\section{Manuscripts}

Michel SAAX, Vogels RRM, Bouvy ND, Knetsch MLW, van den Akker NMS, Gijbels MJJ, van der Marel C, Vermeersch J, Molin DGM, Koole LH.

Utilization of flax fibers for biomedical applications. J Biomed Mater Res Part B 2013; doi: 10.1002/jbm.b.33025

Michel SAAX, Knetsch MLW, Koole LH.

Adsorption of albumin on flax fibers increases endothelial cell adhesion and blood compatibility in vitro. J Biomater Sci, Polym Ed 2014; doi: 10.1080/09205063. 2014.896633

Michel SAAX, van den Akker NMS, Knetsch MLW, van der Marel C, Vermeersch J, Gagliardi M, Molin DGM, Koole LH.

In vitro cytocompatibility and immunogenicity of polydopamine coated flax meshes. Submitted for publication.

Michel SAAX, Basset MGJ, van Tiel F, Maes J, Koole LH.

Studies on the potential use of flax (linen) as a biomedical material. Application of a synthetic antimicrobial surface coating. Submitted for publication .

\section{Abstracts (oral contribution)}

Michel SAAX, Knetsch MLW, Molin DGM, Koole LH.

Potential utility of woven flax fiber meshes in surgical repair of incisional hernias. American Society For Biomaterials, 2013, Boston, MA, USA.

\section{Abstracts (poster contribution)}

Michel SAAX, Knetsch MLW, Molin DGM, Koole LH.

Limits to the utilization of polydopamine coating with the example of flax fibers as a substrate.

American Society For Biomaterials, 2013, Boston, MA, USA. 